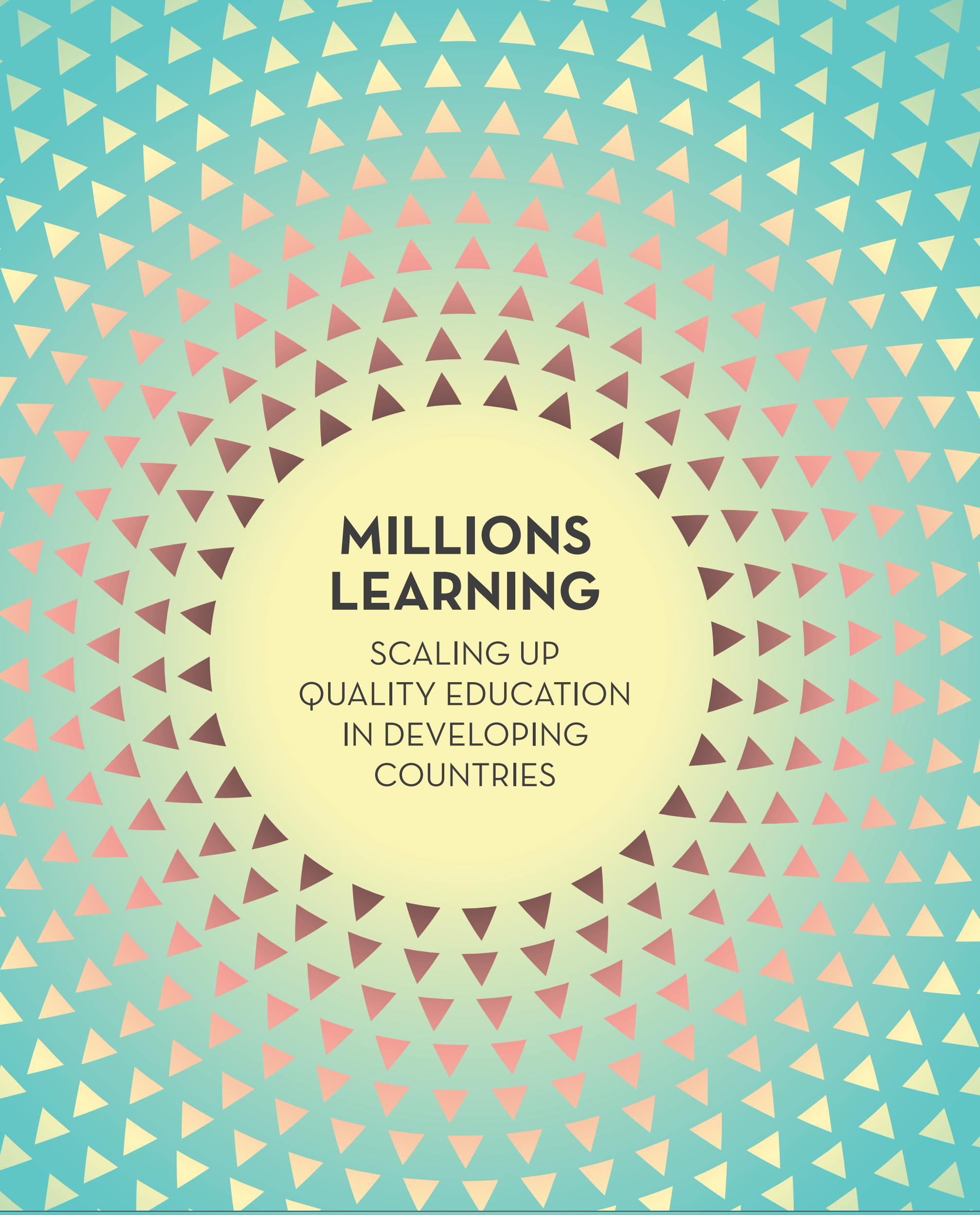




\section{MILLIONS LEARNING}

SCALING UP

QUALITY EDUCATION

IN DEVELOPING

COUNTRIES 


\section{Table of contents}

EXECUTIVE SUMMARY

FILIPE'S STORY: BRAZIL'S NEW APPROACH TO SCHOOLING IN THE AMAZON JUNGLE

This report was written by Jenny Perlman Robinson and Rebecca Winthrop with Eileen McGivney, along with research support from Jenny Alexander and Priyanka Varma, as well as invaluable assistance over the past few years from the Millions Learning team at the Brookings Institution's Center for Universal Education, particularly: Lulwah Ayyoub, Mia Blakstad, Zoe Norris, Priya Shankar, and Samantha Spilka.

Sincere gratitude and appreciation to our Millions Learning consultants who have been equally instrumental in the report: Priscila Cruz, Shushmita Chatterii Dutt, Flavia Goulart, Mayyada Abu Jaber. Haeyeon Jung Christina Kwauk, Alessia Lefebure, Divya Mansukhani, Maria May, Jessica Moore, Ainan Nuran, Daniela Petrova, Martin Roeck. Marijke Schouten, Sheikh Islam Tanjeb, Judith-Ann Walker, and Jillian Yoerges.

We are thankful for the guidance and support from our Millions Learning International Advisory Panel Co-Chairs, the Honorable Julia Gillard (The Brookings Institution) and Homi Kharas (The Brookings Institution), and members: Alice Albright (Global Partnership for Education). Aaron Benavot (Education for All Global Monitoring Report), Madhav Chavan (Pratham), Larry Cooley (Management Systems International), Claudia Costin (The World Bank Group), Elizabeth King (The Brookings Institution), Ruth Levine (The William and Flora Hewlett Foundation), Santiago Levy (Inter-American Development Bank), Daniel Low-Beer (World Health Organization), Lu Mai (China Development Research Foundation), Zbigniew Marciniak (University of Warsaw), Shannon May (Bridge International Academies). Dzingai Mutumbuka (Association for the Development of Education in Africa), Vineet Nayar (Sampark Foundation), Tamela Noboo (Discovery Learning Alliance), Liesbet Steer (International Commission on Financing Global Education Opportunity), and Mark Surman (Mozilla Foundation).

The Brookings Institution is a nonprofit organization devoted to independent research and policy solutions. Its mission is to conduct high-quality, independent research and based on that research to provide innovative, practical recommendations for policymakers and the public. The conclusions and recommendations of any Brookings publication are solely those of its author(s) and do not reflect the views of the Institution, its management, or its other scholars.

Support for this publication and research effort was generously provided by the John D. and Catherine T. MacArthur Foundation and The MasterCard Foundation. The authors also wish to acknowledge the broader programmatic support of the William and Flora Hewlett Foundation, the LEGO Foundation, and the Government of Norway.

Brookings recognizes that the value it provides is in its absolute commitment to quality, independence, and impact. Activities supported by its donors reflect this commitment, and the analysis and recommendations are not determined or influenced by any donation.

\section{ACCELERATED EDUCATION PROGRESS IS URGENTLY NEEDED}

Global goals place a premium on learning for all

Where education has failed: The scope and scale of challenges

Why focus on learning?

III) SCALING SO MILLIONS LEARN: DEFINING A GLOBAL PRIORITY

$$
\text { A focus on scaling }
$$

Addressing an evidence gap

Defining scaling

Methods guiding Millions Learning

\section{FINDINGS: HOW HAS SCALING HAPPENED?}

Scaling success from the margins

dea adoption and delivery innovation:

Two strategies for scaling quality learning from the margins

Scaling learning: 14 core ingredients

(v) DESIGN

Local education needs: Interventions should be designed in response to local demand and should ensure the participation of end-users.

2. Cost-effective learning: Cost structures affordable at scale should be incorporated in the design.

3. Flexible adaptation: Core elements of effective learning approaches should be identified and replicated across contexts while adapting the rest to local circumstances.

4. Elevating teachers: Community expertise should be leveraged to support and unburden teachers.

(VI) DELIVERY

5. Education alliances: All actors need to work together to achieve a common goal.

6. Learning champions and leaders: As scaling quality learning is a political and technical exercise, champions within and outside government and the classroom are crucia. 
7. Technological advances: Context-appropriate technologies can accelerate education progress.

8. Windows of opportunity: Effective education approaches are more likely to take root and spread when they align with country priorities.

9. Better data: Data on learning and scaling play a central role by motivating informed action at the policy and practice levels.

(VII) FINANCE

10. Flexible education financing: Financing should be flexible,

including to build core operational capacity.

11. Long-term education financing: Stable and predictable support is essential.

12. "Middle phase" financing: Financing is required to bridge the critical stage between pilot and broad uptake.

VIII) ENABLING ENVIRONMENT

13. Supportive policy environment: Government policy must safeguard every child's right to a quality education while remaining open to a diversity of ideas and actors to contribute to this common aim.

14. A culture of R\&D: Ensuring that more children learn requires a strong ethos of experimentation, collecting learning data, and using it for continuous improvement.

(IX TOWARD THE FUTURE: THE NEED FOR INCLUSIVE AND ADAPTIVE EDUCATION ECOSYSTEMS IN A CHANGING WORLD

Action 1: Develop a culture of R\&D in education

Action 2: Share new ideas through a network of Idea Hubs

Action 3: Activate talent and expertise outside the classroom

Action 4: Fund the middle phase

Action 5: Measure and learn what works through better learning and scaling dato

ENDNOTES

ANNEXES

Annex 1. Millions Learning case study selection process

Annex 2. 14 Millions Learning case studies

Annex 3. Acknowledgments

\section{LIST OF FIGURES}

Figure 1. A scaling success story: The rapid spread of schooling in the past 200 years

Figure 2. The learning crisis: $38 \%$ of children not learning basic literacy and numeracy

Figure 3. Reaching universal secondary education: Projected gap

Figure 4. Pathways to scale

Figure 5. Case study overview

Figure 6. Learning Metrics Task Force: Seven domains of learning

Figure 7. Scaling success from the margins

Figure 8. Scaling learning: 14 core ingredients

Figure 9. Millions Learning recommendations

\section{LIST OF BOXES}

Box 1. Pathways for scaling effective approaches 38

Box 2. Defining the scope of the study

Box 3. Lesson Study, Zambia

Box 4. Sistema de Aprendizaje Tutoria

Box 5. Bridge International Academies

Box 6. Fundación Escuela Nueva

Box 7. BRAC, Non-Formal Primary Education

Box 8. Aflatoun International

Box 9. Room to Read, Literacy Program

Box 10. Pratham, Read India

Box 11. Educate!

Box 12. Sesame Workshop, Sesame Street

Box 13. Teach For All

Box 14. INJAZ, Jordan

Box 15. Amazonas State Government's Media Center

Box 16. Worldreade

Box 17. Government action to create space for scaling quality learning 


\section{Executive summary}

Around the world, countries are grappling with how to scale quality education for their children and youth. Quality education is at the center of a nation's progress, and it is also enshrined in the United Nations Sustainable Developmen Goals, which 193 countries have recently committed to support. While the spread of schooling over the past 150 years is one of the most widely successful "going to scale" stories, this expansion too often has been met with little mastery of core academic content and higher-order thinking skills.

An estimated "10O-year gap" persists and deve proceeds as usual in the education sector, this gap is not projected to close. Today, 250 million children around the globe-many of them having spent at least four years of school in a developing country-lack the most basic literacy and numeracy skills. Additionally, countries around the world are struggling to help young people develop 21st-century skills, such as critical thinking and collaborative problem solving, which are increasingly demanded by the labor market.

Millions Learning tells the story of where and how quality education has scaled in the developing world. The story emerges from wide-ranging research on scaling and learning, including 14 in-depth case studies, from Brazil and Honduras, to Janda and Zambia, to Jordan and India.

What we found is that from the slums of New Delhi to the rainforest in Brazil, transformational change in children's learning is happening at large scale in that successful scaling of quality learning often occurs when new approaches and ideas are allowed to develop and grow on the margins and then spread to reach many more children and youth. What constitutes the margins varies on Whase-by-case basis. For some, it means a flexible central government giving freedom to its officials within a district to try a new approach. For others, it involves a community movement that develops new ways of reaching marginalized children whose educational options are limited.

Scaling from the margins occurs in two main ways: idea adoption, namely the spread of new approaches across an education ecosystem, and delivery innovation, the development of new ways to deliver education to marginalized children and youth. With the former, effective new approaches to improving process-from curriculum, to materials, to teacher development-have spread across education ecosystems and b adopted by different actors. With the latter, new education delivery approaches for the most marginalized communitiessuch as distance learning models or alternative education programs-have developed and grown within and across countries.

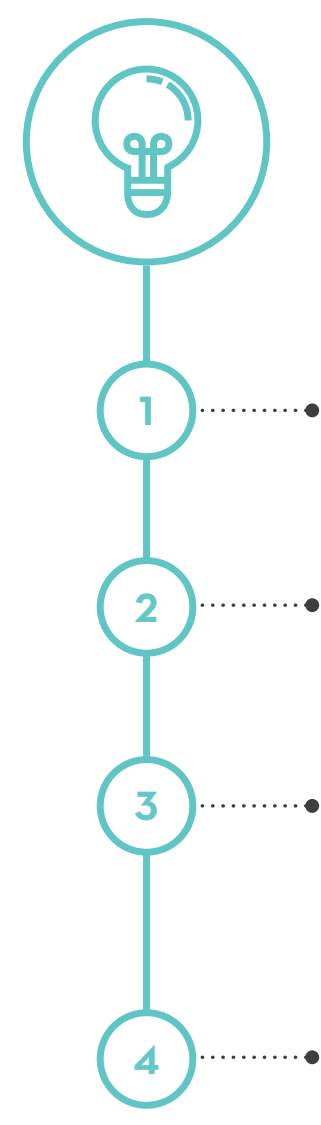

\section{DESIGN}

Improving learning at scale starts with committed leaders planning for scale from the outset. Ingredients necessary to do this are:

\section{LOCAL EDUCATION NEEDS}

Interventions should be designed in response to local demand and should ensure the participation of end-users.

\section{COST-EFFECTIVE LEARNING:}

Cost structures affordable at scale should be incorporated in the design.

\section{FLEXIBLE ADAPTATION}

Core elements of effective learning approaches should be to local and replicated ar

\section{ELEVATING TEACHERS}

Community expertise should be leveraged to support and unburden teachers. 


\section{DELIVERY}

Attention to the operational realities of implementing

or delivering at large scale is essential. This involves a

combination of technical and political actions. Ingredients

needed for this are:

- EDUCATION ALLIANCES:

All actors need to work together to achieve a common goal.

\section{LEARNING CHAMPIONS AND LEADERS}

As scaling quality learning is a political and technical exercise,

champions within and outside government and the classroom are crucial.

\section{TECHNOLOGICAL ADVANCES}

Context-appropriate technologies can accelerate education progress.

\section{WINDOWS OF OPPORTUNITY}

Effective education approaches are more likely to take root and spread when they align with country priorities.

\section{BETTER DATA:}

Data on learning and scaling play a central role by motivating informed action at the policy and practice levels.

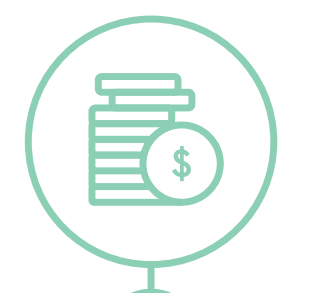

\section{FINANCE}

How resources are allocated matters as much as absolute amounts. Ingredients needed for this are:

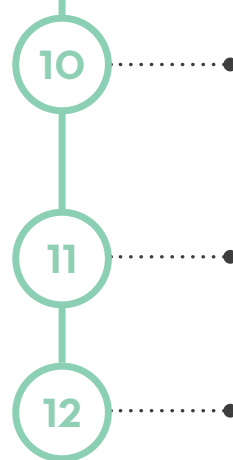

\section{FLEXIBLE EDUCATION FINANCING}

Financing should be flexible, including to build core operational capacity.

- LONG-TERM EDUCATION FINANCING:

Stable and predictable support is essential.

\section{"MIDDLE PHASE" FINANCING}

Financing is required to bridge the critical stage between pilot and broad uptake.

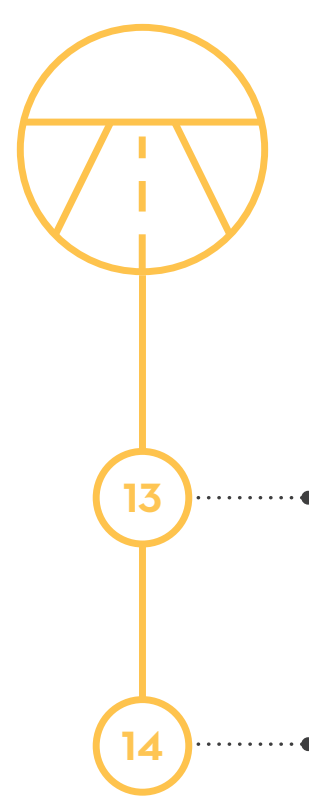

ENABLING ENVIRONMENT

As critical as these three other aspects are, scaling does not happen in a vacuum. Largely guided by governments from national to local, the environment in which programs or policies operate plays a critical role in facilitating or impeding the scaling process. Ingredients needed for this are:

\section{SUPPORTIVE POLICY ENVIRONMENT:}

Government policy must safeguard every child's right to a quality education while remaining open to a diversity of ideas and actors to contribute to this common aim.

A CULTURE OF R\&D:

Ensuring that more children learn requires a strong ethos of experimentation, collecting learning data, and using it for continuous improvement.

Scaling quality learning requires a effectively contribute their expertisemove to a new norm of inclusive and from households, to communities, to for civil society organizations, to the private calls for education ecosystems that sector, and academia. These ecosystems provide space for innovation and must be inclusive and adaptive, experimentation to thrive, and then leveraging all assets these actors actively help facilitate the spread of new bring as well as ensuring that the most ideas or approaches that most effectively marginalized children are reached. This improve learning. Governments play a is the best way to move forward based on pivotal role in this ecosystem. Not only evidence of what has successfully scaled is it their responsibility to deliver on to date. Moreover, it is key to developing every child's right to a quality education a nimble education ecosystem ready to but they must also actively foster an adapt in a rapidly changing world to environment where all actors can whatever the future holds. 
We recommend the following five main actions to create inclusive and adaptive education ecosystems and ultimately help scale quality learning for millions of children and youth:

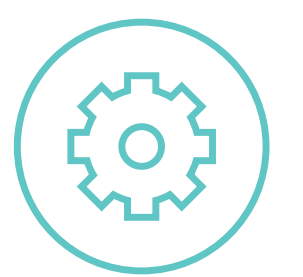

\section{DEVELOP}

A CULTURE OF R\&D IN EDUCATION

Leaders across all parts of the education ecosystem-from government to civil society to business-must embrace new approaches to solving problems at scale. Building a strong culture of research and development (R\&D) within the education ecosystem is a key step. Governments should provide the policy space, funding, and infrastructure support necessary to try new approaches to persistent problems. Donors, civil society, governments, and business should work together to cultivate a cohort of Learning Leaders who have the skills and attributes necessary for pushing forward a culture of $R \& D$ in education

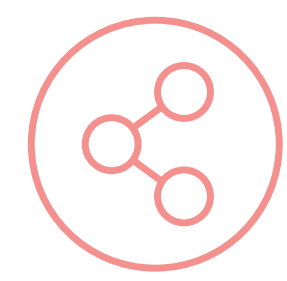

\section{SHARE}

NEW IDEAS THROUGH A NETWORK OF IDEA HUBS

Leaders in governments, in partnership with civil society and the private sector, should establish Idea Hubs for identifying, adapting, and sharing effective approaches to improving learning and scaling them. The Idea Hubs should be nimble mechanisms that allow decision-makers to stay up to date with rapidly changing innovations. Approaches led by all actors-government, educators, business, civil society-should be discussed. These hubs should be linked through a global network to allow for experiences and lessons shared between countries and among regional and global actors.

\section{ACTIVATE}

TALENT AND EXPERTISE OUTSIDE THE CLASSROOM

To scale quality learning in the developing world, including in the communities that are hardest to reach, a creative injection of support and energy is needed. Teachers and other education personnel who are on the front lines are overburdened and require tangible assistance. For addressing tough education problems, expertise from diverse actors outside schools can be one important source of this support. From nonprofit workers and young graduates to business professionals and technology specialists, different types of expertise can be strategically tapped to assist educators, elevate them in their roles, and help reach children who are falling through the cracks. Governments, civil society, and the business community should launch bold All-In Community initiatives, including through leveraging technology, to support teachers and other education personnel in their respective countries.

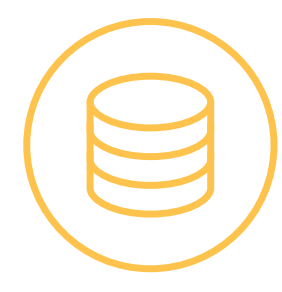

\section{FUND}

\section{THE MIDDLE PHASE}

This is crucial to help effective education approaches cross the "valley of death" to scale. Too often, promising approaches fall victim to a funding gap between new ideas or prototypes and implementation at a national level. Governments, donor agencies, foundations, and investors should develop a more organized ecosystem of education funding to support scaling. Additionally donor agencies and foundations should provide flexible support, including for building scaling capacity.

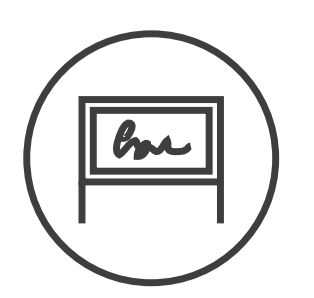

\section{MEASURE AND LEARN}

UIER LERNING AND SCALING DATA

Government and donor agencies should strengthen national student assessment systems, particularly in developing countries where data are sporadic and often of limited use. Data on student learning should start at the classroom level and be used by teachers and move up through national level data on what children can know and do. In particular, new ways of helping teachers assess

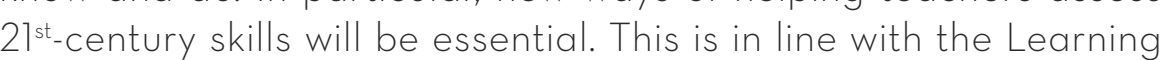
Metrics Task Force recommendation on learning data as a global good. The research community should improve data on scaling through a Real-time Scaling Lab. Such a forum would provide space to examine and document the process of scaling effective approaches to learning as they unfold, contributing to building a body of evidence on how to scale quality learning interventions.

Ultimately, Millions Learning is the quality education for all the world's story of possibility-the story of how collectively the global community can children and young people, enabling to reach their full potential and seize this moment in time and scale contribute to their societies. 



\section{Filipe's story:}

Brazil's new approach to schooling in the Amazon jungle

Filipe is a teenager living in one of the thousands of small communities located along the rivers of the Amazon jungle in Brazil. His village has only 20 families, a total of 78 people. In 2015, Filipe and another teenager were the only two students in their community attending the 11th grade. A decade ago, he would have been faced with two options upon reaching his high school years: move to Manaus, the capital city of Amazonas state, hundreds of miles away, which would take weeks to travel, or stop going to school. Instead, he commutes by boat along with 19 other students from surrounding villages to one of a thousand local government classrooms to receive lessons streamed live from a Media Center teacher in Manaus.

Media Center has made it possible for Filipe and 300,000 other students from 2,300 villages across Amazonas, home to some of the most remote communities in Brazil, to continue their schooling. The innovative approach blending distance education and classroom instruction developed and spearheaded by Amazonas State Secretariat of Education (SEDUC), is the key. It is transforming the educational experiences of young people in Brazil's Amazon region.

In light of the new United Nations (UN) Sustainable Development Goals (SDGs), which aim to achieve high-quality universal education for all the world's children and youth from early childhood through secondary school, nearly every country is grappling with how to reach every child and improve quality. To do this, many countries will need to adapt their current approaches. Brazil's Amazonas state is a refreshing example of an inclusive and adaptable education ecosystem that is harnessing creative ideas and leveraging partners expertise to deliver on every child's right to a quality education.

Media Center grew from an entrepreneurial group of policymakers in SEDUC, who had a vision to close the glaring gaps in secondary education in their remote villages. They had witnessed the failure of traditional distance learning programs, which were unpopular among teachers and the organizations that represented them, and lacked the student participation essential for learning. Amazonas' peripheral status and geographic isolation gave the policymakers more flexibility to experiment without being in the national spotlight Meanwhile, the federal government's 2009 law mandating high school education as a right for all Brazilians to be fulfilled by the states by 2016 forced Amazonas state to find a solution to its very complex challenge of providing schooling and classes in all disciplines to all students scattered throughout the vast Amazon rainforest.
What ultimately made it possible to transform the traditional national approach to distance education into Media Center's more locally relevant approach was the entrepreneurial and pioneering leaders within Amazonas state, former secretary of education Gedeão Amorim and his successor Secretary Rossieli Soares da Silva, who focused their attention on local needs, constraints, and opportunities in education development. In the Media Center model, lectures are broadcast via a bi-directional camera, allowing expert teachers in Manaus to not only lecture but also interact with students in hundreds of classrooms at the same time. Additionally, each classroom has a generalist, tutoring teacher who guides and supports students' learning and handles classroom management and administrative functions.

Along the way, officials from SEDUC worked with teachers and pedagogy experts in Brazil to develop a model that fundamentally reframed the relationship between teachers and technologyultimately they designed it from the ground up with students and teachers in mind. Technology that would work in remote areas and be conducive to student learning was the goal, and to develop an infrastructure in such areas required collaboration with private sector partners, such as satellite service providers and studio operators. The state ministry also brought in Bain Capital, a private sector consulting firm, to help strengthen the management capacity and continue to improve SEDUC. As the program grew from one grade to a full three years of secondary school, they were able to use evidence and adapt its model, collecting data on how students and teachers responded to the lessons and the interactive technology.

As interesting as the model itself has been its ability to scale. What started as an experiment for 10,000 students in the 10th grade in 2007 now reaches 23 percent of all secondary school students enrolled outside of Manaus. It has also been adapted to seven other states across Brazil with remote communities delivering distance education from middle school through high school and adult education. The core components of the model are suited to scaling in remote areas in Amazonas and Brazil, in that students do not need to travel far. centers need one generalist teacher rather than many specialists, and the technology is appropriate for the remote areas. Much of the expansion has been driven by demand from communities-a movement by rural populations to obtain high-quality education for their children. SEDUC was further strengthened and able to scale Media Center by inviting in diverse partners, including international organizations and the private sector, that had a shared vision

Media Center illustrates the power of an inclusive and adaptive education ecosystem. Systems that are spearheaded by leaders with a vision and ability to experiment, armed with evidence of effectiveness, enriched by civil society and private sector collaboration, and driven by student and teacher demand can address the learning crisis for children in even the remotest areas.

Millions Learning takes a deep dive into just how this change is happening across the globe, by examining a diversity of cases such as Media Center, where state 
and non-state actors have pioneered and, in partnership with a range of actors, scaled new approaches to education. Rather than focus on what works to improve student learning, or how access to primary school has spread, this report takes a look at some of the core ingredients behind scaling effective education approaches that improve students' learning outcomes.

We start by outlining the urgent need to accelerate progress in global education detailing the massive gaps in access and learning-and how, at the current pace, the SDGs will be far from met.

we focus on scaling and how we define it as a range of pathways that expand and deepen effective approaches that lead to lasting improvements in people's live. We also outline our methodology for selecting and analyzing the 14 cases we studied. From these case studies and existing literature, we identify 14 "core ingredients" for scaling learning "corerventions, organized into four main areas of how to design interventions with scalein mind, how to deliver andimplement interventions, how finance plays a role, and finally what characteristics of an enabling environment are necessary to foster scaling.

D Millions Learning takes a deep dive into just how this change is happening across the globe, by examining a diversity of cases such as Media Center, where state and non-state actors have pioneered and, in partnership with a range of actors, scaled new approaches to education. 



\section{Accelerated education progress is urgently needed}

The combination of a new global education agenda that puts a premium on improving learning outcomes for all with the massive failure to do so at scale to date provides an urgent and opportune moment to focus on scaling quality learning opportunities. Seizing that moment requires a recognition

that delivering education is not done only by governments. Education is in fact an ecosystem, which includes many related and co-dependent actors, both within and outside the formal system. Scaling quality learning needs inclusive and adaptive education ecosystems as demonstrated so clearly in Amazonas.

\section{Global goals place a premium} on learning for all

In 2O15, 193 countries adopted the SDGs, a new UN global agenda that aims to make progress on everything from income inequality to climate change. Compared to their predecessors, the Millennium Development Goals (MDGs), the goals and targets contained in the SDGs are broader, more ambitious, and more challenging. Goal 4, to "ensure inclusive and quality education for all and promote lifelong learning," exemplifies this when compared to the rather narrow focus of the education MDG to reach universal primary school enrollment. The goal driving the global education agenda from now to 2030 aims for universal education from pre-primary through secondary with relevant and effective learning outcomes.

While to some outside the global education community this might not seem like an ambitious goal, those who have followed trends in education over the past few decades know that ensuring that levels is no easy task. In addition, the new goals focus on both mastering the basics, such as literacy and numerac as well as higher-order competencies, such as global citizenship. For decades, expcation systems have been focused on indeed the spread of schooling around the globe over the past 150 years remains most widely successful "going country in the word has a school system country in the world has a school system demanding, that it fulfill their children's right to an education ${ }^{2}$ While enormous disparities still exist across and within countries, nine out of 10 chldren of primary-school age today are in school around the world compared to five out of ten 50 years ago. all children achieve sufficient learning expanding access to primary school, and to scale" stories to date (see Figure l). with parents expecting, and sometimes
A scaling success story:

The rapid spread of schooling in the past 200 years

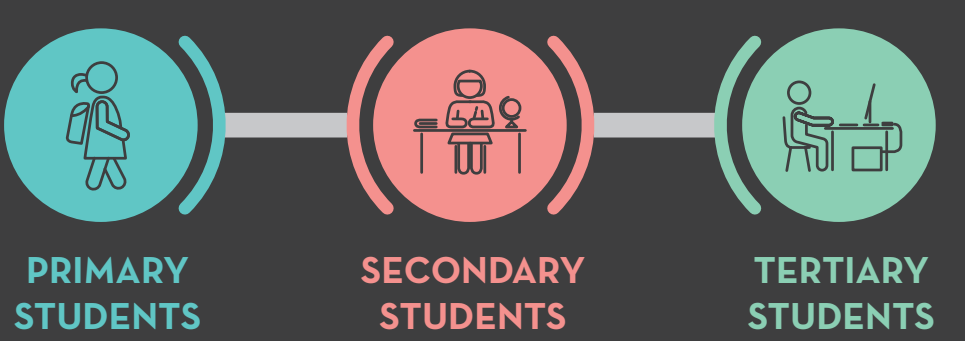

800

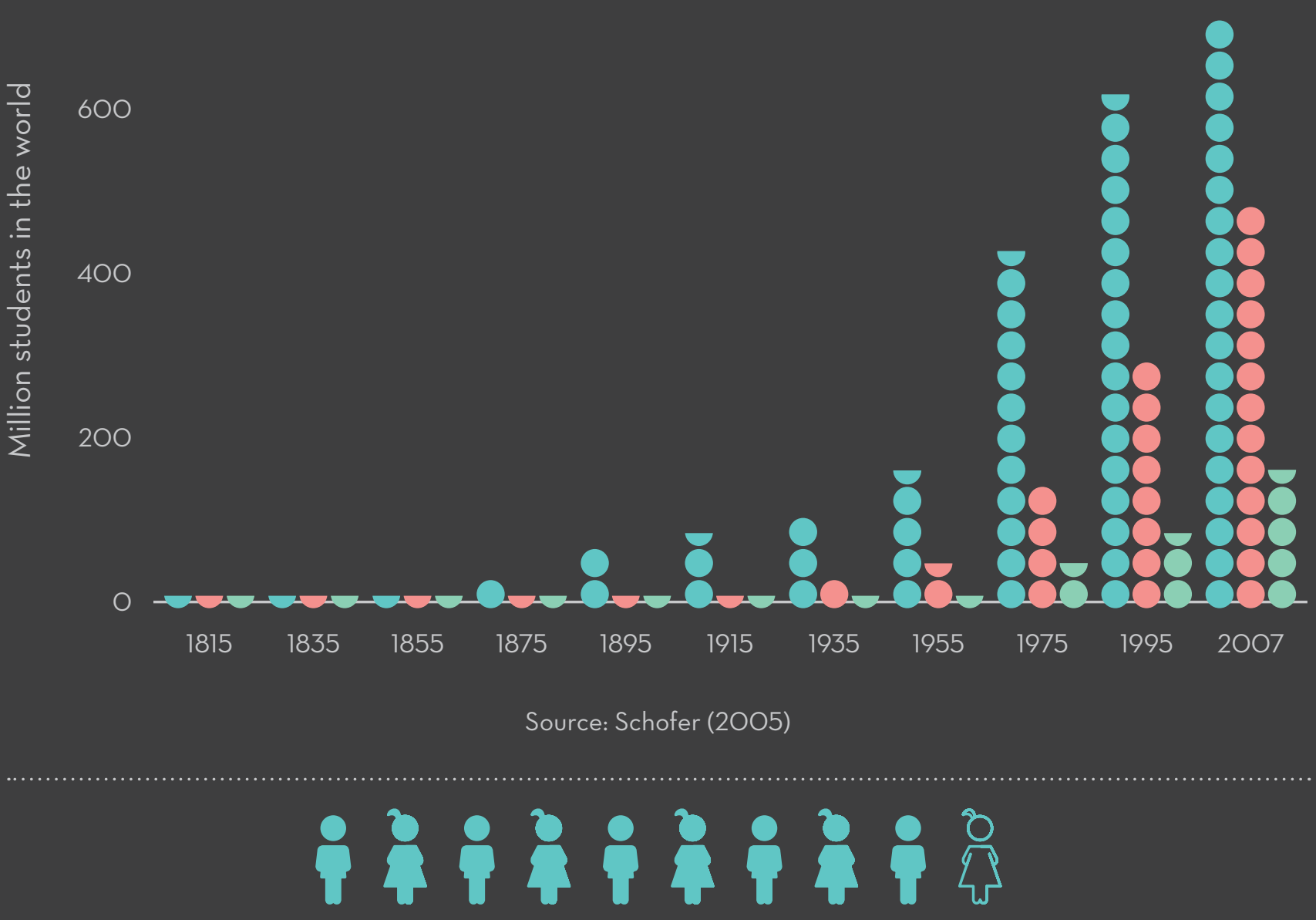

TODAY 9 OUT OF 10

CHILDREN OF PRIMARY SCHOOL AGE ARE IN SCHOOL AROUND THE WORLD 
Where education has failed: The scope and scale of challenges

In low- and middle-income countries, there is a scaling model for enrolling children build schools and make education free and compulsory. However, progress has been far less successful on enrolling early, learning well, and completing secondary school, and there is a "100 year gap" between educational outcomes in developed and developing countriesboth today and into the future

This 100-year gap can be seen clearly by today's low levels of learning in developing countries. Despite the large increases in children enrolling in school, research estimates that more than one-third of children around the world lack basic reading and mathematics skills-including 130 million children who are in school (see Figure 2) ${ }^{4}$ For some countries the situation is staggering In 2008 in Mali, depending on their language and region, 83 to 94 percent of second graders could not read a single word. In India, less than half of rural fifth graders could read a second-grade text in 2014, and just 26 percent could do division. ${ }^{6}$ In Kenya, Tanzania, and Uganda in 2013 , only one-third of third graders were at or above second-grade level literacy and numeracy skills.? The picture into the future is grim as well. Despite limited data, it has been estimated it could take more than 100 years for students in developing countries just to reach today's average level in developed regions when it comes to science-and they might never close the gap in math. ${ }^{8}$

Another aspect of the global education goal that will be hard to achieve every child completing school from early childhood through the end of secondary school. The world's poorest countries are still 100 years behind in terms of schooling completion. In 2010, South Asian and African adults just reached average schooling levels of early 1900 s Europeans and North Americans? Enrollment in pre-primary schoot has increased 64 pre-primary school has increased 64 percent since 1999 across the world, but still less than 50 percent of children attend a pre-primary education program in most countries and few quality early childhood development programs exist for the youngest children. ${ }^{0}$ In general the poor youngest children. plngensal, the poorest and most marginalized children are not benefiting from early childhood interventions."

On the other end of the spectrum, secondary education remains a huge challenge as well. According to projections from the Wittgenstein Centre for Demography and Global Human Capital, it will be decades until all youth have completed secondary education. By 2035, five years past the deadline for the SDGs, only 63 percent of the world's 20 to 24-year-olds will have completed upper secondary school. To reach 100 percent, progress would need to be three times

There is a "100-year gap" between educational outcomes in developed and developing countries-both today and into the future.

\section{The learning crisis:}

$38 \%$ of children not learning basic literacy and numeracy

\section{0 million}

children complete four years
of school and learn the basics.

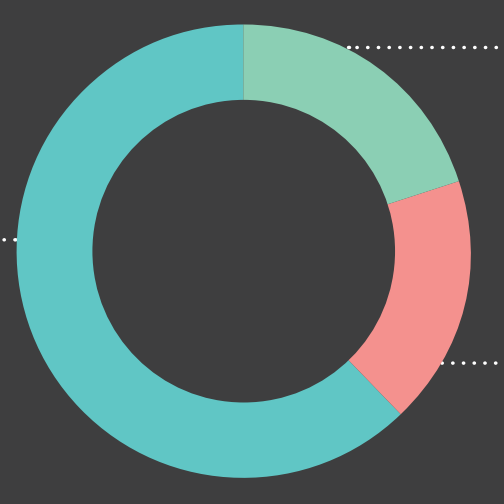

130 million

thout learning

120 million

four years of school.

GURE 3.

\section{Reaching universal secondary education:}

Projected gap'

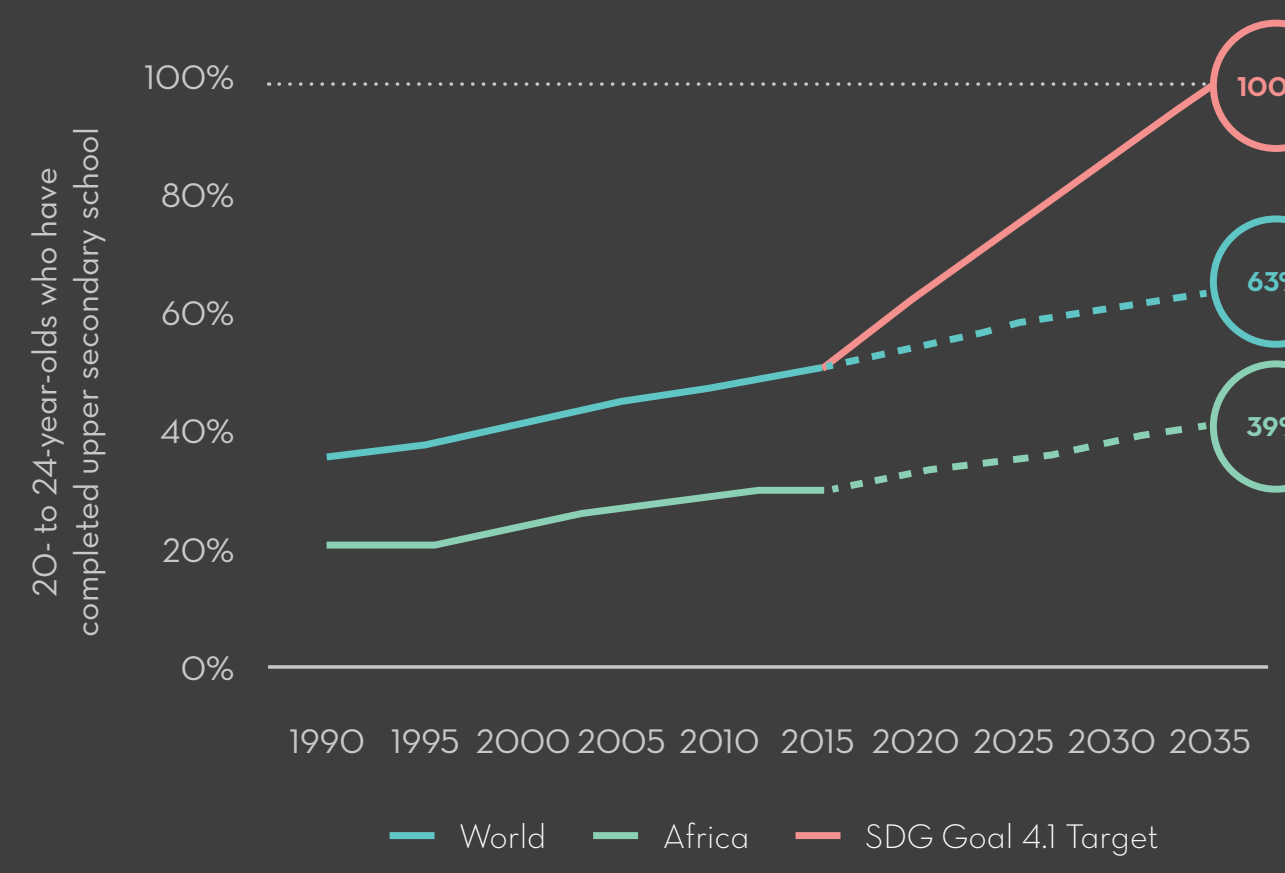

Source: Wittgenstein Centre for Demography and Global Human Capital (2015) 
as fast as current rates (see Figure 3). The challenge is concentrated in lagging regions. In Africa, for example, only 39 percent of youth will have completed secondary school if the current trajectory continues. Again, it is those who are most marginalized who are falling behind.

In addition to the 100-year gap between developedand developing regions itisclear that it is the within countries that are struggling. Massive inequality exists in many countries between the richest and poorest, between boys and girls, and between urban and rural children. In Nigeria, for example, 71 percent of the poorest children are out of school versus only 2 percent of the richest children, and 40 percent of rural children are out of school versus 9 percent of urban children. ${ }^{12}$ Countries around the world, high-, middle-, and low-income alike, are facing these inequalities.

These challenges are further complicated by the fact that we often lack systematic data on learning that can be regularly used by educators and policymakers at a classroom or national level, referred to by the global Learning Metrics Task Force as "the global data gap" on learning outcomes. ${ }^{13}$ A recent study by the Global Partnership for Education estimated that of the 60 poorest countries in the

These challenges are further complicated by the fact that we often lack systematic data on learning that can be regularly used by educators and policymakers at a

classroom or national level. world, only two had the basic elements in place for a student learning assessment system. ${ }^{14}$ Across the developing world, most countries administer annual national exams at the end of a schooling cycle. The exams frequently focus on a subset of academic subjects and are of limited use for real-time adjustments to policy and practice. In addition, countries frequently make use of a variety of assessment tools or programs that are housed outside the country and provide snapshots on specific aspects of children's learning, usually literacy and numeracy. These programs, such as the Programme for the Analysis of Education Systems (PASEC), which is administered across Francophone Africa every three years, or the Program for International Student Assessment (PISA), which is administered by the Organisation for Economic Co-operation and Development every three years, or Boston College's Trends in Internationa Mathematics and Science Study (TIMMS) assessment for math, can be useful exercises for countries and importantly contribute to a global picture on children's learning levels. However, they are no replacement for a well-developed student learning assessment system that is run by countries themselves and gives regular feedback on how students are progressing that can be used by educators and policymakers to inform what changes are needed in policy and practice.

Financing education is an additional challenge in achieving the SDGs. UNESCO estimates that meeting the goal of ensuring that all children acquire quality education from pre-primary through secondary school will require an additional $\$ 39$ billion annually. ${ }^{15}$ Colleagues at the Center for Universal Education (CUE) at Brookings have found that while domestic government spending is increasing and is the largest source of education finance, it remains far short of the amount needed. In addition, declining aid to education over recent years and the fragmentation between different funders will make it difficult to close the funding gaps and reach marginalized populations. They recommend better coordination among donors, an eye toward results and enhanced effectiveness of spending

\section{Why focus on learning?}

Globally, the focus on access to primary school has led to incredible gains. But increasingly data show that it is the learning that occurs in schools, which drives many of the social and economic benefits, including healthy children, prosperous economies, and a strong workforce Scaling education programs that improve both access and learning at the rate primary schooling access has grown will have tremendous impacts on societies and economies.

Early childhood programs lay the foundations for further development in primary school, secondary school, and beyond, largely with a focus on what are frequently called $21^{\text {st }}$-century skills. This includes teamwork and cooperation communication, problem solving selfcontrol, and perseverance. In the words of Nobel Prize-winning economist James Heckman, "skill begets skill ... learning

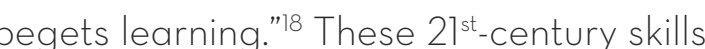
lead to higher academic achievement including literacy and numeracy in primary and secondary school, higher wages, and lower levels of crime.19 Perhaps this is why early childhood development programs have such high returns, by some estimations $\$ 8$ for every $\$ 1$ invested. 20

Beyond individual returns, evidence abounds that the skills learned in school have a profound impact on economies and societies While studies in many woges and improves heath outcople's wages and improves health outcomes, ${ }^{2}$ education economists Eric Hanushek and Ludger Woessmann have recently found that differences in skills-not schooling levels-explain differences in economic growth across countries. For instance,
by comparing learning outcomes with economic growth, their work helps to

Scaling education programs that improve both access and learning at the rate primary schooling access has grown will have tremendous impacts on societies and economies. 
explain why Latin America and East Asia could have similarly high levels of schoo completion yet drastically different levels of economic growth from 1960 to 2000 It was the high level of skills, measured by math and science assessments rather than years of schooling, that contributed to East Asia's rapid economic expansion, while Latin America's comparatively lower levels of learning contributed to stunted growth. In fact, the authors estimate that if all countries possessed the cognitive skill level of Finland, often a top scorer on international exams, global economic growth could be 8.5 to 13.8 percent

Learning the right balance of academic

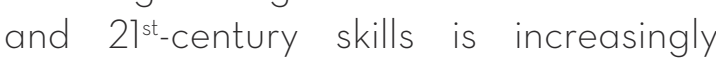
mportant for success in the labor market today and into the future. Employer surveys, labor market analyses, and academic studies all find that across the board there is a significant skills gap between the capabilities of youth and the needs of the labor market, and improvements to technology will only widen this gap. Using data from the United States, economists David H. Autor, Frank Levy, and Richard Murnane found that over time, the share of jobs requiring "routine" skills in the labor market has fallen over the past half century. Those requiring analytical and interpersona skills, however, have grown rapidly. ${ }^{23}$ World Bank research confirms this finding globally using data from 30 developing countries. ${ }^{24}$ The future workforce will need to be equipped with a robust skill set, including literacy and numeracy plus communication, collaboration, and critical thinking skills, to contribute to the economy and lead prosperous lives, meaning there is an urgent need for strong education systems to close the global skills gap.

Equally important as economic benefits, mproved levels of education and learning can have great impacts on health and the environment. For example, research has shown that half of the decline in child mortality globally between 1970 and 2009 is due to mothers having higher evels of education 25 Educated parents are more likely to be healthy themselves and also have well-nourished children, to get them vaccinated, and send them school. ${ }^{26}$ Additionally, educated mothers have fewer children, which in the long run can significantly slow population growth and improve environmental sustainability. ${ }^{27}$ Research has also shown that communities with higher levels of education are more resilient in the face of natural disasters. ${ }^{28}$

In the future, the benefits that education can bring to both individuals and societies will only become more and more vital. Global population growth, coupled with a demographic shift that will see an increasing share of the workforce come from developing regions, calls for more and better education for children and youth, particularly in sub-Saharan Africa and South Asia. Population growth and urbanization will pose new challenges to the environment and health, and young people will need a host of skills, including peple will need a host of skils, including navigate an increasingly connected world. These shifts call for a deeper understanding and greater attention to the drivers behind scaling quality learning opportunities to reach every child in the world.
L D R

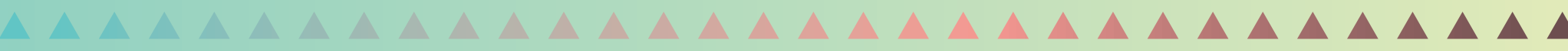

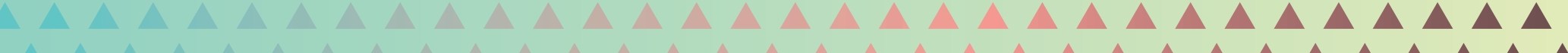
М M

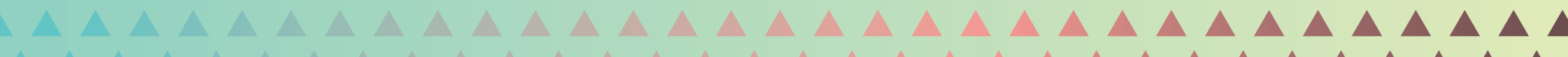

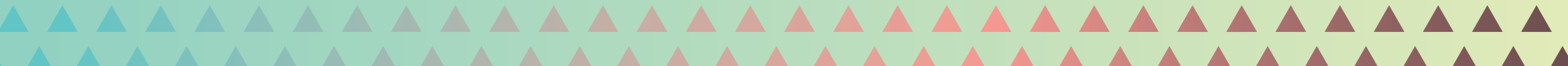

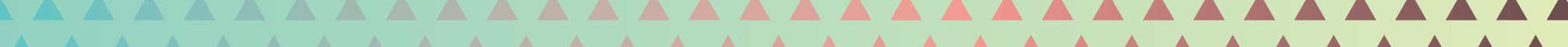

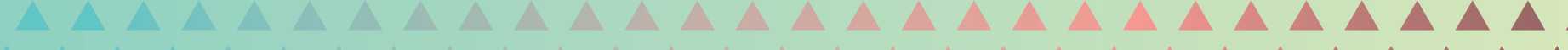

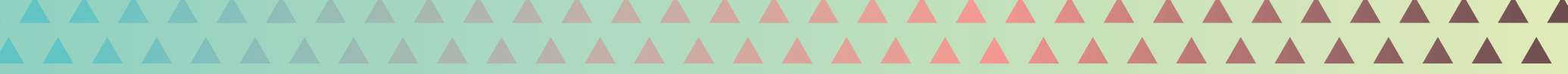
R C

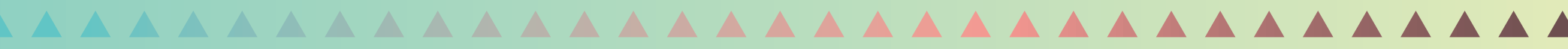

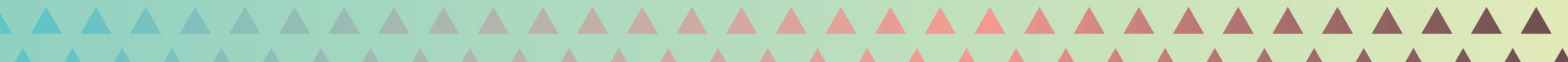

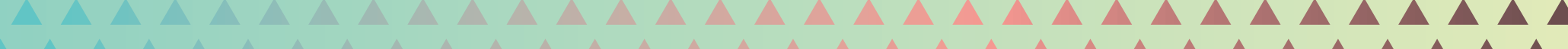

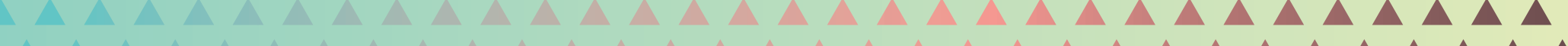

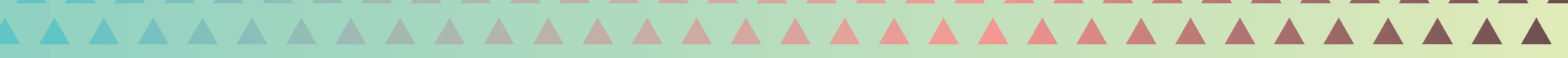
R R R

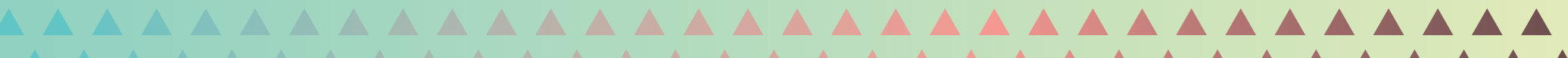

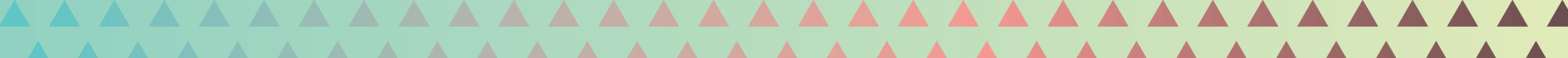

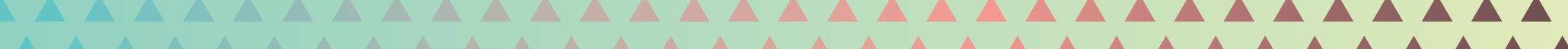

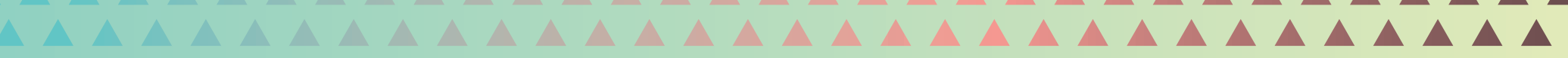

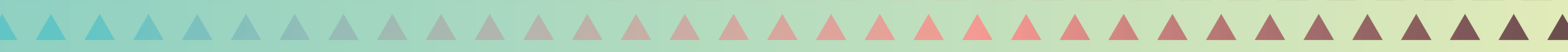
W L

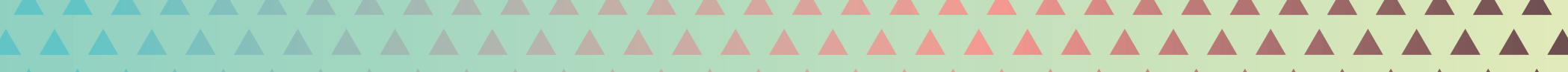
L

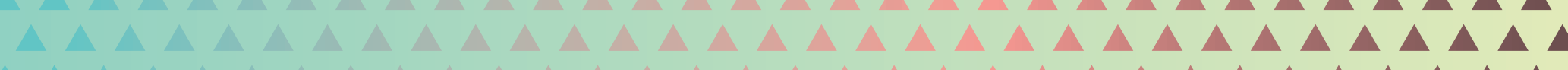
W

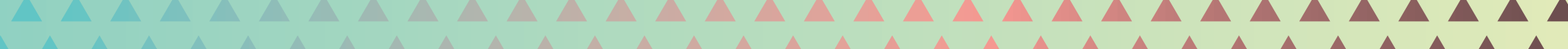

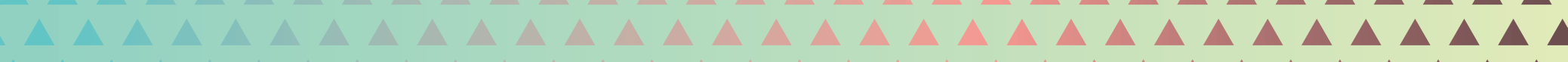

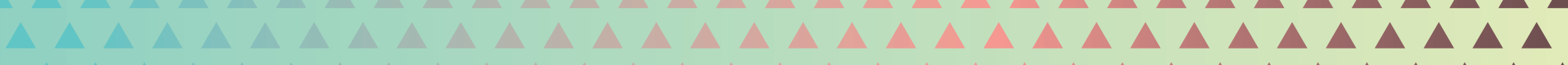





\section{Scaling so millions learn:}

Defining a global priority

A crucial question for the global education community, especially since the adoption of the SDGs, is how to ensure that more children have access to high-quality learning experiences that lead to lasting improvements in their lives. This is the focus of Millions Learning. Our central question is where and how quality education for children and youth has scaled in low- and middle-income countries. We seek to better understand the process behind how effective approaches to improving children's learning have scaled. Our interest in scaling is not focused on expanding brands or fixed models, but rather the process behind spreading the essential principles of effective teaching and learning models, which can be adapted in different contexts. While the term quality education can encompass a wide range of experiences and outcomes, we refer to the term in this report as improving learning outcomes across a diversity of competencies, a critical, although not comprehensive, aspect of quality education.

Millions Learning seeks to contribute to education's scaling story. Our insights

are informed by an in-depth literature review and by careful study of 14 cases (see Annex 2) that have, along different pathways and to differing degrees, successfully scaled approaches that improve children's learning experiences and outcomes. Ultimately we find and outcomes. Ulimately we find ecosystems are essential for effective approaches to go to scale. The goal of Millions Learning is to catalyze a discussion, based on new evidence and insight, around what needs to be done to scale quality education more quickly across the developing world.

While the term quality education can encompass a wide range of experiences and outcomes, we refer to the term in this report as improving learning outcomes across a diversity of competencies, a critical, although not comprehensive, aspect of quality education.

Our central question is where and how quality education for children and youth has scaled in low- and middleincome countries.

\section{A focus on scalling}

Our entry point is effective approaches or innovations to improving children's learning, whether led by government or nongovernmental actors, and how these approaches spread and are taken up across the education ecosystem. We focus on the action of scaling. How do approaches that have been demonstrably effective in improving children's learning become increasingly taken up, ultimately leading to actors across the system changing their policies or practices? In this way we are interested in the process by which effective practices or innovations have lasting influence on education ecosystems that support children's and youth's learning.

Here we focus on the education ecosystem, meaning the broad constellation of government, civil society, and private sector actors that are all engaged in educating children and youth in a particular country or context. Within this constellation there invariably is a mix of formal and nonformal learning opportunities for children and youth, although frequently not all

are strategically connected. ${ }^{29}$ In this ecosystem of actors, it is ultimately the government of ensuring that all children, especially those with little opportunity or resources, can exercise their right to a quality education

This focus on the process of scaling complements ongoing work on atscale education reforms, for example, the Overseas Development Institute's Development Progress initiative, the World Bank's Systems Approach for Better Education Results (SABER), and the Organisation for Economic Co-operation and Development's Strong Performers and Successful Reformers in Education series. ${ }^{30}$ Clearly, these perspectives of scaling and at-scale reforms have important intersections. However, we do not seek to duplicate the important work on at-scale education reform and hence have concentrated on the process by which effective interventions grow and expand in an effort to add to existing research on improving learning for all children.

\section{Addressing an evidence gap}

Fortunately, the education community and Patrick McEwan, has reviewed has been studying effective approaches numerous studies to identify effective for improving children's learning for approaches to improving student some time. For example, John Hattie, a learning. ${ }^{32}$ Across the developed and widely cited education researcher, has developing world, these various metacalled on the education community to analyses have demonstrated a number "stop ignoring what we know and scale of similarities, such as the importance of up success."31 Hattie, along with other student-centered interventions that focus researchers such as Katharine Conn on teaching and learning. While there 
is undoubtedly a need to continue to explore what works to improve learning across different skills, ages, and contexts, an equally pressing need is to scale effective approaches that have been shown to make a difference.

Where evidence on scaling and education does exist, it is frequently on expanding access to school and not on improving learning outcomes. This may be because across developing countries, one of the greatest scaling stories has been of expanding access to education, particularly at the primary level. Government policies, innovative programs, and foreign aid support have all played a role in helping get millions more children into school. Most recently global efforts have coalesced around this as it has been the central focus of the UN's past Millennium Development Goals. Additionally, the education literature for developing countries that is focused on improving learning primarily examines questions of what works and not how to scale what works. ${ }^{33}$ Reviewing the evidence related to Africa, Professor Martial Dembélé, Professor Joel Samoff, and Ambassador E. Molapi Sebatane stated that "accessible systematic empirical research on scaling up promising education initiatives in Africa is unfortunately quite limited." 34

In the research on internationa development outside of education, there is a growing evidence base on the process of scaling. This includes the publication Getting to Scale: How to Bring Development Solutions to Millions of Poor People and other ongoing work by Brookings Institution colleagues, ExpandNet, Management Systems International, and others 35 Unfortunately
We seek to build on the emerging body of evidence on how to scale not only children's access to education but also access to an education that helps them learn the skills they need to be successful in life.

education is not well covered in this scaling literature. One review of existing studies on international development and scaling found that only 16 of 158 included a focus on education.

How to scale education that delivers quality learning experiences and outcomes for children is an abiding concern for governments and civil society groups. Questions of what policies are effective, how to allocate resources, and what special programs merit long-term investment are being debated in the halls of ministries of education across the developing world. But how to support government or nongovernmental actors to scale effective approaches to learning is also a concern for the internationa development actors that support them. For example, a 2013 survey of 36 bilateral, multilateral, foundation, and corporate investors in global education identified going to scale as the biggest challenge they face in supporting developing countries to improve learning outcomes. ${ }^{37}$ In a review of international development projects, a mean duration of external assistance of less than two years virtually guarantees that they have not achieved results at scale and that they will not. ${ }^{38}$ As Professor Arntraud Hartmann and nonresident senior fellow at Brookings Johannes F. Linn state in their review of scaling in international development, "the focus on innovation is endemic in the aid industry and the development business, usually to the detriment of an adequate focus on learning and especially scaling up."

Hence, Millions Learning seeks to better understand education's scaling story. We seek to build on the emerging body of evidence on how children's access to education but also

\section{Defining scalling}

How scaling is defined influences how policymakers develop scaling strategies, how programs and policies are designed and implemented, how donors fund these interventions, and how researchers study the problem. There is not a single accepted definition of scaling that is used across sectors and actors. Rather, the term "scaling" has been used throughout the international development literature in many different ways, describing a variety of processes-expansion, replication, spread, explosion-and outcomes, such as expanding to new countries or institutionalizing practices. Building off definitions in the scaling literature, we use the term "scaling" to represent a range of pathways that expand and deepen effective approaches that lead to lasting improvements in people's lives. ${ }^{40}$ These approaches may consist of a policy, program, practice, or idea. Borrowing from the influential work of Cynthia

We use the term "scaling" to represent a range of pathways that expand and deepen effective approaches that lead to lasting improvements in people's lives. 


\section{Pathways to scale}

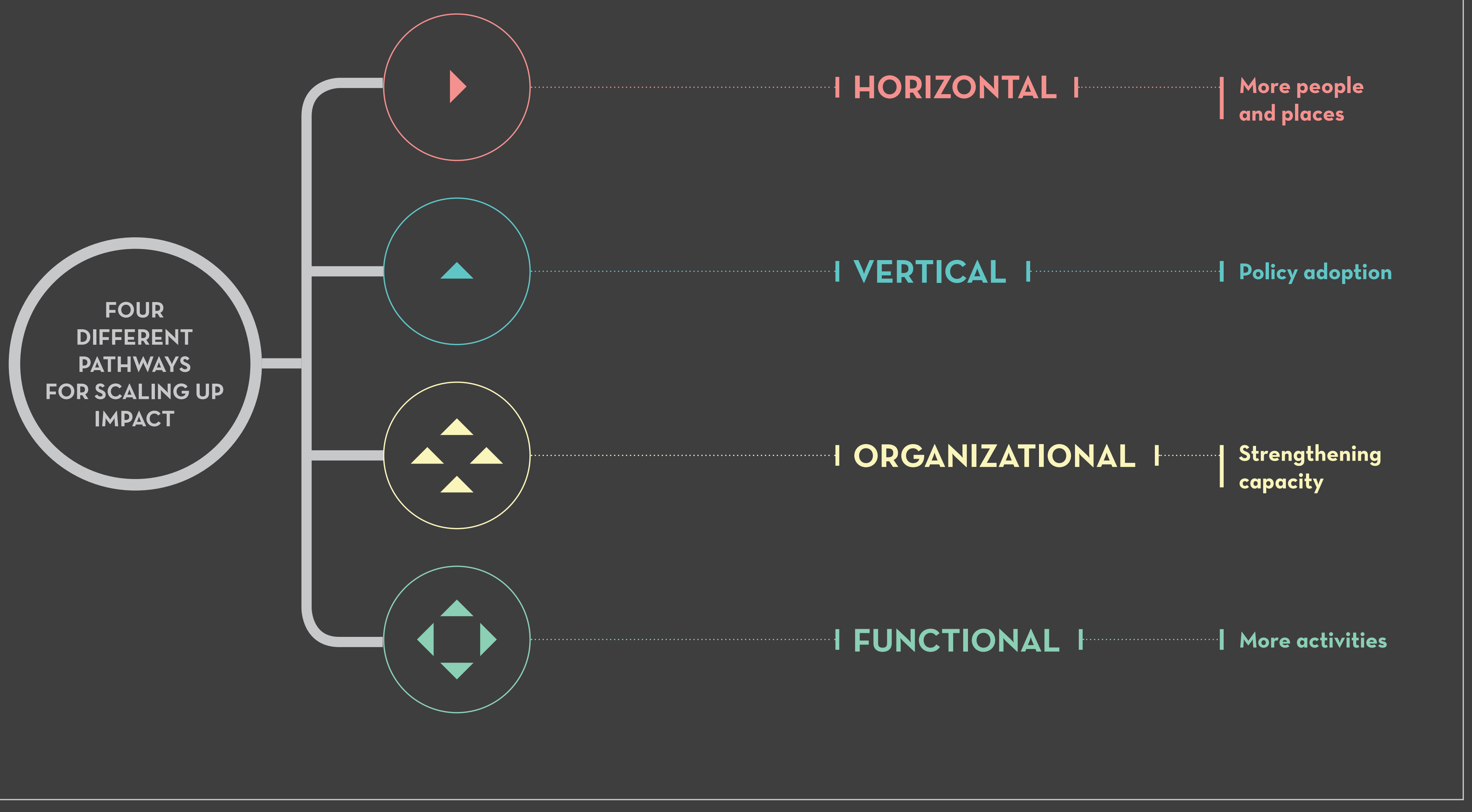


Box 1. Pathways for scaling effective approaches ${ }^{42}$

HORIZONTAL SCALING: More people and places

Pertains to breadth of coverage of an intervention, the expansion from one geographic area to another to reach more people and communities. The Zambion government, for example, piloted an approach to teacher development in one district, and today it has been expanded across all 10 provinces of the country. Sesame Workshop, started in the United States in 1969 with the goal of preparing children for school by combining entertainment with education. Today, Sesame Street reaches millions of children in more than 150 countries around the world.

VERTICAL SCALING: Policy adoption

Pertains to initiatives moving from local to nationwide engagement. The nongovernmental organization (NGO) Educate! is an example. It started os a school-based initiative in 2009, building a skills-based teaching approach and curricula on entrepreneurship, leadership, and workforce readiness skills across five districts in Uganda, targeting secondary schools. In 2012 after close collaboration with Educate!, the Ministry of Education in Uganda incorporated this effective approach into national policy by rolling out a skillsbased curriculum for the secondary school entrepreneurship subject.

\section{ORGANIZATIONAL SCALING: Strengthening capacity}

Pertains to increasing organizational strength to improve effectiveness, afficiency and sustainability of activities. This can also include the involvement of other institutions or the creation of a new entity. An example is Aflatoun International spinning off Child and Youth Finance International to create a broader global social movement to strengthen the financial capabilities of children and youth. The idea behind this global network is to pool resources and strengthen existing efforts of individual entities committed to financial inclusion and economic citizenship education for children and youth worldwide.

\section{FUNCTIONAL SCALING: More activities}

Pertains to the expansion of the type of activities or areas of engagement. The NGO BRAC started in Bangladesh in 1972 as a small rehabilitation project to help refugees returning from the country's liberation war. Over time, the NGO has expanded its work to include health interventions, nonformal and formal education, and microfinance, among other areas of community development.

\section{PURSUING MULTIPLE PATHWAYS}

As discussed, these pathways often happen in combination. For example, in 2012, Discovery Learning Alliance (DLA), a nonprofit organization using media to improve student learning and teacher effectiveness, had established "learning centers" in almost 500 schools in 16 countries. In 2015-2016, in a public private partnership with Discovery Communications and U.K. Department for International Development (DfID)'s Girls' Education Challenge (organizational), DLA expanded to 1,000 additional schools across new regions of Ghana, Kenya, and Nigeria (horizontal). In addition, DLA produced popular magazine-style talk shows in all three countries, which are changing attitudes and practices around girls' education (functional).

\section{Methods guiding Millions Learning}

To help answer our central question of where and how quality learning for children and youth has scaled in low- and middle-income countries, we have conducted primary and wecondary research. We have focused and youth, particularly early childhood through secondary education. Our analysis has looked at student learning across multiple competencies and relied on data from existing learning assessment tools to demonstrate improvements. Box 2 provides a detailed summary of the scope of the project.

Using a case study method, we conducted in-depth analysis of 14 cases where quality learning for children has been scaled to varying degrees. Out of more than 100 potential cases reviewed, cases were selected that demonstrated a measurable improvement of learning

differing degrees in a low- or middleincome country across a diversity of contexts and levels (see Annex 1 for complete selection criteria). We have endeavored to bring to light local, less well-known cases, as well as bettercases. The cases are not meant to represent the best models or approaches to improving learning; in fact, some of the approaches are being debated. Rather, we selected these cases to examine their scaling experience. an interesting story to tell-some contentious issue addressed, some bold course correction made in the process of expanding, a new angle or aspect that has yet to be explored. This was all a thanced against the desire to identify a range of scaling pathways and types of interventions from early childhood to secondary programs, as well as diversity in geography and populations reached. 


\section{Case study overview}

WORLDREADER

69 countries, starting in Ghana

Literacy in primary and secondary school

Over 5.6 million people to date \& 1.1 million people

reading digital books per month

SISTEMA DE APRENDIZAJE TUTORIAL (SAT)

Brazil, Colombia, Ecuador, Honduras, Nicaragua Alternotive secondery school progrem

Alternative secondary school program

300,000 students to date

EDUCATE!

Rwanda, Uganda

Secondary education, Entrepreneuric

development, Teacher training

120,000 students in 350 partner schools
or $12 \%$ of Ugandan secondary schools

SESAME WORKSHOP, SESAME STREET

More than 150 countries, starting

the United States

Early childhood development, Cognitive

Approximately 156 million children

FUNDACIÓN ESCUELA NUEVA

16 countries, starting in Colombia

Alternative primary and lower secondary school program

Over 5 million students

AMAZONAS STATE GOVERNMENT'S MEDIA CENTER

\section{Amazonas State, Brazil}

Formal secondary school distance learning program

300000 studts 2200 tutoe thing

\& 60 lecturing teachers to date

\section{LESSON STUDY, ZAMBIA}

\section{Zambia (all 10 provinces)}

Teaching training in primary and secondary schools

1.8 million students \& 46,000 teachers to date
TEACH FOR ALL

39 countries, starting in the United States and United Kingdom Alternative pathways to teaching in early childhood, primary, and secondary schoo 1.1 million students \& 52.323 tecch

INJAZ, JORDAN Jordan (all 12 governorates) Financial literacy, Work readiness, Entrepreneuricl
development in secondary school 1.2 million students \& over 23,000 volunteers to date

ROOM TO READ, LITERACY PROGRAM Bangladesh, Cambodia, India, Laos, Nepal, South Africa, Eorly gro, Early grade reading, Teacher training 110,000 students and 2,000 teachers (Literacy Program specifically) a IO

AFLATOUN INTERNATIONAL

116 countries, starting in Indic Entrepreneurial development, Social and financio early childhood, primary, and secondary school Almost 4 million students \& 34,000 teachers,
facilitators, and peer educators each year

BRAC, NON-FORMAL PRIMARY EDUCATION

Afghanistan, Bangladesh, Pakistan, Philippines, South Sudan Alternative primary school program Escuela
Nueva ? $\rightarrow$
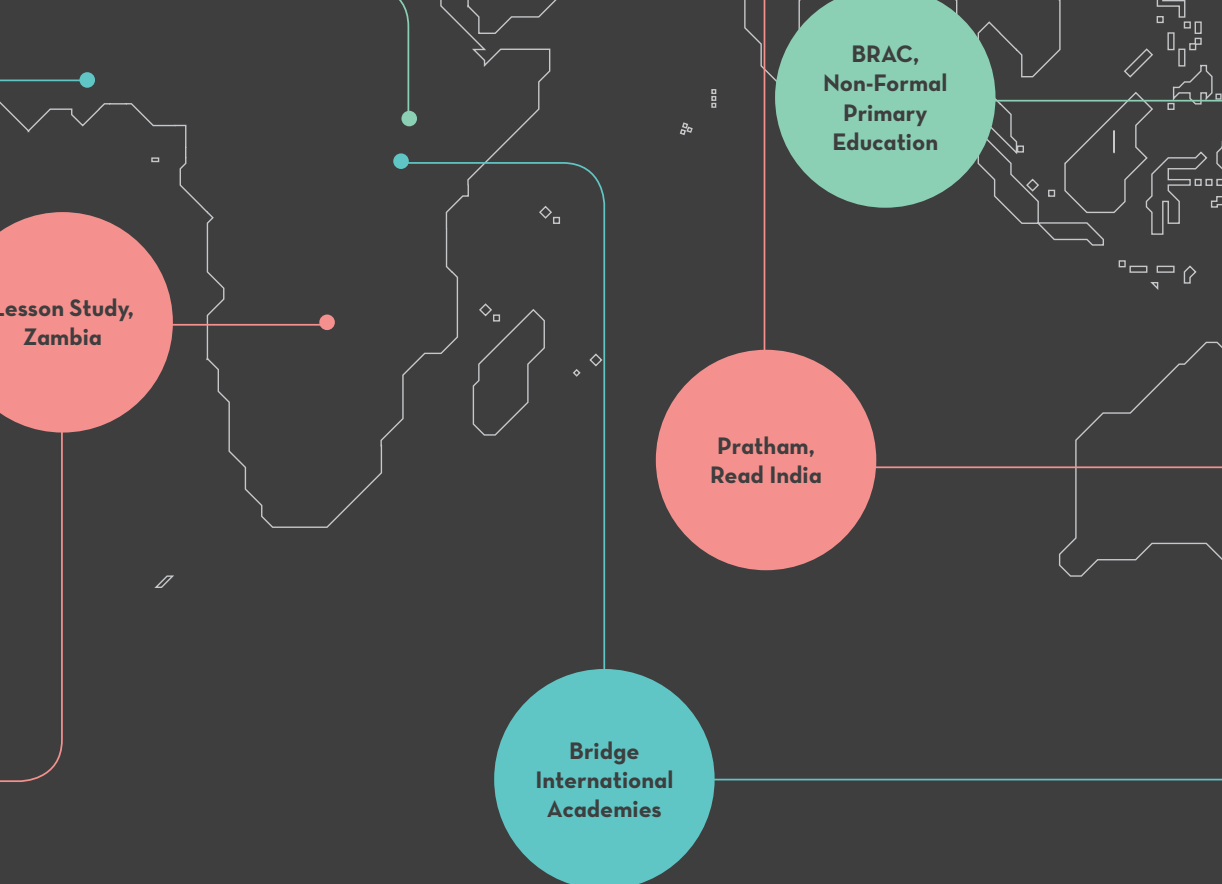

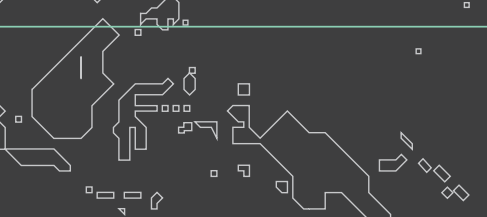
dents in Bangladesh \& over 900,000 students in other four NFPE countries each year PRATHAM, READ INDIA $\diamond_{\text {o }}^{\text {India (across } 23 \text { states) }}$ Oye 350,000 students directly in rural areas from 2014-2015 \& BRIDGE INTERNATIONAL ACADEMIES 
Box 2. Defining the scope of the study

LEARNING:

Learning is defined as a process whereby people develop a range of knowledge, skills, and attitudes that ultimately enrich their lives..$^{43}$ Learning can be measured across multiple competencies, including literacy, numeracy, science, social and emotional learning, and critical thinking. We are guided by the global Learning Metrics Task Force, which has engaged a broad range of policymakers, academics, and other actors on the topic of what competencies are important for all children and youth. The task force identifies seven domains of learning as particularly relevant, as seen in Figure 6 below. ${ }^{44}$ As such, learning can take place in diverse relevant, as seen in Figure 6 bellow. "As such, learning can take place in diverse international, regional, or national assessments; household surveys; evaluations; or other methods that are clearly defined to demonstrate progress in learning; or strong indication of improvements in learning, along with proxy indicators, such as decreases in dropout rates and increases in progression rates.

Figure 6. Learning Metrics Task Force:

Seven domains of learning

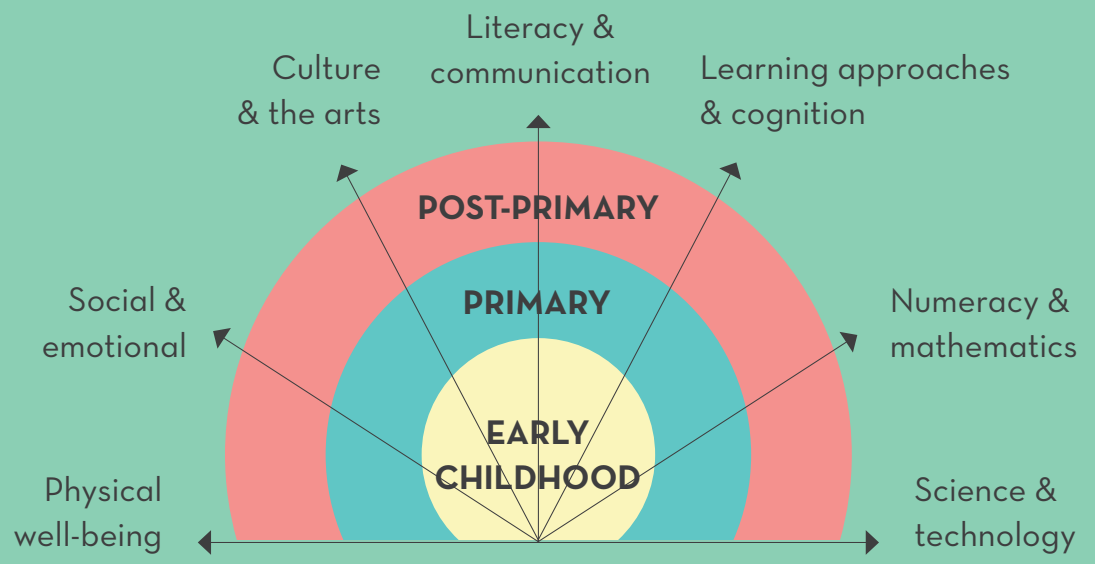

Source: Learning Metrics Task Force

EDUCATION INTERVENTIONS:

While many factors, such as improved nutrition, contribute to children's learning, we have focused on examining education interventions. These can be programs or policies that take place in formal or nonformal settings where intentional learning occurs.

\section{CHILDREN AND YOUTH:}

We have focused broadly on children and youth. We have not used a stric age criterion in the study but three main educational levels instead, using the internationally accepted definitions of the following:

EARLY CHILDHOOD: Approximate age range is zero to 8. Birth through school entry, including early childhood education or pre-primary.

PRIMARY EDUCATION: Approximate age range is 5 to 15 . Includes formal primary school and nonformal programs, such as accelerated learning.

SECONDARY EDUCATION: Approximate age range is 10 to 19. Includes formal lower and upper secondary and nonformal education, such as vocational training and second-chance learning programs. ${ }^{45}$

\section{LOW- AND MIDDLE-INCOME COUNTRIES:}

For our purposes, we are focusing on lower, low-middle, or upper-middle income countries as defined by the World Bank which classifies economies based on gross national income (GNI) per capita. ${ }^{46}$ Within this country context, we are particularly interested in marginalized groups, such as children and youth living in extreme poverty, crisis-affected areas, girls from rural areas, children and young people with disabilities, and ethnic minorities, where access to quality learning has been particularly limited.

To examine the cases, we analyzed data from a mix of desk-based research, indepth interviews, and field visits. We also surveyed various literatures on scaling, including literature on international development and scaling, implementation science, product development, behaviora economics and psychology, and design thinking. We have been generously guided by an International Advisory Panel, made up of experts who represent government, philanthropy, business, nonprofits, and academia, including from sectors outside of education, such as technology and health (see front cover interior for complete list of advisors and affiliations).
We have also greatly benefited from extensive consultations, through a series of roundtables, with practitioners, funders educators, academics, and business leaders.

In addition to the 14 cases where we conducted an in-depth review, we drew from other cases that illustrate specific findings in the report These included. Camfed, Discovery Learning Alliance, M-PESA Naandi Foundation, Dunjab Education Sector Reform Program, Rapid Results Institute, Rocketship Education, RTI International, Schools of Tomorrow, and STIR Education. 



\section{Findings:}

How has scaling happened?

Millions Learning finds that scaling children's access to quality education is possibleeven in some of the most marginalized communities. From the slums of New Delhi to the rainforest in Brazil, transformational change in learning is happening in many places around the world.

Inclusive and adaptive education ecosystems that allow space for new approaches and adapt policies or practices to take up approaches that are effective are central to this transformational change. Scaling quality learning requires governments, along with civil society, business, and other actors, to pivot and adapt and come up with creative solutions to roadblocks. More frequently than not, it also requires these education actors to work togethe

How did the 14 cases examined do it, and what can we learn from them? What follows is the education scaling story that these cases reveal and the contributions they make to the existing body of evidence on scaling in international development.
Perhaps it is not surprising that where we do see more radical overhauls to how to improve learning, they often occur in new, chaotic spaces where innovations can flourish.

innovation theory, described it in 1962 as "the process in which an innovation is communicated though certain channels over time among the members of a social system." ${ }^{48}$ Hartmann and Linn explain the relevance of Rogers' model to the discussion of scaling by noting that it "highlights key attributes that facilitate successful application and expansion of innovative ideas and techniques." 49 The journalist Malcolm Gladwell popularized this concept in his 2002 bestseller
The Tipping Point as the moment when there is critical mass acceptance of an idea or intervention. Other authors provide further insight into this notion of moving from the margins to the center. For example, author Simon Sinek, in describing how great leaders inspire action, discusses the law of diffusion of innovation and the adoption curve for a product, service, or idea. He focuses on the 13.5 percent of the population who are the "early adopters" as being critical to achieving mass-market success. Author Geoffrey Moore describes the moment of securing the 13.5 percent of early adopters as "crossing the chasm" 50 One useful framework developed by Nesta, a UK-based international ${ }^{2}$ by illustrates the pathway along which an innovation can move from the periphery to the center.

\section{Scaling success from the margins}

We examined cases that for the most part began at the margins-in some instances under the radar-rather than large-scale reforms inside mainstream education systems. Often, because of choices made earlier, it can be more difficult to reform an existing system than to scale from scratch. One reason for the difficulty of tackling at-scale education reform could be that when it comes to education, we are talking about addressing an already "at-scale" problem such as poor learning outcomes. ${ }^{4}$

Therefore, perhaps it is not surprising that where we do see more radical overhauls to how to improve learning, they often occur in new, chaotic spaces where innovations can flourish. We found that more often than not, the effective new approaches started on the margins before the idea spread and was taken up more broadly. What constituted the margins varied by case. For some it was a flexible central government giving freedom to its officials within a district to try a new approach. For others it was a community movement that developed new ways of reaching marginalized children who had limited educational options.

This notion of moving from the periphery to the center is one that has long been found in theories of scaling innovation. Everett Rogers, a sociologist who is recognized as the father of diffusion of
Box 3. Lesson Study, Zambia

Lesson Study is a Japanese-originated practice of peer-to-peer collaborative learning, whereby primary and secondary teachers share knowledge and skills to improve teaching through planning, demonstrating, and assessing lessons. Lesson Study has spread to more than 50 countries. The government of Zambia, in partnership with the Japan Internationc Cooperation Agency, started Lesson Study in 2005. The approach aims to strengthen school systems by encouraging teamwork among teachers and improving the supervision of school managers. Lesson Study has reached 1.8 million students and 46,000 teachers in all 10 Zambian provinces to 1.8 million students and 46,000 teachers in all 10 Zambian provinces to Study, Zambian students have more opportunities to conduct hands-on ctivities and develop critical thinking, presentation, and teamwork skills. Furthermore, teachers switched from traditional chalk and talk methods to an inquiry approach, allowing for students' learning to transform from instructed study to creative thinking. 


\section{Scaling success from the margins}

A NEW IDEA OR APPROACH OFTEN BEGINS ON THE MARGINS BEFORE BEING TAKEN UP MORE BROADLY

Experimentation

can happen

under the radar

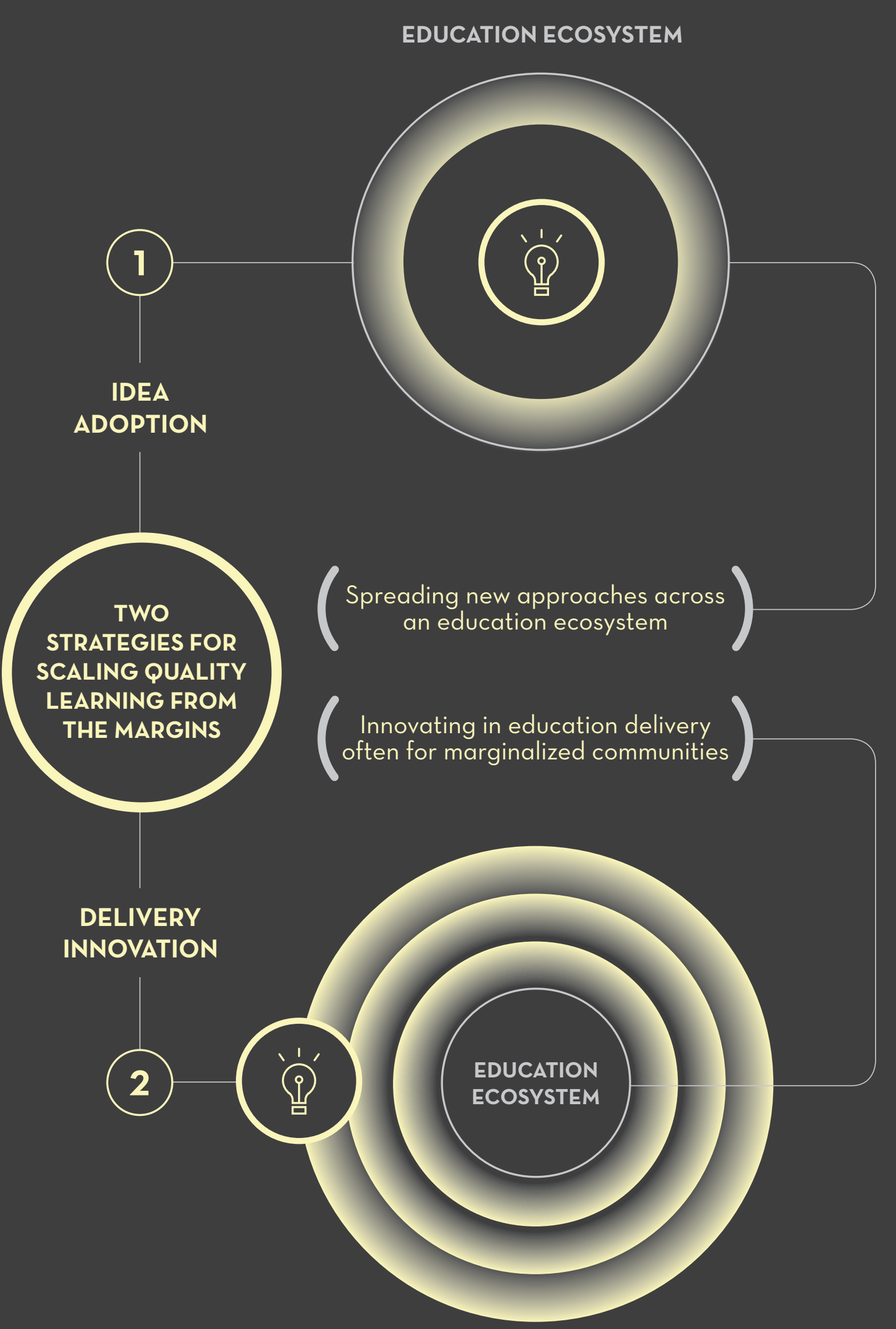


Idea adoption and delivery innovation: Two strategies for scaling quality learning from the margins

Scaling quality learning from the margins has occurred along two primary pathways within developing countries: by spreading new approaches across an education ecosystem and by innovating in education delivery for marginalized communities. With the former, idea adoption, effective new approaches to improving components of the teaching and learning process-from curriculum, to materials, to teacher development-have spread across education ecosystems and been adopted by different actors. Lesson Study is an example where the government of Zambia, in partnership with the Japan International Cooperation Agency (JICA), adapted a Japanese-originated practice of peer-to-peer, collaborative learning for teachers to the Zambian

context. With the latter, delivery innovation, new education delivery approaches for the most marginalized communities have been developed and grown within and across countries An example is Sistema de Aprendizaje Tutorial (SAT) in Honduras, a specifically tailored and targeted alternative secondary education program that is delivered by an NGO, with support from the national government, to meet the education needs and realities of rural youth.

Looking across the range of programs and policies discussed, some common patterns and themes emerge. These are the core ingredients that have enabled the scaling of quality learning in the 14 cases and that are supported across the broader scaling literature.

\section{Box 4. Sistema de Aprendizaje Tutorial}

Sistema de Aprendizaje Tutorial (Tutorial Learning System), or SAT is an alternative secondary education program for rural youth in Latin Americo. The program's trained teachers, or tutors, utilize a "learn by doing" methodology to promote rural education and community development in marginalized communities. SAT integrates relevant theory and practice into teaching methods, such as learning mathematics and science in the context of agricultural innovation. The Colombian NGO Foundation for the Application and Teaching of the Science (FUNDAEC) developed SAT in the ate 1970s. Today it is implemented in Colombic, Honduras, Nicaragua, Brazil, and Ecuador (Guatemala also hosted an SAT program until 2005) and has reached an estimated 300,000 students to date. SAT is accredited and recognized by governments in Colombia and Honduras, and as a result, graduates can continue on to college or get jobs that require secondary degrees. $\Delta$ number of peer-reviewed studies indicate that $S \Delta T$ in Honduras improves learning outcomes, women's empowerment, and civic responsibility.

\section{Scalling learning: 14 core ingredients}

We have identified 14 core ingredients that are organized around four main areas

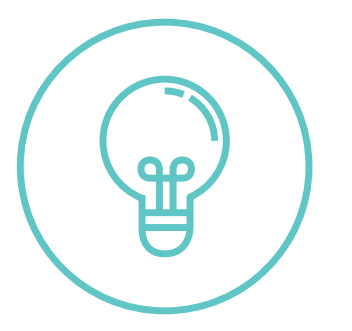

\section{DESIGN}

Improving learning at scale starts with committed leaders planning for scale from the outset.

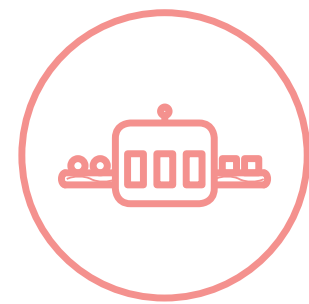

\section{DELIVERY}

As important as design is, attention to the operational realities of implementing or delivering at large-scale is essential. This involves a combination of technical and political actions.

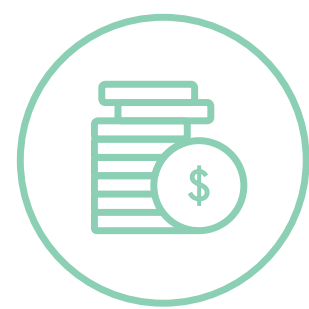

\section{FINANCE}

While resources certainly matter when it comes to scaling, what matters is often as much about how they are allocated as about absolute amounts.

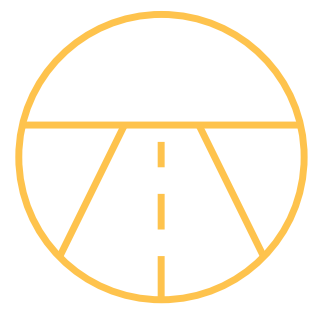

\section{ENABLING ENVIRONMENT}

As critical as these three other aspects are, scaling does not happen in a vacuum. Largely guided by governments from national to local, the ecosystem in which programs or policies operate plays a critical role in facilitating or impeding the scaling process.

The right combination of ingredients depends on the context. Clearly, no onesize-fits-all model or blueprint to scale can be replicated across countries. Reviews of scaling education in Africa found that context often explained why scaling of a reform succeeded or failed in a given setting and resulted in just the opposite outcome in another. ${ }^{5}$
Similarly, Linn finds that the most important drivers of scaling are the specific organizations and political economy considerations facilitating or impeding the scaling process. ${ }^{52}$ Indeed, we see a range of ingredients deployed in various combinations that, depending on the context, can promote the scaling of children's learning 


\section{Scaling learning:}

14 core ingredients

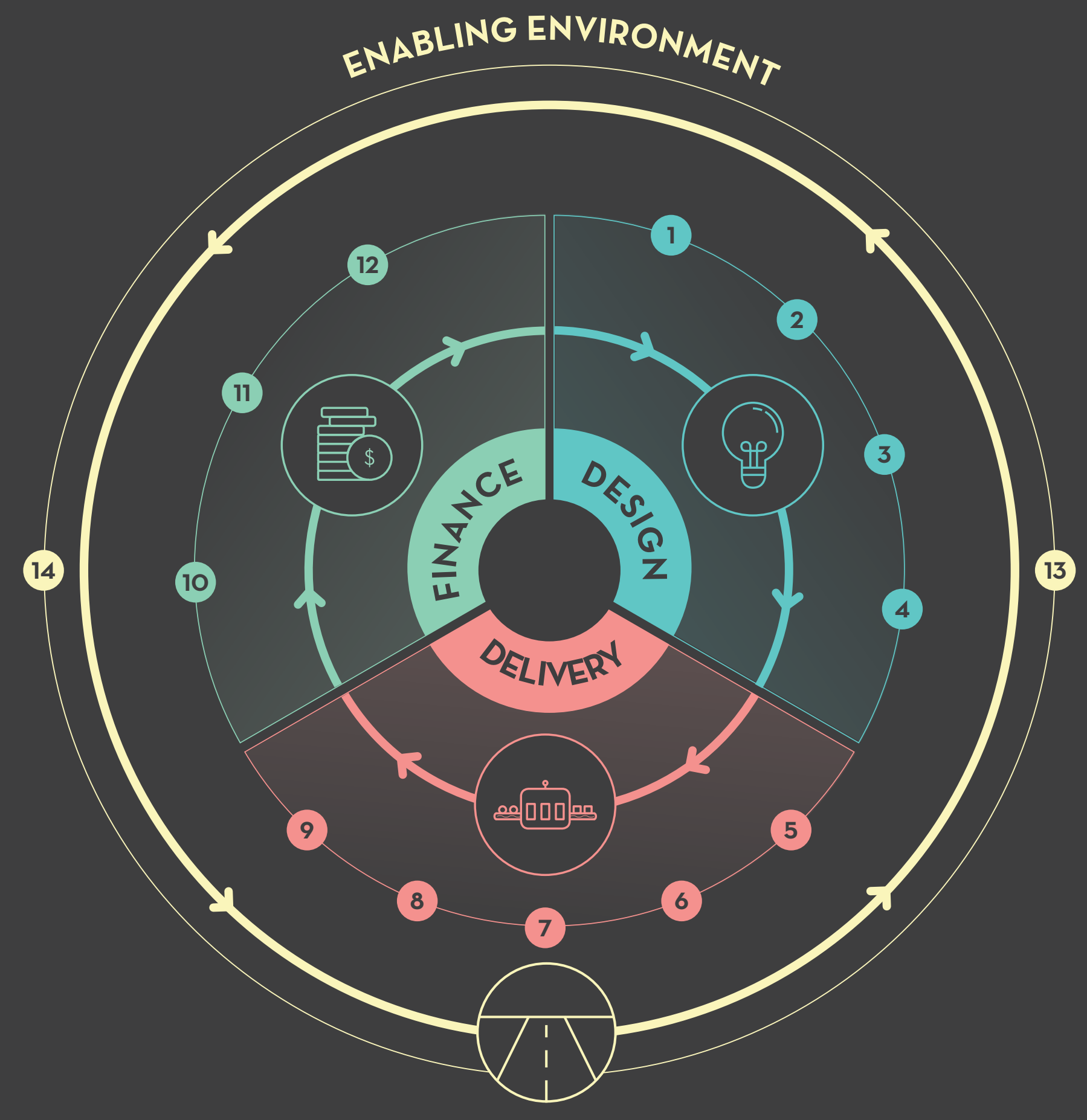

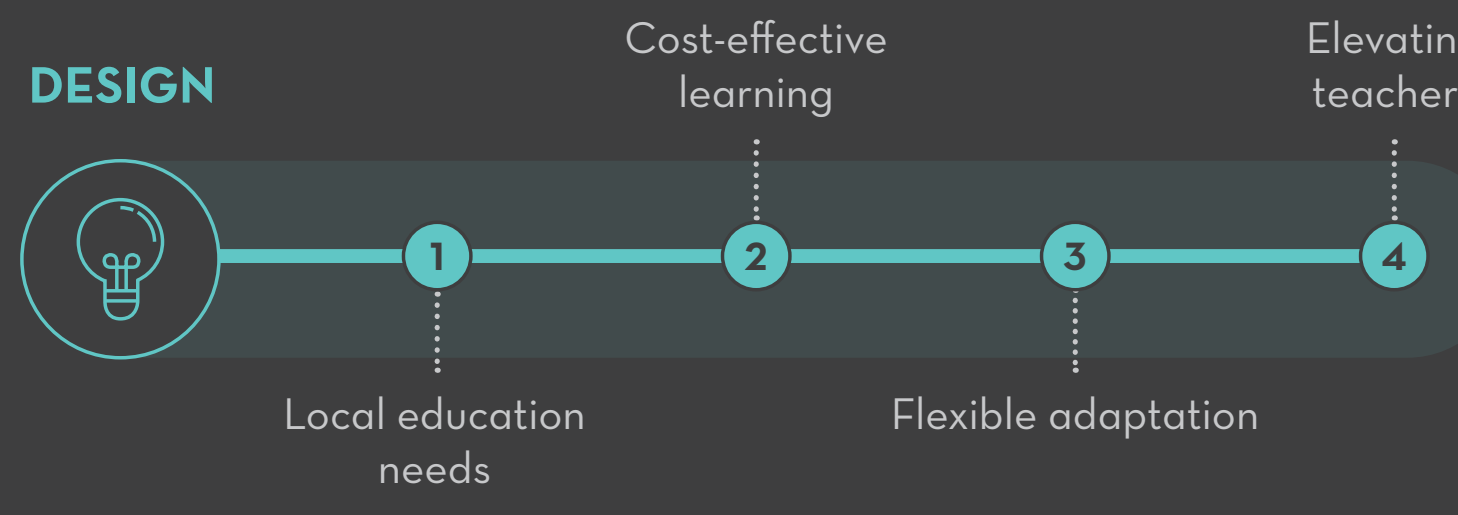
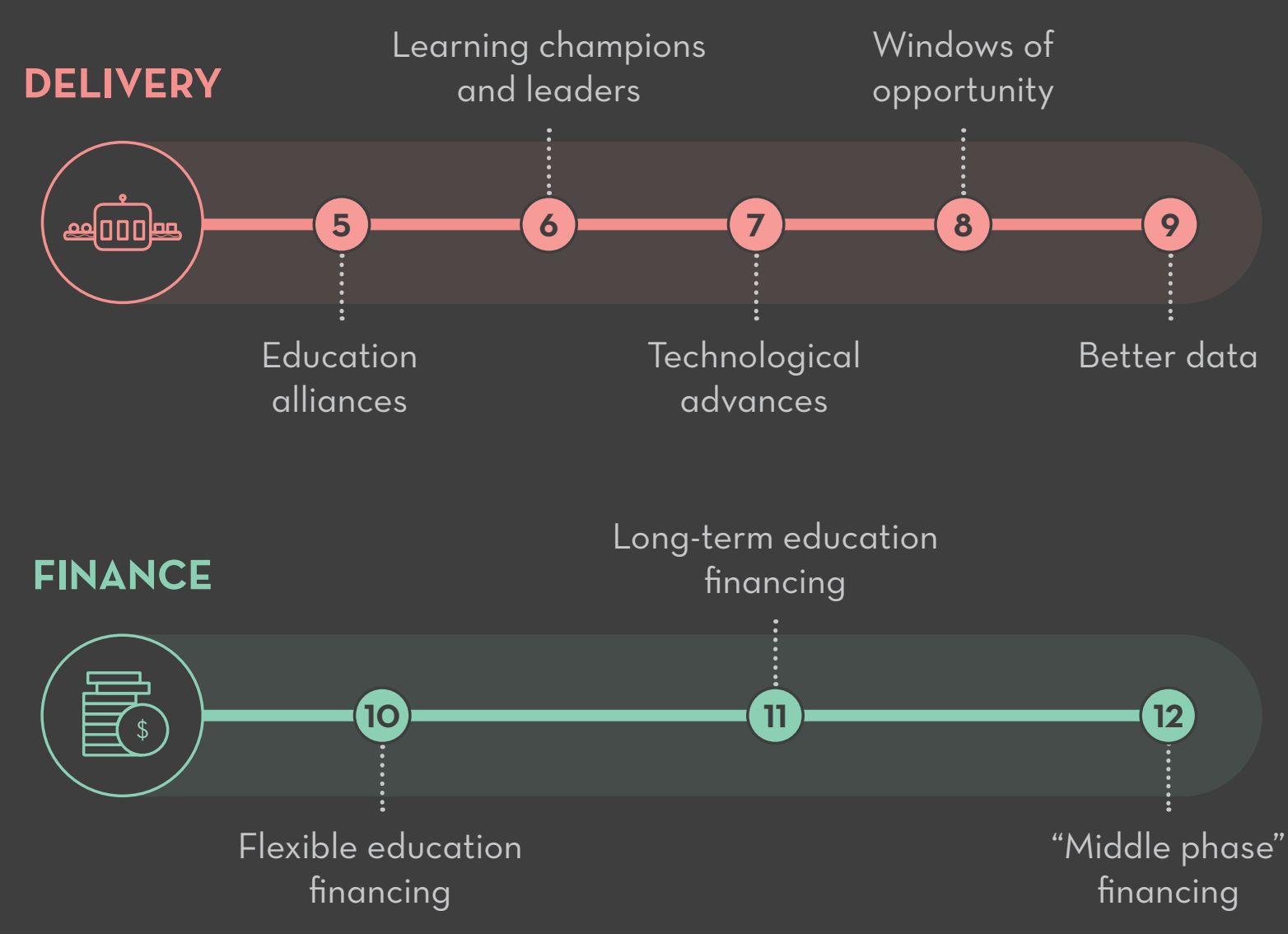

ENABLING ENVIRONMENT

Supportive policy

environment

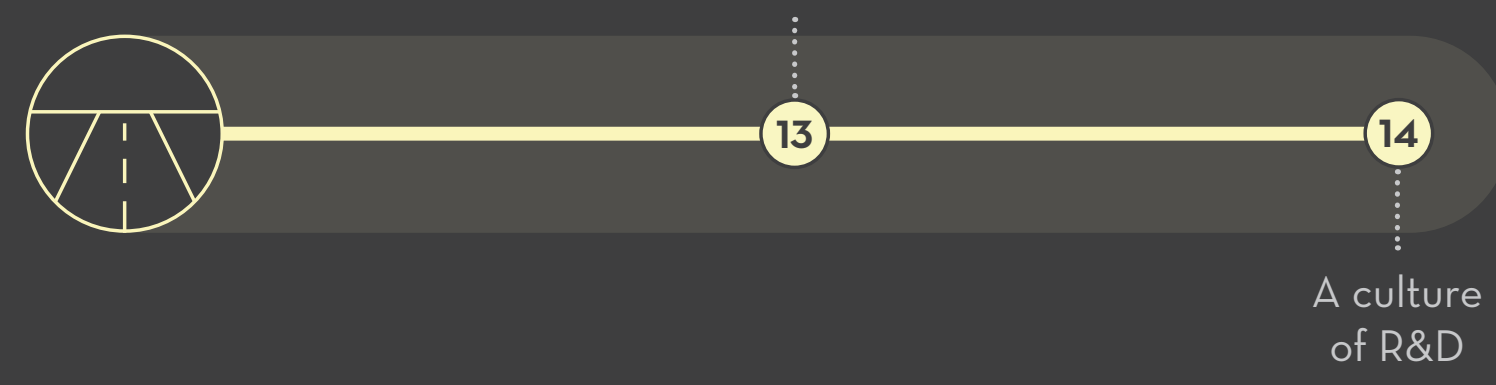




\section{Introduction}

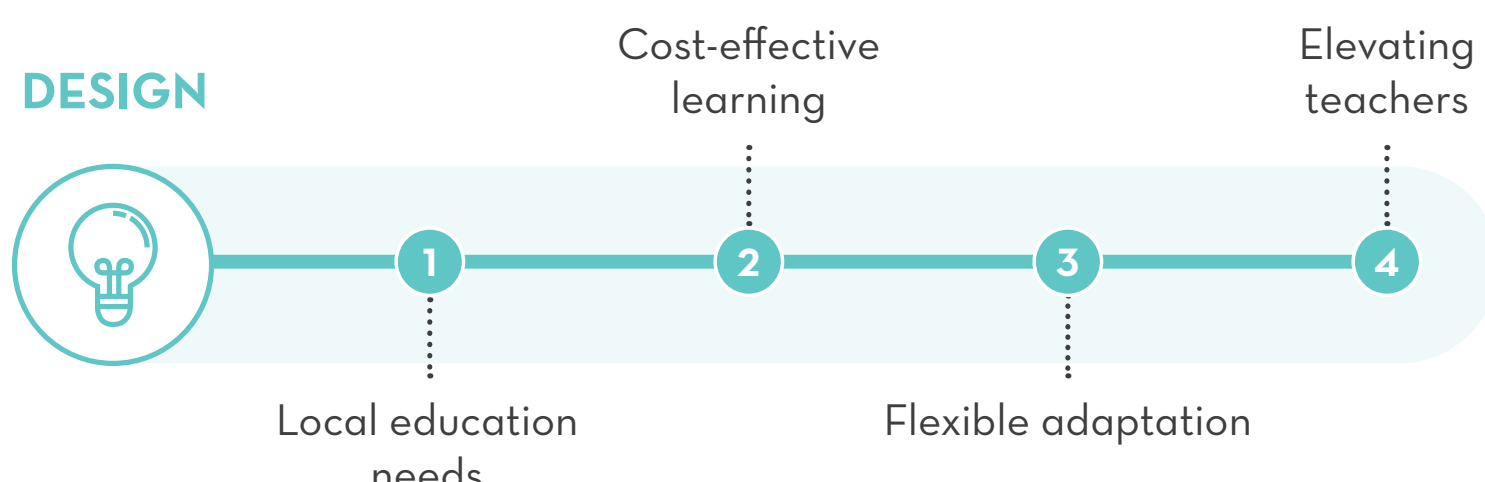

The guidance from the scaling literature strongly suggests that going to scale must be designed for from the outset..$^{53}$ This does not imply limitless scale, but rather, a clear vision of what the endgame is and a theory of change about the best way to get there. ${ }^{54}$ For example, an endgame could be government adoption of a practice, and a strategy to get there could be through advising the Ministry of Education on a curriculum reform. It is worth noting that not every effective intervention should scale; some are effective by the very nature of their small size. But if scale is the objective, then experience in education and other sectors shows that it should be carefully planned from the start.

The case studies reviewed and additional evidence examined point to the following actions that are central to designing for scale from the outset. First and foremost, any program or policy must tap into local education needs as identified by any and all of students, teachers, and parents. However, responding to local demand is not enough. Interventions must also ensure that costs are feasible at scale as well as ide that are integral to the success learning intervention, while adapting other pieces based on the local context. Lastly, elevating teachers and leveraging community expertise have been an important approach to scaling in lowresource environments.

Going to scale must be designed for from the outset. This does not imply limitless scale, but rather, a clear vision of what the endgame is.

\section{Local education needs:}

Interventions should be designed in response to local demand and should ensure the participation of end-users.

One essential element of designing with a way that was locally relevant-think scale in mind is to develop programs computers or textbooks gathering dust and policies that students, parents, or in cabinets. Even in the case studies teachers actually want-not just what examined for this report, there are governments, implementers, or donors examples where programs did not initially think they need. While this sounds take into account a community's needs obvious, there are countless examples of and needed to make changes along the well-meaning and thoughtful education way. In particular, the cases underscored interventions that are not taken up simply the importance of ensuring participation because there was not a real demand from the community from the start and for them or they were not designed in building in local accountability.

One essential element of designing with scale in mind is to develop programs and policies that students, parents, or teachers actually want-not just what governments, implementers, or donors think they need.

\section{Ensuring participation of local community}

Beginning in the 1970s in response to criticisms of what were seen as topdown approaches in development participatory approaches to local development increasingly gained attention and importance. The underlying premise was that enabling communities and citizens to define priorities and engage in the design of a program or policy would ensure a process that was more inclusive and responsive to the needs of the poor. ${ }^{55}$ As Jeffrey Bradach partner and co-founder at The Bridgespan Group, writes, "success of transformative scale often hinges on involvement of local communities in formulation and implementation of solutions."56 Participatory approaches not only ensure more appropriately designed interventions but also generate the buy-in and create champions needed to support and sustain scale. 
According to the Monitor Group, "People living at the base of the pyramid should be seen as customers and not beneficiaries; they will spend their money, or switch livelihoods, or invest valuable time, only if they calculate the transaction to be worth their while."57 For example, even though students in SAT's alternative secondary schools, known as "centers" in Honduras, scored higher on tests than students in traditional schools, some parents were initially resistant to sending their children, as they believed alternative education to be an inferior form of schooling. ${ }^{58}$ Over time, once families could see the results of the program, including university admission exam scores, they became supportive and the stigma disappeared. Bridge International Academies, a forprofit company that owns and operates low-cost private schools, originally opened

for business in Kenya without uniforms in an attempt to keep the school affordable for families living under the poverty line. It quickly learned, however, that communities wanted uniforms because they bestowed a sense of identity and pride in the students, regardless of the additional expense.

Escuela Nueva, started by the not-for-profit organization Fundación Escuela Nueva, is an alternative primary school moder that began in ruct areas of Colombia in the mid-1970s and today has reached 5 million students in 16 countries, from Honduras to Vietnam to India..$^{59}$ It effectively tapped into the demand among parents in marginalized communities to have their children enrolled in scho ools that foster earning and development. It did this by emphasizing participation-of students, teachers, school administrators, and the

\section{Box 6. Fundación Escuela Nueva}

Fundación Escuela Nueva, a nongovernmental organization behind the Escuela Nueva school model, works to improve the quality of rural primary and lower secondary schools. The model emphasizes student, teacher, school administrator, and community participation in its active, cooperative, and personalized learning model, by which students teach each other and themselves, while teachers and administrators act as facilitators and coaches, respectively. Established in Colombia in 1987, Escuela Nueva grew pectively. Established in Colombia in 1987, Escuela primary schools that dates back to the 1970 s. Since then, Escuela Nueva has been adopted as a national Colombian policy and has scaled to 16 countries, reaching more than 5 million students. According to an independent study, students in grades three and five in Escuela Nueva schools in Colombic have achieved higher language and mathematics scores, with significantly lower dropout and repetition rates, in rural schools with the program than in traditional schools without the program.

broader community. In the Fundación Escuela Nueva approach, the curriculum is designed to enable students to pace themselves and to foster collaboration through "cooperative learning" techniques. Fundamental to Escuela Nueva's model are its learning guides, which enable self-paced, self-directed learning in a structural pedagogical way. Teachers and students validate these learning guides for relevance and usability. The school calendar is adjus account that children's learning was being disrupted because of seasonal demands to work in the field.

Bridge International Academies designs its program based on vast amounts of data collected via various methods from community members, students, parents, and teachers. Constant revisions are made based on student results and teacher and family feedback and preferences, aided in part by innovative mechanisms, such as a 24-hour customer care hotline that receives more than 2,000 calls a day. Bridge and Fundación Escuela Nueva demonstrate that, regardless of the financing structure, any effective largescale education program must tap into local demand and needs.

Other examples from Asia to Africa to Central America also highlight how initiatives that are designed to be relevant to the educational needs and interests of low-income communities can scale-and how they fail to do so when they have not adequately engaged or understood community demand.

One of BRAC's initial projects in the early 1970s, adult literacy classes in a remote rural area in Bangladesh, was considered 
to be a "dismal failure." $\$ 0$ It built village centers in northeast Bangladesh, where villagers could come in the evening to take free literacy and numeracy classes. BRAC candidly shared why after 18 months, only 5 percent of the original 5,000 villagers still came to the centers: because the idea originated from BRAC senior management and not the villagers. BRAC had assumed that villagers would want to come together to learn to read and write, but after a long day's work people wanted to learn things that were more immediately usable in their daily lives. BRAC conducted a survey to identify the villagers' actual concerns and revised the classes to teach more relevant subjects, such as animal husbandry, health, nutrition, and child care. The reintroduced classes became so popular that parents asked for something similar for their children. Thus, BRAC's Non-Formal Primary Education (NFPE) program was launched, and it has become the world's largest private, secular school system, ${ }^{61}$ accounting for roughly 5 percent of all primary school enrollment in Bangladesh, with formal recognition by the government.

BRAC learned this lesson once again when designing its Empowerment and Livelihoodfor Adolescents (ELA)program, which is active in five sub-Saharan African countries. In South Sudan, the program sought to serve young women 15 years and older, in conformity with the an econon provided funding for ELA in that country. However, BRAC found that in order to achieve its objectives, including reducing

\section{Box 7. BRAC, Non-Formal Primary Education}

BRAC's Non-Formal Primary Education (NFPE) program provides children who dropped out of or never enrolled in primary school with an opportunity to learn. It condenses the general, five-year primary school curriculum into four years, allowing students, upon completion, to take national secondary school exams and transition into public or private secondary schools. The program is taught by local teachers, recruited from the community (who usually stoy with each cohort of children for the entire four years), and focuses on cognitive subjects, such as Bengali, English, mathematics, science, and social science, and noncognitive subjects, such as arts and communication. BRAC was launched in Bangladesh in the early 1980s, and over time, its NFPE program has expanded to Afghanistan, Pakistan, Philippines, and South Sudan. Today, BRAC NFPE reaches 670,000 students in Bangladesh and over 900,000 students in BRAC's other four NFPE countries each year. The organization works closely with the Bangladeshi government, and many consider it to be the largest private school network in the world. BRAC's dropout rate is below 5 percent, and its pass rate routinely surpasses government school rates in Bangladesh.

Box 8. Aflatoun International

Aflatoun International aims to build children's personal, interpersonal, financial, and entrepreneurial skills through social and financial education programs in formal early childhood, primary, and secondary school settings, as well as in nonformal settings. Taking a social franchise approach, Aflatoun International works through local partners that train teachers and trainers to educate children, both those who are in school and those who are out of school, about their rights, financial savings, and how to start enterprises. Established in Indiain 1991, Aflatoun is engaged in 116 countries and reaches almost 4 million children and 34,000 teachers, facilitators, and peer educators each year. Recently, Aflatoun and its partners have been working with governments in 28 countries to integrate social and financial education into national curricula. Findings from a systematic review and meta-analysis of 21 randomized controlled trials on financial education interventions targeting children and youth found that Aflatoun's effect on financial behavior, or savings and resource allocation habits, was more than double the average effect across the 26 interventions studied.

child marriage and promoting sexual and reproductive health and rights, ELA needed to reach girls earlier, at ages 11 to 14 , and revised its program accordingly.

Often overlooked is the role and interests that teachers have in they work. Alladoun Internationa, a social they work. Aflatoun International, a social and financial education program in early childhood, primary and secondary school

\section{Strengthening accountability to respond to local education needs}

Improving accountability between As Linn argues, "The longer the chain education providers and clients (students, of accountability between design and families, and teachers) is another important ultimate beneficiaries, the greater the strategy for tapping into local demand. likelihood that interests will diverge." 62 The 
World Bank highlights this relationship in its triangle of accountability. Most public sector production uses the "long route" of accountability, whereby citizens or clients must rely on political processes to leverage their voices and influence the state's compact with providers rather than the ability to hold service providers directly accountable. ${ }^{33}$

Many cases reviewed used a community co-investment model as a strategy for gauging community interest and promoting ownership and accountability. As part of any new project activity, Room to Read, an NGO focused on improving literacy and gender equality in education, requires a community contribution to the overalt effort of approximately 15 percent of total costs. This can be in the form of cash, labor, or in-kind donations such as land use, front commitment generates a different set of expectations for project outcomes, creates a real sense of partnership, and increases the likelihood that projects will not only be implemented on time, but that communities are more inclined to sustain project activities themselves for the longer term. It opens the door for a strong community interest in learning the details of programmatic activities, providing input and feedback about the efficacy of overall program designs in the community and accountability for the use of resources. Room to Read staff in Tanzania reported community leaders losing their jobs in elections because they had not been accountable enough for the community funds pledged toward school-building construction. ${ }^{64}$ construction materials, or books. This up-

\section{Box 9. Room to Read, Literacy Program}

Room to Read is a nongovernmental organization focused on improving literacy and gender equality in education. Its Literacy Program uses a coinvestment approach to work in collaboration with local communities, partne organizations, and governments to ensure that schools have a structured library with books in the children's local language and that teachers and librarians are trained in evidence-based reading and writing instructional methods. Literacy coaches are placed in classrooms alongside teachers to provide instructional support. Together, these intervention components aim to develop literacy skills and a habit of reading among primary schoo children. Since it was founded in Nepal in 2000, Room to Read has expanded to nine other countries across Asia and Africa and overall, benefited 10 million children across 17,500 communities. More specifically, its Literacy Program has reached 110,000 students and 2,000 teachers to date. Compared with an evaluation of 70 educational interventions in low- to upper-middle-income countries (of which Room to Read was not a part), Room to Read's impact is nearly 10 times that of the other interventions' average impact.
Camfed's model, a secondary education program for rural marginalized girls living in five sub-Saharan African countries, has begin with a focus on the individual girl in rural Africa as its client-looking at the world from her perspective and identifying the barriers that must be overcome to ensure she can receive a quality and empowering education Camfed approaches "shareholders," "shareholders," ensuring that all systems and processes are accountable to them While many critics said that this approach could not scale because of its focus on the individual girl, Camfed found that it was actually that specific angle that allowed the project to scale and to do so at pace, achieving sixfold expansion in the number of girls receiving support in Malawi, for example, from 2,000 to 12,000, within three months. This approach to scale is premised on its governance model, refined over the past 23 years, that places accountability to girls at its core and dovetails with local education systems. This has enabled it to scale a needs-based financing mechanism that mobilizes extensive local infrastructure and assets to address girls' school-going requirements, including provision of school fees and other education costs alongside learning assistance and psychosocial support. Camfed scaled its model from reaching tens of thousands of girls to hundreds of thousands of girls within just a few months, supporting them through a full cycle of junior secondary school.

This is relevant even beyond non-state provision of education. Experiments are under way within the public system to shorten the route of accountability between the state and citizen, such as the Punjab government's Education Sector Reform Program (PESRP) in Pakistan, an initiative supported in part by assistance from the United Kingdom. ${ }^{65}$ The program was created to complement the Punjab Education Reform Roadmap, with the intention of improving the province's quality of improving the province's Provindary education. To shorten accountability between the government and its citizens, PESRP established approximately 56,000 school councils to promote community participation and parental involvement in their designated Punjabi public schools. Through this process, local citizens are empowered to monitor school performance, while school councils are granted annual budgets to respond to community needs. ${ }^{60}$

Scaling effective learning practices or approaches requires being responsive to local education needs, in particular those of students, teachers, and parents. It also requires accountability not only to the government and external partners but most importantly to these "endusers." Local community participation and ownership of a program or policy are also essential to sustain an intervention for the long term. While being responsive and inclusive are necessary conditions for scaling an effective learning intervention, alone they are insufficient. At times, more information is needed to demonstrate and persuade communities of the benefit of education. It also requires some of the following key ingredients. 


\section{Cost-effective learning:}

Cost structures affordable at scale should

be incorporated in the design.

Understanding what is relevant and desired by students and parents is crucial to designing an effective intervention that harnesses community demand. However, if the costs of the intervention are too high for a government to adopt or for an actor to replicate at scale, then no matter how aligned it is to community needs, it will not scale. Ensuring the right costs-for whoever is taking it up, the government or parents-is another crucial component of successfully scaled interventions.

Too often, interventions are designed at the outset solely for effectiveness and not for the efficiencies that are required for scale. This leaves "the bridge to scale too far to cross." ${ }^{\prime 7}$ As lan Thorpe writes in his blog Knowledge Management on a Dollar a Day, many pilots start with "a kind of loving attention and specific starting conditions that couldn't easily be replicated." "68 If you begin with the luxury, gold-plated model, it becomes very difficult to determine which pieces to remove-either because psychologically people come to expect them, or pragmatically it is difficult to determine which elements are responsible for driving improvements. Even if a program is highly effective, if it relies on too many resources to reach too few children, the approach it uses holds little promise of spreading and being taken up by others. As Robert Sutton and Huggy Rao, professors at the Institute of Design at Stanford University, write, "scaling requires both addition and subtraction the problem of more is also a problem of less." 69

A surprisingly large number of pilots focused on improving children's learning pay scant attention to costs In a review of costeffectiveness analysis of education and health interventions in developing countries, McEwan discusses how impact evaluations cannot always inform resource allocation decisions unless the costs of interventions are considered alongside their effects. He gees on to argue that "costeffectiveness analysis is a straightforward but underutilized tool for determining which of two or more interventions provides a (non-pecuniary) unit of effect at least cost." He finds that "across multiple sectors, education and health projects are, by far, among the least likely to report results of a CBA [cost-benefit analysis] at project appraisal." ${ }^{\prime \prime}$ In a review of scaling in development more broadly, Hartmann and Linn stated that "research on the cost implications of scaling has been limited

Too often, interventions are designed at the outset solely for effectiveness and not for the efficiencies that are required for scale. This leaves "the bridge to scale too far to cross." and what research has been carried out has been hampered by the scarcity of relevant cost data reported in the public domain."7l A review of scaling in nutrition found that detailed costing studies that

provide unit costs of interventions are usually unavailable for a given context. This leads to underestimating or overestimating an intervention, which can have a negative an intervention, which can have
Ensuring the right costs-for whoever is taking it up, the government or parents-is another crucial component of successfully scaled interventions.

\section{Balancing cost and quality}

Few would argue with the logic of finding a cost structure that allows scaling, including scaling that reaches the most vulnerable young people, which is often a more costly endeavor. ${ }^{73}$ But the question is how this can be achieved without sacrificing quality.

First and foremost, it requires understanding from the outset the longerterm cost implications of sustainably scaling-and delivering at scale-based on sound cost projections. ${ }^{74}$ This requires identifying the incremental cost of all resources (i.e., personnel, facilities, materials) incurred by all stakeholders (i.e., schools, government, householders) for the development, implementation, and maintenance of an intervention as and after it scales ${ }^{75}$ At the same time, as Laurence Chandy, a fellow at Brookings, and colleagues write, there are real challenges in developing cost projections, as scaling involves changing cost curves, altering beneficiary behavior and the policy environment.

Room to Read considers cost-effectiveness as one of the core design features in its program development. In 2014, for example, the organization went through a controversial change in its literacy instruction approach. Previously, it had used a large number of manipulatives in its classroom activities. These included flash cards, literacy wheels, dice with words on them, small series of six- to 10 page decodable texts, and individual student writing books. Teachers reportedly enjoyed these resources because they were fun and broke up the monotony of the school day. However, the diversity of preparing activities and switching among them took too much of the school period. Room to Read has therefore consolidated its classroom materials into a single, nondisposable student book per grade per country. It includes the same engaging activities, but they are relatively less expensive to produce on a per-child basis. These books, which can be used over multiple years, are much closer to a price point that can be absorbed by Ministry of Education budgets over time.

This same logic explains why Fundación Escuela Nueva has, despite multiple offers by technology companies, very cautiously analyzed the value add and implications 
of integrating tablets or mobiles for teachers or students into classrooms where the organization works. ${ }^{77}$ Its point is that a pedagogical transformation at the classroom level needs to happen first for technology to meaningfully and effectively impact learning. In addition, the cost-effectiveness of the model has to be guaranteed. Adding even relatively inexpensive technology could increase the cost per child and make it harder to scale across contexts, including communities with limited financial and human resources.

Detailed cost projections are partly how Bridge International Academies could expand as rapidly as it has. It prioritizes the quality education it expects at a particular price point. For example, Bridge expects to provide $r$ esults that are as good as or better than those of neighboring public schools at a price that families living on less than $\$ 2$ per day can afford. According to Bridge, the average household income of its pupils is $\$ 136.22$ per month, with an average of four or five members per household, meaning that 4.4 percent of a family's average income is spent on each child's education. ${ }^{78}$ Maintaining this average price of $\$ 6$ per month has driven the team to be ruthless about driving down costs. ${ }^{79}$ Any proposed addition to the current model is translated into the number of families that can no longer be served.

Policymakers say that it is important to not only have costs per unit but also cost comparisons to the alternative to help channel resources to the most effective intervention. At first glance, an intervention might appear expensive, but compared with the alternative or to the savings it will generate, it might be a great value for the money. In 1992, as part of a larger donor-sponsored report on BRAC's NFPE program, a team from a well-respected national accounting and cearch firm undertook a small survey to compare the private and public cost of rural government primary schools and BRAC NFPE centers in Bangladesh. The study concluded that the public cost per enrolled student was on par with the formal and nonformal BRAC schools but that the high dropout rate from formal schools resulted in public and private costs per third grade completer more than four times the cost per NFPE completer. ${ }^{80}$

Cases reviewed demonstrate ways that costs were kept low without sacrificing quality. This includes through leveraging technology, community engagement, existing government structure, and experimenting with cost-recovery measures.

Leveraging technology:

In many of the examples reviewed, technology played an important role in reaching a scalable cost by generating efficiencies, by automating work and optimizing the use of resources as programs and policies scaled. Bridge (academies has leveraged technology through a smartphone with a customized Enterprise Resource Planning (ERP) to monitor all payments in and out of the school-school fees, teacher and staff salaries, and so on-reducing financial transaction costs and allowing it to need only one nonteaching staff member at each school. The role of technology will be discussed further below.

Leveraging community

engagement and resources:

As discussed further below on elevating

the role of teachers and leveraging community resources, many of the cases also creatively leveraged community members expertise to both unburden the teacher he he experience, lower cost structure. In many instances, this double or triple win helped reduce expenses while also bringing a level of energy, commitment, and authenticity to the program

\section{Creatively using}

government infrastructure:

Maximizing the effectiveness of positions and buildings within the government can help keep costs low, for both government and nongovernment actors. For example, Pratham's Read India, a remedial education program that helps children in grades three to five learn reading, writing, and basic math, intentionally kept costs low and avoided creating parallel structures by trying to rejuvenate and optimize existing but underutilized positions and structures within the government. Read India's teacher-led summer camps energized existing cadres of Cluster Resource Center Coordinators (CRCCs) (1) $^{1}$ to oversee teaching and learning activities. Traditionally, CRCCs were considered fit for only routine administrative and regulatory tasks. However, Pratham's attempt to institutionalize Read India through CRCCs revitalized their roles. Pratham trained CRCCs for four days and then had them practice in the field for 20 days. After that, Pratham trained teachers in the new methodology of grouping and teaching at the right level. In this way, Read India's teacher training activities were less radical, more cost-efficient, and more easily replicated.

\section{Box 10. Pratham, Read India}

Pratham's Read India initiative works to ensure that children in grades three to five acquire the ability to read simple text and do basic arithmetic. This tevels, regardless of age or grade, and grouping them by level for instruction, an approach referred to as "teaching at the right level." Pratham's Read India program schol affected more than 350,000 primary school students directly in rural areas from 2014 to 2015 and 6 million students indirectly through its partnerships with state or district governments. A series of randomized evaluations conducted by J-PAL of Pratham programs found significant gains in learning when children are grouped by level rather than by grade. Pratham also facilitates the Annual Status of Education Report (ASER), a nationwide citizen-led household survey that assesses basic reading and arithmetic levels of children in over 550 of India's rural districts. ASER has been carried out every year starting in 2005 , and since 2008 , began functioning as an autonomous unit within the Pratham network. 


\section{Questions on cost recovery}

A number of the cases in which NGOs did the scaling have been experimenting with cost recovery efforts, with varying degrees of success. These organizations rely heavily on philanthropic support and are interested in diversifying their funding base. For example, with Educate!, a leadership and entrepreneurship training program in secondary schools in Uganda, its original financial plan included charging partnering schools along a sliding scale and increasing the amount over time, starting at $\$ 200$ per year per school and eventually charging \$600. This fee did improve school buy-in, but Educate! found that the time and effort involved in collecting payment was not worth the amount it was charging. Therefore, it recently decided to keep a nominal fee for partner schools to demonstrate commitment but not as a cost recovery mechanism for the program. Today, more than 80 percent of its revenue comes from foundations. Room to Read recently launched a technical assistance arm called train other organizations and government partners that are interested in implementing similar delivery models. Room to Read Accelerator takes best practices from its core work, codifies them, and systematizes the approach, charging partners a fee sufficient to recover its costs. The idea is 列 to allow Room to Read to scale and serve even more children in areas that it would not otherwise be able to reach through direct implementation. ${ }^{82}$

Whether costs were kept low from leveraging existing infrastructure, creatively tapping community resources, or utilizing appropriate technologies, it appears that there are a number of lessons to learn from low-resource environments. In these contexts, actors did nothave a choice but to keep costs low as they scaled. Room to Read Accelerator to share and

\section{Box 11. Educate!}

Educate! is a nongovernmental organization that addresses the mismatch between secondary education and employment opportunities in sub-Saharan Africa, as well as a tradition of rote memorization and theoretical teaching methods, with the ultimate goat of teaching African youth to solve poverty for themselves and their communities. It provides students with skills training in leadership, entrepreneurship, and workforce readiness, along with mentorship to start real businesses at school, and the model itself is delivered through trained teachers and youth mentors. Educate! began in Uganda in 2009 and now reaches 120,000 students in 350 schools, or 12 percent of Ugandan secondary schools, having advised the reform of Uganda's upper secondary entrepreneurship curriculum and incorporated its model into Rwanda's national secondary school curriculum. Midline results from Educate!'s randomized controlled trials indicate that its secondary students' incomes are doubled after graduating secondary school and that they are 64 percent more likely to start a business and 123 percent more likely to initiate a community project.

\section{Flexible adaptation:}

Core elements of effective learning approaches should be identified and replicated across contexts while adapting the rest to local circumstances.

Ultimately, even if a pilot effectively meets educational needs with a scalable cost, it can face obstacles when expanding because the design is either too rigid or too flexible. In the cases and literature examined, there appeared to be an optimal point between wholesale replication and costly customization. The key appeared to be flexible adaptation of the model. This requires what Nesta refers to as "identifying the core" 83 essential aspects of the model that must be maintained as it scales. The reviewed case studies established an important balance between those elements that are nonnegotiable and replicated across contexts and the other aspects that are more flexible and should be adapted to each location. The challenge is striking the right balance between local adaptation and fidelity to the original model.

In the literature, striking this balance is most often associated with understanding what is essential to achieving impact. ${ }^{84}$ In discussing the spread and adoption of innovation, Anna Davies, professor at Trinity College Dublin, outlines that the diffusion process should reflect replication of the "core content" of an idea, rather than exactly replicate every aspect of the original 85 In Nesta's interviews with "what's fixed and what's flexible-in relation to the model, scaling routes, goals and aims." 86 Often, the core is a practice, mission, or approach rather than spreading a specific education model.

For SAT, the underlying philosophy of developing a generation of socially minded young people who can serve as engines of sustainable development in their communities is the core approach to

The reviewed case studies established an important balance between those elements that are nonnegotiable and replicated across contexts and the other aspects that are more flexible and should be adapted to each location. The challenge is striking the right balance between local adaptation and fidelity to the original model. 


\section{Box 12. Sesame Workshop, Sesame Street}

Sesame Workshop's Sesame Street uses television, radio, videos, websites, books, and social media to educate preschool-aged children on literacy and math, emotional well-being, health and wellness, and respect and understanding. The show began in the United States in 1969 and has since expanded to more than 150 countries, reaching approximately 156 million children and serving as the single largest informal educator of children in the world. Studies demonstrate that Sesame Street is an effective learning tool for children with a positive impact across countries. A meta-an with a positive impact across countries. A meta-analysis of its is comparable to that of other early childhood interventions, with scale being its key distinguishing factor. every school in every country. In addition to sharing a common value, the curriculum, or 80 texts developed by the parent organization in Colombia, Foundation for the Application and Teaching of the Science (FUNDAEC), is a core component that is shared across the countries. implementation is determined by the local context. This includes when and where to meet, the number of hours per week to meet, and the coordination structure in each country.

While BRAC schools incorporate a country's national educational curriculum into its program, the classrooms look and feel remarkably similar across the various countries, as diverse as Afghanistan, South Sudan, and Philippines. BRAC's core components include hiring female teachers from the local community and supporting them with regular training. Low-income children, girls, and other Beyond the curriculum, much of SAT's marginalized youth are given priority, and many steps are taken to minimize the formal and informal costs of attendance. Parents are engaged regularly.

Sesame Workshop, the nonprofit behind the children's television show Sesame Street, provides a framework for its international Sesame Street co-productions that share a universal style, target age group, and whole-child approach for core learning goals for that age group, but leave it to local production teams to develop the series based on the needs of children and the specific education goals of each country

Teach For All, an international network of local, independent organizations that recruit and train recent top-performing graduates and professionals to commit two years to teaching in their countries' underserved schools and communities, attributes much of its success to its proach of ensuring that each network partner operates with full ownership for developing its program and organization. The Teach For All network comprises 39 share a mission and commit to principles determining how best to achieve them

Of course, striking this balance between universal replication and local adaptation can be hard, even when being deliberate. Sometimes, the elements that are assumed to be core are not necessarily what are behind a program's success. In an example outside the education sector, what was ultimately found to be responsible for the exponential spread r M-PESA, the mobile money platform in Kenya, was not the moble technology but the distribution netwok of local vendors who served as M-PESA agents to register new customers and facilitate

cash transactions. This was also the case with the scaling of Lesson Study across Zambia, a peer-to-peer teacher training this Japanese-adapted practice be seen as part of Zambia's national teacher professional development reform, what was key to its success was the existing countrywide network of Teacher Resource Centers with officers tasked with guiding and monitoring these new practices.

The cases reviewed addressed the tension between localization and scale by identifying core elements that were be it an underlying principle, a piece of network. At the same time, there was flexibility to adapt the model or approach to the local context as needed. independent partner organizations that integral to an intervention's successtechnology or an existing distribution

\section{Box 13. Teach For All}

Teach For All is an international network of local, independent organizations that recruit and train recent top-performing graduates and professionals to commit two years to teaching in their country's underserved schools and communities, with the goal of developing a pipeline of future education leaders. Teach For All was co-founded by Teach For America and the United Kingdom's Teach First in 2007 and has since become a global network of 30 country partners. The network has reached 1.1 million students and 52,323 teachers and alumni to date and has had an impact on both individual students and overall education systems. Studies from partner countries demonstrate learning gains, such as a Mathematica Policy Research study that found students taught by Teach For America math fellows demonstrated an additional 2.6 months of learning over the course of the year compared with students taught by novice and veteran teachers. At a systems level, Teach For All has contributed to broader education reform and change through its fellows and alumni, as 50 to 80 percent of alumni from most partners stay full time in the education sector. 


\section{Elevating teachers:}

Community expertise should be leveraged to support and unburden teachers.

Teachers are perhaps the most important actors in children's educational experiences, especially for marginalized children. Evidence from numerous studies shows that the quality of teachers significantly influences children's learning

in school..$^{87}$ In a study of 15,000 teachers across Latin America, learning outcomes of students were less influenced by being in a good or bad school than they were by being taught by a strong or weak teacher. ${ }^{88}$

\section{Overburdened teachers}

Teachers' jobs are very complex, and around the world, teachers are being asked to do a wide range of tasks not directly related to their core job of instructing children. For example, a typical day for a teacher includes instructing during school hours, preparing lesson plans, grading student progress, managing classroom behavior, tracking and reporting data, communicating with parents, providing extra assistance to students falling behind, mentoring or providing social support for children with difficult family circumstances, meeting with school personnel, buying school supplies... and the list goes on. Some argue that education, and by extension teachers, is being asked to solve a wide range of social problems. ${ }^{89}$ This view, that education is a panacea solution to many social ills, places a very large, and perhaps unfair, burden of responsibility on teachers.

In addition, in many developing countries teachers face seemingly insurmountable hurdles. Many teachers have classes with more than 40 students, surging up to $0 \mathrm{O}$ in some countries after adop free universal primary education. ${ }^{90}$ Many teachers are doing the best they can amid difficult environments. In some places, teaching positions are used by politicians as a form of political patronage and are assigned not to those who are motivated and trained to be teachers, but to those supporters for whom politicians need to curry favor.91 This puts a heavier burden on those teachers who are motivated to try to compensate for their peers who are not. In some post-conflict contexts, teachers go months without salaries 92 In Liberia, a national survey of teachers after the civil war showed that most teachers-in some areas 90 percent-held multiple jobs (i.e., farming and tutoring in addition to teaching) to make ends meet. In the developing world especially, there simply are not enough teachers. Recent estimates suggest a global teacher shortage of 2.7 million primary school teachers in 2015.93 Projections estimate that to provide every child with a primary education by 2030,258 million teachers will need to be recruited ${ }^{94}$

To address this shortage, many schools have adopted a double shift system, requiring teachers to work 12 hours per day, teaching two separate groups of kids back-to-back, leaving no time

A number of the cases reviewed for this study designed effective approaches that could scale quality learning by elevating the role of the teacher, leveraging expertise that exists in the community, and providing multiple pathways to bringing motivated people into the teaching profession.

\section{Activating community expertise and technology to unburden teachers}

From India to Uganda, elevating teachers' roles and attracting other resources to support teachers, whether through technology or through expertise that is outside of the school in the community, has been a strategy used across multiple cases we studied. Room to Read, Educate! Read India, and INJAZ, a Jordanian nonprofit organization that provides entrepreneurship and work readiness training for secondary and postsecondary students, are all examples of rethinking who in the community can add to students' education without requiring teachers to take on more responsibilities. Across the cases it varies whether these community members are volunteers or employees, but in each case they are not only adding support to teachers but also building passion in communities to prioritize education.

For example, INJAZ partners with private sector companies and trains its employees who volunteer to teach the lessons. This helps teachers by not burdening them with yet another subject they have prepare and teach. On average, since 2015 , a cadre of 3,170 individual volunteers have delivered 2,500 sessions each year, forming the largest network of committed volunteers in Jordan today. A byproduct of this collaboration has been advancing a culture of volunteerism in Jordan. Beyond volunteering to teach, private sector companies support INJAZ by adopting schools, sharing information and data, and providing employment and internship opportunities to graduates.

Similarly, Educate! in Uganda has leveraged community members to teach Uganda's entrepreneurship curriculum alongside teachers in schools, relying on entrepreneurs and employees from local businesses. To deliver the lessons, Educate! primarily hires alumni of its program who are young entrepreneurs themselves. Its model allows teachers to be supporters of the subject, but as with INJAZ, relieves teachers of having to get up to speed on new topics. This strategy is coupled with teacher training programs, which are tied to long-term government education reform goals. 


\section{Box 14. INJAZ, Jordan}

INJAZ, an independent Jordanian nonprofit organization, specializes in youth empowerment programs and leverages the public, private, and social sectors to help bridge the skills gap between the secondary school system and the changing needs of the labor market. INJAZ programs, delivered through o network of more than 23,000 trained volunteers, provide youth from seventh grade to university level and post-graduation with content and activities that improve their financial literacy, ethical leadership, teamwork, creative thinking, communication, and interpersonal skills. For older youth in colleges and universities, youth centers, and vocational training institutes, the majority of the programs offered provide direct links to real-world opportunities and support for them to gain work experience or otherwise develop their professional and entrepreneurial skillset. Since its inception in 1999, INJAZ has scaled across all 12 governorates and has reached 1.2 million youth to date. The program has been integrated into Jordan's official school sched to and, according to an internal study, INJAZ graduates had an unemployment rate of 19 percent compared to the national rate of 32 percent.

Other programs reach out to a school's parents and community members to help unburden teachers. Room to Read's Girls' Education Program, for example, trains educated, empowered women from the community to be "social mobilizers" to work directly with the more than 30,000 girls in the program as their mentors, counselors, and advocates. In addition to serving as excellent role models, these women provide critical personalized emotional guidance and life skills training that many teachers do not have the capacity to provide every girl in the classroom, plus out-of-school engagement and home visits that can be unrealistic for teachers to undertake. This added support system improves girls' school participation and life skills, and it has resulted in other positive externalities, such as empowering women and developing more female role models in the community.
Pratham has used a number of strategies to implement its Read India model for teaching at the right level. Across all of them, government officials have played important roles from sanctioning the experimentation with this approach to actively participating or putting resources behind it. In some cases, community volunteers are trained to teach children literacy skills in summer and outside schools. In other cases, government teachers, Pratham staff, and community volunteers work with students during the school day. This strategy is effective because it leverages community resources to help support teachers and to reach and teach students who are falling behind. As in the other cases, the community engagement model had a dual benefit: elevating and unburdening teachers to provide remedial tutoring along with instruction and engaging 10,000 wolunters and bringing them into the "battlefield against poor learning," something Pratham's CEO said no advocacy campaign could have accomplished. ${ }^{96}$

This is not to say that relying on community members and volunteers is without challenges. While some community members were paid and others volunteered, their training was a crucial element of the program's success. Quality control and delivery standardization can be difficult in these models. INJAZ, for example, faced this issue, to which it responded by implementing mandatory volunteer trainings at the beginning of each semester before volunteers can teach a class. Read India also struggled with quality control and actually scaled back after its first phase to work on its training. Today, whether it is community volunteers or teachers implementing the Read India program, Pratham requires a heavy dose of training. For example, in Pratham trainings, participants leave the training location to go into nearby schools and "practice" the techniques they have learned in the training sessions. In many cases, especially when Pratham is working with the government, officials have to "practice" the Pratham method in their schools every day for 15 to $2 \mathrm{O}$ days to build mastery of the approach.

With the right design and flexible adaptation as programs scale, leveraging community members' expertise is in many cases an effective strategy for helping improve student learning, along with supporting more traditional teachers inside and outside the classroom. Governments that are flexible and help sanction, support, or sustain this approach are crucial in the scaling process.

In cases from both Brazil and Kenya, the way teachers' roles are configured and how technology is leveraged unburdens them from the normally overwhelming list of tasks they face. For example, in Amazonas state in Brazil Media Center a distance learning formal secondary education program, is designed for two types of teachers: a specialist lecturing teacher who communicates via satellite from a central studio, and a generalist tutoring teacher who facilitates learning in the classroom. Lecturing teachers are highly trained and research their subjects of expertise, develop content for the lectures, and reach thousands of students at a time, whereas the tutoring teachers work directly in the classrooms to guide student learning support classroom interactions, monitor student activities, and perform administrative duties, without being responsible for instruction, content delivery, or deep knowledge of any one subject.

In cases from both Brazil and Kenya, the way teachers' roles are configured and how technology is leveraged unburdens them from the normally overwhellming list of tasks they face.

In other cases, technology has been leveraged to split the traditional responsibilities of a teacher into those creating lessons versus those teaching lessons. For example, a core component of Bridge International Academies' model is that teachers receive a daily teacher guide with lessons via tablets, which is essentially a scripted lesson plan for them to follow. By centrally developing all the teacher and learner materials, teachers 
Box 15. Amazonas State Government's Media Center

Brazil's Amazonas state government's Media Center initiative is a locally developed, formal secondary school model seeking to address the disparity in education access between urban and rural areas. It employs digital satellite technology to deliver live lessons from "lecturing" teachers at the Media Center studio in the capital, Manaus, to up to 1,000 classrooms across Amazonas state, with "tutoring" teachers located in each classroom with anywhere from five to 25 students. This initiative allows for bidirectional interactivity, meaning students can stream the teacher's lecture at the studio and present information back thereby appearing to all other classrooms and to the lecturing teacher in the studio. Established in Amazonas state in Brazil in 2007, Media Center's 60 lecturing teachers and 2,200 tutoring teachers have reached 300,000 students across 2,300 communities-approximately 25 percent of secondary school students outside of Manaus-to date. The Media Center model has been adapted to seven other states in Brazil to serve difficult-to-reach populations. Since its establishment, lower to upper secondary school progression rates have increased, dropout rates have nearly halved between 2008 and 2011, and children's learning in Amazonas state has steadily improved as reflected on the Brazilian Education Quality Index.

are relieved of the burden of creating content and lesson plans and are able to spend more time focusing on their students' progress. One Bridge teacher in Nairobi expressed that the scripts gave her confidence and allowed her to focus on students who needed additional support.97 This approach also frees up teachers from a range of administrative tasks. For example, the tablets allow centralized fata collection and analysis, facilitating central monitoring of many aspects of teaching and learning that would traditionally be the responsibility of teachers to collect and monitor.

Unburdening teachers from the multiple demands placed upon them, and finding new ways to deliver some of the tasks previously assigned to teachers, is known as "unbundling" the role of the teacher. ${ }^{98}$ This approach is beginning to be employed by a range of programs, including one by a range For example, Preston Smith cofounder and CEO of Rocketship Education, a network of U.S. public charter schools for low-income students, argues that elevating the role of teachers by unburdening them and allowingthem is an important factor in the program's success. Effectively teaching children in marginalized communities takes, he says, "a great deal of rigor." The more time teachers can focus on teaching and instruction, and the less time they spend on tasks not related to teaching. the better off both teachers and students will be. Rocketship does so through several strategies, including deploying other personnel and using technology to take on administrative tasks usually handled by teachers. In the future, Smith envisions a further optimizing of the teacher's role where teachers specialize according to their strengths in instruction, technology provides real-time analysis of student learning progress, and parents engage more deeply with schools.

These examples show how technology enables scaling when it comes to teachers. From Media Center to Bridge International Academies, some approaches unbundle teacher responsibilities into those that technology can enable them to scale-namely lecturing lesson design, and tracking

\section{Diversifying pathways to teaching}

Given the different ways in which the role of the teacher is configured across the cases, it makes sense that there are different pathways to becoming a teacher. The traditional formula of completing higher education, specializing during pre-service teacher training, and then teaching in the classroom is supplemented by other routes. The approach varies in the different cases-inside and outside communities, in and out of schoolsbut they exemplify the need for diverse pathways into the teaching profession, especially for underserved areas.

The case studies are backed up by literature that finds that hiring teachers from local communities helps close the cultural and linguistic gap between teachers and students, thereby improving learning outcomes and enrollment. In areas experiencing regular teacher student progress and administrative data-intensive tasks-versus those that cannot, such as classroom facilitation and student interaction. Interestingly, this dynamic was almost the opposite when groups leveraged parent and community workers rather than technology to unburden teachers. From Pratham to Room to Read, it was the extra personto-person support interaction, and attention to students and their needs that community members took on to help alleviate teachers. Ultimately, all of the cases examined focused on quality interaction and instruction as central to children's learning experience even as they often thought quite differently about how this should be achieved. shortages, hiring para-teachers from within communities has helped address the teacher shortage in remote areas, and having teachers who are of the same demographic background helps close the "social distance" between teachers and students and ultimately improves student learning. ${ }^{100}$

For example, SAT in Latin America does not employ the term "teacher" but uses "tutor" to signify a less hierarchical conception of how the learning process unfolds. Tutors, who are often secondary school graduates from the community where they will ultimately be teaching, undergo intensive training in SAT content and pedagogy, with a heavy focus on student-centered learning. Tutors have neither the typical teacher profile nor the typical teacher role. Tutors are meant to learn along with their students, and they 
stay with one cohort during their six years of lower and upper secondary school. The job of the tutor is to facilitate students active engagement in SAT lessons and actively develop their own skills as they go by participating in 10 days of training every three months. These tutors are actively involved in the communities and often in the students' lives as well, building close relationships and spending time with students of lessons. In Honduras, the government has adapted to the community needs and supported this new pathway for becoming a teacher by agreeing to pay the tutors' salaries.

Teach For All takes a different approach. Instead of leveraging members of the community, its network is built on the idea that countries should be channeling much more of their top talent toward improving education for vulnerable children. Partners in the Teach For All network diversify the pathways into teaching by recruiting and training outstanding university graduates and young professionals, many of whom did not plan or study to be educators, to teach in marginalized communities. Again, the focus is much more heavily on in-service rather than pre-service training and the "fellows" in the Teach For Al organizations around the world receive the bulk of their training after being deployed to a school and classroom. A global network of Teach For All fellows and alumni supports sharing of lessons learned, and training opportunities are available throughout the two years that fellows are in the program.

Governments are almost always crucia partners in this effort and across the 39 countrieswhereTeach For Allindependent
In activating resources from local community members or technology-either directly or through opening up additional pathways to becoming a teacher-ensuring that teachers are supported and respected is an important element of lifting some of the burden from their shoulders.

partner organizations operate, providing a mix of in-kind or financial support to help deve pathway to becoming a teacher. Initially this approach may help fill a teacher shortage in an underserved community, but the organization's ultimate goal is to build a movement of talented individuals who become lifelong educators, innovators, and advocates for expanding opportunities for marginalized children. Across their network partners, more than 60 percent of their alumni stay within education and many others work on issues related to education and lowincome com policy, medicine, and law.

In activating resources from local community members or technologyeither directly or through opening up additional pathways to becoming a teacher-ensuring that teachers are supported and respected is an important element of lifting some of the burden from their shoulders. The experience of the Zambian government in Lesson Study is a powerful reminder of the importance of respect. In the initiative, the government has flipped its teacher training approach from one that emphasizes what teachers lack (known as a deficit approach) to recognizing the assets teachers bring and giving them the space to build on these assets. Teachers at school are able to produce their own ideas to improve their lessons and are empowered to be the main agents, with support from peers, in their own training.

A new approach initiated in India reinforces the importance of this respect. STIR Education, which focuses on improving teaching, has worked with more than 12,000 teachers in India and Uganda identifying teacher "changemakers" who are inspired to innovate in their classrooms, supporting them and connecting them to a network of other innovative teachers to collaborate. more important han salaryor tro motivating teachers. Preliminary results have shown promise-in some Ugandan schools, teachers were four times as likely to arrive on time after completing the STIR program. ${ }^{10}$

In conclusion, activating resources from outside of the school and developing new pathways to do so sustainably can play an important role in unburdening teachers and helping to improve learning. 


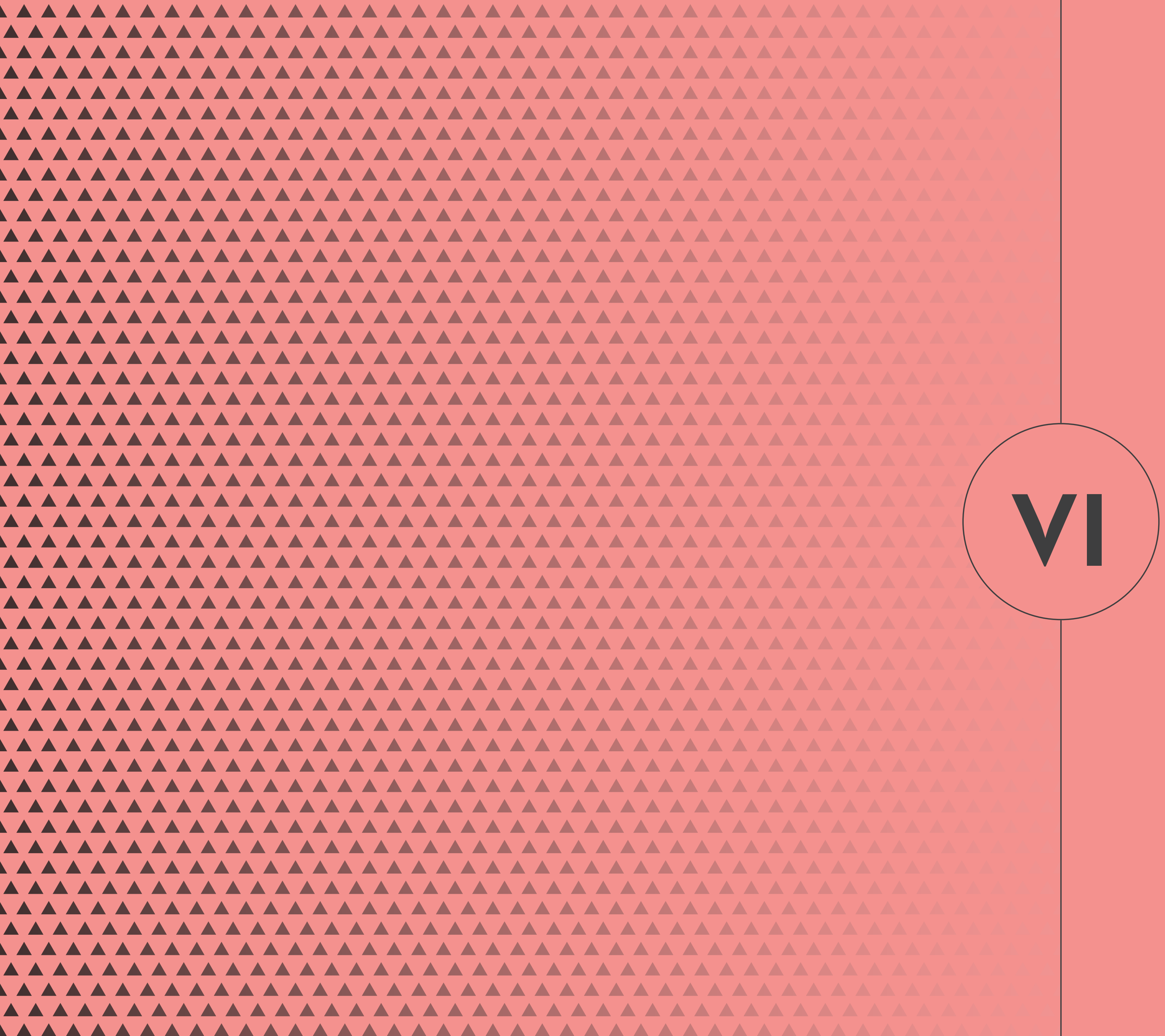

DELIVERY

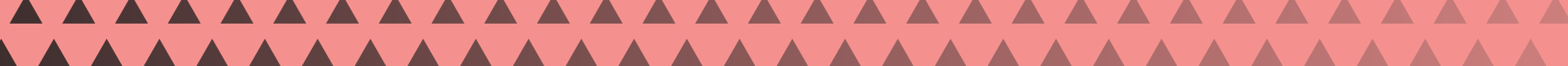




\section{Introduction}

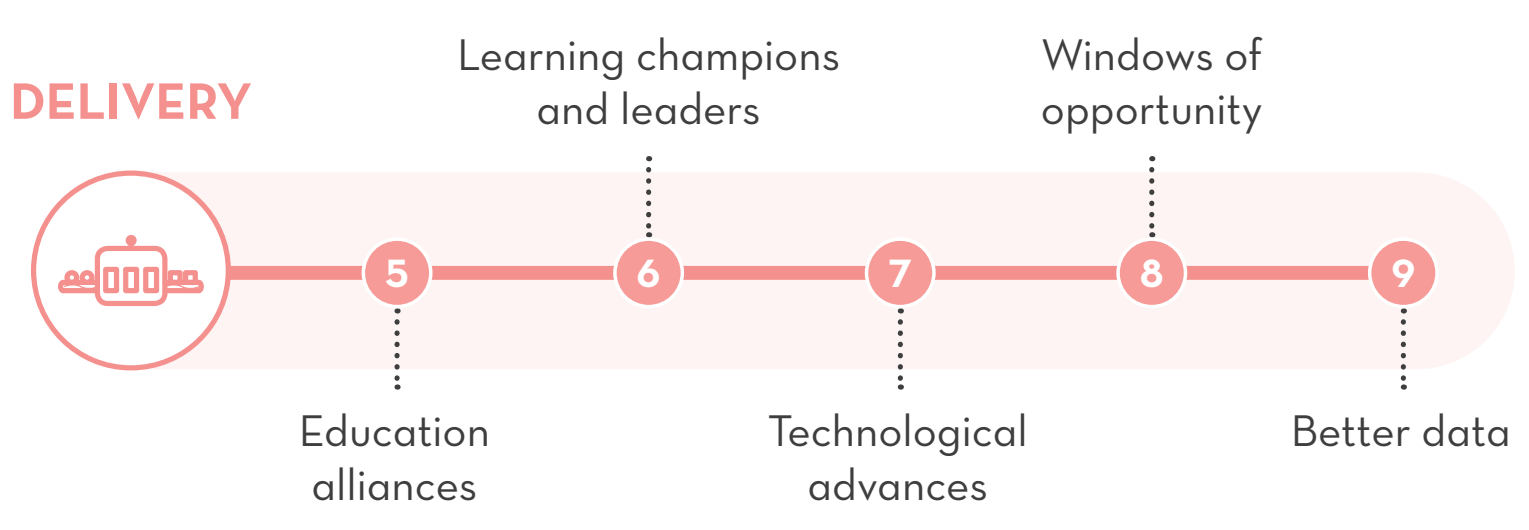

Designing for scale is half the battle. At the end of the day, however, whether or not an education initiative successfully and sustainably scales depends as much on how it is implemented. As Chandy and colleagues write, "Delivery is what makes getting to scale not merely difficult but complex."102 As a result, they identify the difficulties of scaling as a process challenge. Through a review of cases and literature, our andysis found that delivering at scale requires a combination of both technical and political strategies. These include leveraging the diverse

resources and skills of various partners for large-scale gains in learning; cultivating "learning" leaders and government and classroom; seizing key moments more open to spreading and adopting new ideas to improve learning; utilizing appropriate technologies to drive efficiencies and overcome contextspecific barriers to learning: and using a range of data to continuously drive improvements in programs and policies as well as to motivate and sustain action in support of scaling quality learning

\section{Education alliances:}

All actors need to work together to achieve a common goal.

"Social change depends, in other words, on alliances between what could be called the 'bees' and the 'trees.' The bees are the small organizations, individuals and groups who have the new ideas, and are mobile, quick and able to cross-pollinate. The trees are the big organizations-governments, companies or big NGOs-which are poor at creativity but generally good at implementation, and which have the resilience, roots and scale to make things happen. Both need each other, and most social change comes from alliances between the two, just as most change within organisations depends on alliances between leaders and groups well down the formal hierarchy."

Although partnerships are notoriously difficult and some evidence shows they are not always effective, across the 14 cases we reviewed, they were essential in bringing all the right skills sets to the table. The enormous challenge of ensuring quality learning for all in the 21st century requires bringing all actors and assets to bear-both the bees, such as social innovators that can experiment and nimbly cross-pollinate, and the trees, such as government agencies, which are essential for any education effort, including reaching those most disadvantaged, to spread nationally. It is rare for any one actor to encompass all the skills required to scale sustainably and equitably. Even when governments are leading the way, as they are in some of the cases we reviewed, they often reach out to civil society, communities, or the private sector to bring in key expertise they are lacking. Certainly, however, governments are essential in ensuring all children and youth-not just those in the right place at the right time-are learning well.

Partnerships contribute to scaling quality learning by pooling resources and ensuring an appropriate division of labor. ${ }^{104}$ The role of partners may include

The enormous challenge of ensuring quality learning for all in the $27^{\text {st }}$ century requires bringing all actors and assets to bear-both the bees, such as social innovators that can experiment and nimbly crosspollinate, and the trees, such as government agencies, which are essential for any education effort, including reaching those most disadvantaged. 
bringing financing, providing technical While not exhaustive, these elements are assistance, or generating political interdependent and include: establish a support Cases and literature reviewed clear shared goal; align incentives toward identified some of the key elements that meeting this goal; ensure accountability contribute to partnerships working to to the learners; and build trust among partners. ${ }^{105}$

Cases and literature reviewed identified some of the key elements that contribute to partnerships working to enable a scalable approach to delivery. While not exhaustive, these elements are interdependent and include: establish a clear, shared goal; align incentives toward meeting this goal; ensure accountability to the learners; and build trust among partners.

\section{Establish a clear, shared goal}

Interventions that have effectively leveraged partnerships for scale have focused on addressing a binding constraint that is present in multiple contexts, such as a lack of high-quality early childhood educational opportunities, a shortage of qualified teachers, or a mismatch between labor demand and supply. Successful interventions also approach these challenges, many of which are incredibly complex, with simple ideas that are understood and resonate with a broad audience-students, parents, teachers, government officials, and any other stakeholders. In fact, the greater and more complex the challenge, such as addressing a country's poor learning outcomes, the more important it is to have a clear definition of the problem being targeted, shared outcomes to achieve, and a strategy to address it.

One of the main learnings from Pratham's 15 years of experience in partnering with government systems is that the best results come when all elements of the teaching learning ecosystem prioritize common learning goals and align themselves to achieve them. It is essential that learning goals are clearly articulated in a way that teachers can understand and that they are achievable. If training academic support materials, teaching-learning methods, and measurement are all aligned to support each other, then the chances of success are high.

Sesame Street, the world's largest informal early childhood educator, began in 1969 with a well-founded, simple idea to address the inequity of children's school readiness, particularly among disadvantaged children, by combining entertainment with education. More than 40 years later, Sesame Street reaches more than 156 million children in over 150 countries by adhering to this same principle of developing engaging content that creates an emotional connection with its target audience of preschoolaged children. Sesame Workshop's term success has depended on a broad base of partners, including funding agencies, local production partners, broadcasters, government ministries, the education and academic communities, local NGOs, and other private and public partnerships. Sesame Workshop's content creation model is a collaborative process among producers, educational content specialists, and researchers. Producers and writers are responsible for educational content and the creative elements of the production, whether it

\section{Align incentives}

Effective partnerships for scale require aligning incentives so that time, skills, knowledge, and efforts of multiple individuals are channeled in ways that produce jointly valued outcomes. ${ }^{106}$ A focus on shared outcomes is a good way to align incentives. Hartmann and Linn identify incentives as a key to drive behavior of actors and institutions toward scaling. They discuss how in the absence of a profit motive in education, other incentives are needed to substitute for market forces. These can include rewards, competitions, evaluations, and pressure through political processes. ${ }^{107}$

Worldreader's approach to scale, which provides digital books on low-cost e-readers and mobile phones, has been to identify "non-exclusive and growthoriented partners" where interests align. ${ }^{108}$ This includes publishers interested in expanding their market share with digital content and cellphone carriers interested in increasing customers' usage.
Best results come when all elements of the teachinglearning ecosystem prioritize common learning goals and align themselves to achieve them.

be television, radio, print, or other media, and researchers represent the voice of the child and provide information about the program's effectiveness. While local needs and contexts can differ around the world, Sesame Street partners share the objective of using media to meet the critical needs of young children.
Demonstrating intermediate results can also help keep actors engaged so that they see the benefits to partnering

For example, in 2003, the Naandi Foundation, in partnership with the government of Andhra Pradesh, established a midday meal program in response to the Supreme Court of India's decree that all regional governments must provide public school children with daily lunches. The program was initially designed to provide nutritious and hygienic food to 150,000 children in Hyderabad, free of cost. By the end of 2013, as a result of additional state government partnerships, the program was feeding 1.1 million children across 10,453 schools in Andhra Pradesh, Chhattisgarh, Madhya Pradesh, Odisha, and Rajasthan. Through these partnerships between the Naandi Foundation and regional governments, Naandi was able to function with 
government subsidies in the form of free grain, operational funding, and kitchen space, while regional governments, in turn, were able to fulfill their commitment to the Supreme Court's ruling that "cooked midday meals" are a necessary component of children's education. In addition to public sector partnerships, the Naandi Foundation partnered with private sector organizations, such as the Global Alliance for Improved Nutrition, as well as social sector organizations, suc as PATH, to add nutritional diversity to midday meals. ${ }^{19}$ Ultimately, these publicprivate partnerships helped the Naandi Foundation develop a very efficient process for addressing malnutrition. Britannia Industries Ltd and Faith Foods,

\section{Box 16. Worldreader}

Worldreader provides culturally and linguistically relevant digital books to the developing world through low-cost e-readers and mobile phones. It aims to improve literacy skills and instill a love of reading by providing children and their families with immediate access to teaching, learning, and reading materials. The organization uses an integrative approach that combines context-appropriate technology, access to more than 31,000 books in 43 languages, teacher support, and community engagement. Since its first programs launched in Chana in 2010 , the organization has reached in excess of 5.6 million people, and as a result of the program, 11 miltion people in 69 countries are reading digital books every month. Data from an evaluation of Worldreader's early grade reading program in Ghana demonstrate improvements in oral reading fluency and reading comprehension, as well as the development of positive reading habits, among student users.

\section{Ensure accountability to learners}

Successful alliances for scaling quality learning ensure that each partner is held to account for mutually agreed upon results. According to Hartmann and Linn, a functioning accountability system includes three elements: availability and use of information, mechanisms for monitoring performance, and existence of adequate incentives for compliance. When it comes to scaling quality

learning, it is not just accountability as to whether a program or policy is achieving good learning outcomes, but also whether it is creating the conditions for effective scaling of successful interventions. ${ }^{.10}$ At the same time, such an accountability system must not lead to a rigid compliance system of tracking milestones against inflexible models that might undermine the experimentation, risk taking, and long-term commitment required to scale. Rather, accountability systems for scaling quality learning allow for rapid learning and adaptation.

Camfed, a secondary education program for rural marginalized girls living in five sub-Saharan African countries, flips the premise of bottom-up accountability to one of bottom-up decision-making and top-down accountability. Communities are empowered with control over resources and determine how these can best be deployed to tackle local obstacles to girls' education-obstacles that they identify and understan firsthand. This reinforces a sense of

\section{Build trust}

At the core of these partnerships is trust. This has proved to be especially important during the startup phase. In the case studies reviewed, initial investments in the idea were crucial-and these were generally based on the investor's trust in the founder. As one early investor in Bridge International Academies shared, "we bet on the jockeys, not the horse." This was the case with Pratham getting started more than 20 years ago with an initial investment from the former chaiman of the Industrial Credit and Investment Corporation of India, DfID's early investment in Asociación Bayán in Honduras in the 1990s, and early and long-term support of INJAZ in Jordan by the United States Agency for International Development (USAID). Aflatoun International defines its socia franchise as a "trust-based" network that gives partners local autonomy accountability for girls' welfare; these are girls entitlements, for which communities are responsible. In turn Camfed ensures that communities have full access to program data, including on how well girls and schools are doing, so that they can be responsive and informed in their approach to tackling the obstacles girls face. This approach to governance and accountability has been critical to scaling Camfed's program and impact, and it challenges the common perception that community participation and efficient, accountable management are incompatible in the transition from small single-community initiatives to large-scale, multi-community or multicountry programs. over program implementation and the freedom to advocate for curriculum integration at the national level. Trust can be one of the most important assets for a partnership, particularly in contexts where there are few guarantees, formal contract law is rarely enforced, and infrastructure is limited.

While government remains the primary duty bearer of ensuring the right to a quality education for all, improving learning at scale requires the combined efforts of many actors to leverage diverse resources, capacities, and skillsparticularly related to financing, service delivery, and knowledge generation. This requires the interaction of state and non-state partners at various levels and across various sectors, such as education, health, nutrition, workforce development, and economic growth 


\section{Learning champions and leaders:}

As scaling quality learning is a political and technical exercise, champions within and outside government and the classroom are crucial.

Scaling quality learning requires champions and leaders at all levelsinside and outside the classroom and education ecosystem. Addressing learning challenges at scale requires dedicated individuals-visionary leaders

to create or lead an initiative, champions with political will and capital to scale and sustain an idea, and local leaders who might not be as well known but whose everyday efforts are contributing to children learning.

\section{Visionary leaders}

A common feature in scaling studies across disciplines is the critical role that visionary leaders played in driving the scaling process."II These leaders came from all sectors-government, civil society, and private sector-and served as the founders or leaders of their organizations or policy programs. They included people such as Amorim and Soares da Silva, the two secretaries of education in Amazonas state who created Amazonas State Government's Media Center; Madhav Chavan, co-founder of Pratham; and Joan Ganz Cooney, founder of Sesame Workshop. As Hartmann and Linn outline, common features of these leaders are their persistence, networking, and

coalition-building skills, and their ability to articulate a clear vision and motivate others."12 They also invested significantly in leadership development within their respective organizations and systems. While some are born leaders, others are cultivated through their experiences and practices. This, for example, is the idea behind Teach For All's partners placing individuals in classrooms, so that through the experience of working in communities and collaborating with parents, schools, and students, they gain a deep understanding of the problems and the potential solutions and then go on to become education leaders inside and outside schools.

\section{Political champions}

In many of the cases reviewed, a government champion at a national or local level was found to be the linchpin behind experimentation and greater participation in policymaking. In the case of INJAZ, the entrepreneurial training program in secondary schools that has been integrated across all 12 directorates in Jordan, Her Majesty Queen Rania AlAbdullah provided early support that was instrumental in providing INJAZ with credibility and access to a wider network. Additionally, government support, specifically INJAZ's partnership with Jordan's Ministry of Education, has been crucialforscaling the school program, given the ministry's role in institutionalizing and accrediting programs in schools. In 2011, the Ministry of Planning and International Cooperation became another key partner in helping INJAZ expand into Jordanian colleges and universities. co-creation of an initiative, rather than bringing them a fully baked, evaluated model to Education, which is catalyzing a teacherled movement to reclaim teaching and improve students' learning, found success in working with governments in Uganda and India to co-create the initiative rather than presenting an already developed model for adoption.

Political champions need not reside at the national or state level. Sometimes, it is more effective to focus on policymakers who are closest to the problem-officials who see the challenges firsthand, understand the necessary action to address the issue, and can be held accountable if actions are not taken. Over the course of its 20-year history, Pratham has cultivated government supporters at all levels with mixed results. It has found that while timeconsuming it is often easier to cultivate champions at the local level, as those closest to the problem are generally more likely to understand the nature of the problem and be supportive of the actions required.

The cases reviewed often benefited from continuity or stability in leadership. Media Center in Amazonas benefited from relatively stable and continuous political leadership. The current secretary of education, Rossieli Soares da Silva, assumed office in 2012, but he had been working with the previous secretary, Gedeão Amorim, for five years before that. Research by McKinsey and Company 
If there is clear evidence of impact, people come to expect it and it becomes much more difficult to reverse.

identified leadership continuity as essential in not only catalyzing a reform but in sustaining it. It found that the median tenure of education leaders of improving systems is seven years. This is in stark contrast to the norm. For example, the average tenure for superintendents of urban school districts in the United States is three years; for education secretaries in England, it is two years; in France, it is two years. ${ }^{4}$

When continuity is lacking, the challenge becomes to sustain the reform beyond a champion's time in office. In the case of SAT, despite its success with cultivating local champions, Asociación Bayán finds it is an ongoing, time-consuming process to sustain this support particularly in political systems that have high turnover of administrations and/or personnel. Pratham has also had the experience of programs unraveling when champions have left office, causing the associated government partnerships to disappear. The reforms that tend to survive are those that are firmly entrenched. Because citizens often feel strongly entitled to the reforms, it becomes politically impossible to retract them. This is another reason for strong community participation in change processes.

Beyond human relationships, organizations can take steps to help expand and sustain reforms. In its review of 17 large-scale health interventions, Millions Saved found that "mobilizing political leadership and champions takes a little luck and a lot of preparation,"115

Drawing from our review of 14 education cases and the literature around the issue, three approaches have demonstrated some degree of effectiveness. The first is to work across political party lines. One of the core tenets of Teach For All is that any country partner must be a non-state entity working in partnership with the public and private sectors. As a result, the partner organizations are less vulnerable to leadership changes. This has been the case with Teach First, which represents $2 \mathrm{O}$ percent of new teachers in disadvantaged schools across England and Wales, 16 after growing almost 25 percent per year during its first 11 years. ${ }^{17}$ Part of this success is attributed to its deliberate approach to work across party lines. As a result, it was the only education initiative supported by all three political parties during the 2010 UK general election."18 SAT has also insulated itself from changes in power and potential political patronage by retaining control of tutor hiring, placement, dismissal, and management.

A second approach is to build innovation or reform leaders and champions throughout the system so that continued support is not dependent on one champion. This was part of the motivation behind Fundación Escuela Nueva's founding. In the regions where Fundación Escuela Nueva has managed to bring partners together to integrally implement the model, educational outcomes have flourished.

The third approach relies on data to catalyze and sustain the political will needed for scaling. Often, evidence has been used to demonstrate the severity of the problem so that policymakers and other leaders cannot be in denial. It has also played an important role in offering policymakers credible alternatives to show that the Pratham has been effective at providing decision-makers with a tested and proven menu of options for implementing its "teaching at the right level" approach.

If there is clear evidence of impact, people come to expect it and it becomes much more difficult to reverse. This was

\section{Champions within the classrooms}

In addition to government support teacher buy-in is critical for any largescale intervention to succeed. Whether teachers directly deliver the program or support others to do so, experiences demonstrate that involving teachers as key agents of change is vital in scaling interventions. In the case of Lesson Study in Zambia, teachers were not merely taught a new teaching technique during an in-service workshop; they were also empowered to identify what was needed, collaboratively develop a lesson plan, and then practice delivering it and discussing the experience with peers. ${ }^{120}$ This is also STIR's approach, where teachers are encouraged and supported to lead positive changes in their classrooms, through sharing and putting into action their own ideas for improvement through "micro-innovations." "21 They then are supported to build their own teacher networks and become "change agents" in pushing for broader systematic change within their schools and districts.

This does not mean, however, that teachers must be responsible for the delivery of any the experience with Schools of Tomorrow, a government initiative that focuses on reducing school dropout rates and improving learning in disadvantaged schools in Rio de Janeiro's favelas. While the effort was initiated under the former secretary of education in Rio de Janeiro, Claudia Costin, it has lasted into the term of her successor. Arguably, one of the factors behind this longevity is the new program, policy, or practice for it to be scaled successfully. In fact, case studies reveal that sometimes it was preferable that they were not responsible for it. But it was critical that teachers understood and were behind the reform. Educate! experimented with teachers delivering its co-curricular entrepreneurship, leadership, and workforce readiness program in secondary schools but encountered some resistance as teachers viewed it as an additional task that was not part of their job description or assessment. As previously discussed, Educate! found greater success (in terms of impact) by training mentors, who were graduates of the program, and young entrepreneurs to deliver the entrepreneurial curriculum and modeling new teaching methods that teachers could eventually integrate into the classroom. It also developed teacher associations to provide teachers with practical in-service training to develop the core interactive teaching skills and ultimately be better positioned to effectively adopt national education reforms. Similarly, Pratham works to ensure that head teachers and teachers are 
supportive of its remedial program before in which trained volunteers, rather than bringing it to schools, even in instances teachers, deliver it.

\section{Paying attention to those} who stand to lose

As critical as it is to dedicate time to cultivating champions, it can be equally important to understand those who stand to lose as a result of an effective approach scaling. Literature finds that programs may have failed at scale because they did not pay sufficient attention to institutional incentives, vested interests, and how those who stand to lose out would react. ${ }^{122}$ Some of the latter may not be apparent until after the pilot stage if the intervention is showing success at scaling. ${ }^{123}$ This can quickly undermine any gains made. Daron Acemoglu, an economist at MIT, dubbed this the "seesaw effect"-making a change without redistributing power or the equilibrium of power usually leads to a counteracting force so strong that the change is unlikely to have significant impact. ${ }^{124}$ This was experienced with the scaling of a contract teacher intervention in Kenya. While an NGO-led pilot in western Kenya found the hiring of contract teachers to be effective in raising students' tests scores, its impact

As critical as it is to dedicate time to cultivating champions, it can be equally important to understand those who stand to lose as a result of an effective approach scaling. implemented the intervention across the country. ${ }^{125}$

Getting consensus around a new and relatively unproven model is difficult, particularly if it requires reallocation of funding resources, adjustments in human resources, and other politically difficult activities such as curtailing some Those who benefit from additional resources are likely to be excited by the prospect, while those who stand to lose through reallocation will predictably feel otherwise. It is important to think about what it takes to generate partnerships and overcome opposition where people stand to lose.

Often, there is reluctance to redraw lines, close down programs, or replace existing resources. Jaideep Prabhu, a Cambridge professor who has written extensively about innovation, calls these kinds of changes a "willingness to cannibalize" and considers them a key characteristic of innovative systems. ${ }^{127}$ Many cases we reviewed were strategic about launching an intervention where it would likely not threaten vested interests or upset power balances. Media Center, for example, did not start with its distance-learning program in the capital of Amazonas, but rather, in the middle of the jungle where it was not threatening to existing actors. disappeared when the government services and replacing them with others.

\section{Technological advances:}

Context-appropriate technologies can accelerate education progress.

To date, the vast majority of developing country governments' engagement with technology in education at scale has been putting computers into classrooms. However, this was not the situation with the cases reviewed. Where technology was used, it was to overcome a context-specific barrier, such as poor infrastructure or a lack of materials or trained teachers. Media Center employed multi-point videoconference capabilities to overcome long distances (and few roads) between communities and secondary schools. Bridge International Academies addressed the shortage of trained teachers by recruiting high school graduates from local communities and supporting them through not only training but comprehensive teacher guides developed by expert subject matter teachers and delivered via tablets. While seasoned teachers would for obvious reasons feel constrained by scripted lessons, Bridge argues that the new teachers in their schools are reassured by the guidance and it is the best way to ensure all their students learn. At its inception, Worldreader aimed to address the lack of appropriate books and other reading materials in developing countries

Technology brought cost saving and efficiency-

generating processes.

by digitizing a variety of textbooks, storybooks, and reference materials that could be accessed through e-readers and cellphones.

In some cases, as discussed earlier, technology brought cost saving and efficiency-generating processes, such as automating payment through cellphones and automating data collection and analysis systems. Bridge International Academies' teacher guides have been important in freeing up time for teachers to focus on teaching and individual engagement, rather than on lesson planning, attendance tracking, administrative paperwork, and other activities that detract from active engagement with students in the classroom. Similarly, by automating and centralizing all of the back-office work. managers can focus on monitoring and supporting teachers and students, rather than time-consuming administrative work.
Where technology was used, it was to overcome a contextspecific barrier, such as poor infrastructure or a lack of materials or trained teachers. 
Educate! has identified mobile money as one of the biggest cost- and timesaving measures as it has scaled. The staff working across Uganda no longer have to travel back and forth to Kampala to receive their biweekly paycheck or money for their programs. That saves time, which frees them up to focus on their day-to-day work. It also saves money that would have gone for travel, gas, and lodging.

As technological advances occur, many of the cases reviewed underscored the central importance of human involvement in the process of integrating technology within their operations. In the case of Pratham, having people interact with, analyze, and interpret the data is important for learning from data. Pratham CEO Rukmini Banerji described the human interface as the glue between back-office technology and frontoffice visualization. Unfortunately, far too many interventions have fallen into the trap of choosing a technology first and then looking for an educational problem to solve with it, rather than the other way around. Teacher training, power supply, and systems for maintenance have not received equal attention. Many of the cases reviewed underscored how technology has to be appropriate for the context and the users, and that "high tech" was not always the best solution, especially in the contexts of low resources or low literacy. Sesame Workshop's projects, for example, use technology that run the gamut from hightech (i.e., tablets and smartphones) to lowtech (i.e., print materials, radio, and radio over basic mobile phones). In addition to creating content that directly targets children, Sesame Workshop also develops resources to support caregivers using technology. In India, for example, it has used mobiles phones as a tool to remind teachers about the Galli Galli Sim Sim videos and activities they should use with their class each week; preloaded feature phones and pico projectors to bring content to classrooms in low-income communities; and interactive voice response systems to enable users to access radio episodes on their mobile phones.

One potential risk of leveraging technology for scaling is that it often targets and benefits those who already have access to the Internet and therefore may perpetuate inequalities that exist in access to technology. For example, in many countries, men tend to control the household phones. However, with deliberate, targeted action, technology can be leveraged to help overcome historical inequities. Worldreader found that, on average, women spent six times as much time reading on mobile phones as men. The organization is examining the reasons further but hypotheses include that the mobility and privacy of digital reading-and perhaps technology in general-drive adolescent women and girls to read more.

While there is great potential in the ways technology can accelerate progress in learning at scale, the cases reviewed identified more modest, albeit important, ways that technology was contributing to scaling. This included so called frontoffice technology that interfaced with leaners and teachers, such as interactive videos in Media Center, e-readers and mobile apps with Worldreader, and television with Sesame Street. The cases also identified how technology provided critical back-office support that helped to improve operations, such as Bridge International Academies and Educate! generating cost savings by automating payments and more rapid collection and processing via tablets and mobile phones. All of this ultimately helped to in accountability and to free up educators' and implementers' time. At the end of the day, the cases underscored that it was not about a specific piece of technology but rather about how technology enabled society to do something better.

\section{Windows of opportunity:}

Effective education approaches are more likely to take root and spread when they align with country priorities.

Scaling requires a certain aptitude for opportunism-not bound by rigid strategy, but flexible enough to take advantage of windows of opportunity Programs that were successfully integrated into the national education system often identified opportunities for a win-win proposition. Case studies demonstrated how innovation more readily takes root and spreads when it responds directly to challenges facing the state and aligns with existing government priorities and policies. As Chris Dede, professor at Harvard's Graduate School of Education and colleagues write, "If an innovation is designed to fit a larger reform agenda, that innovation will almost certainly be more sustainable and therefore scalable" 28

SAT has benefited from, and in some cases strategically leveraged, key external moments to advance its mission. For example, in the 1990s, many Central American governments felt political pressure to provide secondary schooling in rural areas. In some cases, such as in Colombia, Nicaragua, and Honduras, the government was open to alternative models to help address the problem of teacher shortages in rural areas. SAT was ready to step in and provide its program. Today, Central American governments are motivated by the challenge of stemming the tide of rural to urban migration. At various strategic points from the 1970s to present day, SAT has been poised to leverage recognition by national governments that space exists for both traditional and alternative programs.

Scaling requires a certain aptitude for opportunismnot bound by rigid strategy, but flexible enough to take advantage of windows of opportunity. 
Media Center, the state-led distance learning secondary school program in Amazonas, launched at an opportune time in Brazil, as the country was in the process of enacting a law guaranteeing universal secondary education. By 2016 , states would be responsible for ensuring that all children have access to three years of secondary school-an enormous achievement for a middleincome country like Brazil, where more than 2 million children are not attending secondary school. ${ }^{129}$ It is also an enormous task for under-resourced states such as Amazonas, where only six of the 62 municipalities are connected by road to the capital. For the thousands of young people living in small communities scattered along the Amazon jungle, it could take days or even weeks to travel to secondary school by boat. Ensuring that all children stay in school for all 12 years would have been difficult to achieve without innovative models such as Media Center.

Bridge International Academies had not originally planned to open in Nigeria in its first phase of international expansion, but it responded to a DFID request for bids to improve learning outcomes in the private market for education serving more than 1 million children in Lagos. Bridge now works in Lagos as part of a government-sanctioned program, the result of a multiyear relationship between DfID and the Lagos State Ministry of Education.
As Educate! expands into additional countries beyond Uganda, it has made the strategic decision to target countries with active skills-based reforms that align to its model. For example, Educate! decided to enter Rwanda in 2015, when the country was undertaking curriculum reforms to its secondary education, with a stated goal of a competencybased curriculum. Educate! had clearly identified gaps in both the Uganda and Rwanda school systems, where the skills being taught did not match the labor market demand. It had also pushed for reforms to teaching methods that moved from rote learning to practicebased education and from more theoretical to skills-based education. That positioned Educate! to provide the education ministries with an evaluated and effective solution to an urgent problem that the country needed to address, rather than trying to create a parallel structure.

Crises have also provided moments more amendable to adapting or reforming existing systems. Room to Read was one of the first organizations that the government of Nepalturned to for support after the devastating earthquakes in 2015. In this unprecedented situation that destroyed more than 700,000 homes and 47,000 classrooms around the country, the thought was that Room to Read could distribute storybooks to affected communities in ways that would create some joy and learning.
D Case studies demonstrated how innovation more readily takes root and spreads when it responds directly to challenges facing the state and aligns with existing government priorities and policies.
Although this request fell outside of the regular programming, staff were very happy to use Room to Read's resources and distribution networks to support the recovery efforts. The organization mobilized the movement of 500,000 books to affected communities.

Through the global financial crisis, Aflatoun International found itself as one of the few organizations providing financial education in primary and secondary schools around the world through its network of NGO partners. It has been able to leverage the interest of national actors, including central banks, ministries of finance, and financial institutions, to support 28 education departments on integrating financial education into their education systems.

Governments can also serve as "pull" forces, conducting due diligence to find partners that meet their needs or that can carry out a reform agenda. In Liberia, following reforms in the civil service and Ministry of Health that enabled the government to better engage with citizens' needs and drive service delivery, President Ellen Johnson-Sirleaf sought improvements in the delivery of education. ${ }^{130}$ This led to review of education interventions in Africa, formation of a public-private partnership technical committee, and ultimately, the Partnership Schools for Liberia program, where education service providers are contracted to operate public schools on behalf of the government, financed by government and free to children's families. Bridge International Academies was asked to host an inspection by the Liberian government, and after several months of engagement, agreed to become a public school operator in Liberiastarting with a pilot of 50 schools. What made this possible for Liberia was that the cost basis of the delivery of service of the Bridge intervention at scale is comparable to the ministry's per capita spending for primary education. Consequently, Bridge can deliver its model and not reduce teacher salaries from public sector levels. A budget limited by a parent-funded model, having demonstrated learning impact at scale, is now serving government needs and is being integrated into the public sector.

This example demonstrates a government's willingness to experiment and allow different partners to participate in the delivery of education while retaining ultimate responsibility for achieving good quality outcomes. However, this is not to underestimate the challenges such a partnership needs to overcome in order to succeed. It is yet to be seen to what extent Bridge will need to deviate from its original model to adhere to government demands, and if in turn this will affect the quality or innovation of the schools it is operating. In addition, the pilot may uncover some evidence about the impact of Bridge's model for the poorest children who would be unable to access any school that required a fee to be paid by parents.

What the case studies underscore is that change depends to a great degree on the social and political atmosphere. The organizations that were most successful seized those moments where there were supportive, positive attitudes toward change. These cases successfully framed their intervention as an effective means of achieving the education priorities of the country. 


\section{Better data:}

Data on learning and scaling play a central role by motivating informed action at the policy and practice levels.

The case studies and literature underscore the central importance of evidence in scaling efforts. Various forms of datafrom experimental, scientifically designed evaluations, to qualitative data, to student testimonials-all play an important role in

shaping policy and practice. Across the case studies, data play at least three important roles in the scaling process: motivating action to address the problem; shaping the design and implementation of the response; and sustaining the response.

\section{Motivate action}

In each of the case studies, data have been instrumental in cultivating key champions by arming decision-makers with the information needed to make difficult decisions about where to invest finite resources. As Adele Cassola, PhD student at Columbia University, and Jody Heymann, Dean of the Karin Fielding School of Public Health describe, Fidencebased decision making is about the best use of scientifically based knowledge in a realistic time frame with limited resources.131 One of the best weapons against the status quo is actionable data. Worldreader's use of e-book sales data has been key in demonstrating the viability of digital publishing to African publishers, by proving the existence of a robust local market and a nascent international one Vicky Colbert, co-author of the Escuela Nueva pedagogical model and founder of the nonprofit Fundación Escuela Nueva, claims that a strong research and evidence base was a major reason Escuela Nueva was successful in affecting national policy in Colombia and scaling to other countries. ${ }^{132}$

Case studies also revealed that various forms of evidence have been effective in influencing policymakers to scale certain interventions. Impact evaluations certainly can play a role in building a chowled ce base of "what is working here," but experience shows that the spread and integration of interventions may important for policymakers. This is supported by Rogers' seminal work, in which he writes, "Most individuals evaluate an innovation, not on the basis of scientific research by experts, but through the subjective evaluations of near-peers who across the case studies was that once key results firsthand the program or policy was expanded. There was typically a pivotal moment when information-often require firsthand knowledge of change in a community, which can be particularly have adopted the innovation."133 A pattern decision-makers saw an intervention's in the form of rigorous evaluations-was translated into an emotional imperative to act. Educate! found that some of its earliest champions knew students who had gone through the program and were impressed with its impact. Policymakers identified that this secondhand evidence, which was then backed up by more rigorous quantitative data, contributed to the incorporation of Educate!'s curriculum into Uganda's national education system.

Asociación Bayán's leadership, the organization behind SAT in Honduras, was savvy and brought along local politicians and donors to visit schools (known as centers) since the program's inception. It invited the DFID to participate in an early evaluation so that DFID could see the impact firsthand. Similarly, Asociación Bayán spent considerable time inviting local politicians to personally see the changes in students. Once local policymakers were onboard, Asociación Bayán worked tirelessly to turn political support into binding legal frameworks and agreements.

While even the most rigorous and accessible data will not necessarily be acted on, they certainly can play an important role in changing behavior. Experience shows that the first step in motivating action is often to show the severity and urgency of the problem, demonstrate that change is possible, and ensure that capacity exists to take action. This is the premise behind Lesson Study in approaching teachers as key change agents. Teachers work collaboratively to identify challenges in their classroom, develop lesson plans to address the challenges, and practice delivering the offering constructive feedback.
It is also part of the premise of a movement to understand how well children are learning to read in their first years of primary school. RTI International, with support from USAID developed the Early Grade Reading Assessment (EGRA) in 2006, motivated by the concern that limited reading skills in the first years of school were holding many children back from successfully proceeding through school. Because RTI made the EGRA tool open source and freely available, its use spread rapidly across the developing world, and today, the tool has been adapted and used by governments, schools, civil society organizations, and the private sector in over 40 countries. Data from the wide range of contexts in which EGRA has been used, which showed the surprisingly low levels of reading proficiency within many countries, provided a wake-up call to many education actors, from teachers to ministers to global policy leaders.

The case studies and literature, particularly in behavioral economics and psychology, show the importance of quick wins to demonstrate that change is possible. This is also the theory behind Rapid Results, an approach that focuses on mobilizing communities to overcome specific challenges through leveraging their own assets. The idea is based on the premise that what is lacking in development is not specific information, money, or technology but the motivation and confidence to use available resources. Rapid Results Institute widely implements this approach with great success across developing countries, including with corporations in Ethiopia to increase HIV testing of employees, in Nicaragua to improve dairy farm's milk quality and in Rwanda to double the less than 100 days. 134 


\section{Shape design and delivery}

A common feature of interventions that have successfully scaled is that they rarely follow a linear path of research to action..$^{35}$ Rather, they undergo a more circular process of experimentation, learning, and course corrections. This requires ongoing testing, evaluation, and revision of modelsbeyond proving the initial efficacy of a model as it continues to expand. Historically, there has been much greater attention to and support of the proof of the concept phase, with too few resources and attention to scaling plans after the initial intervention is proved. ${ }^{36}$ As a result, it should not come as a surprise that many pilots do not survive beyond their beginning phase. ${ }^{137}$

From Sesame Workshop's start, research played a prominent role in its content creation model. Programming is a continuous process that begins with the assessment of need and includes ongoing formative research and, where possible, summative evaluations of the program's impact. All of this, in turn, feeds back into thinking about the needs for the next season of programming. Every season of Sesame Street is an experiment The integration of research into the production process and the spirit of experimenting have resulted in programs that are examined critically, where teams test new ideas and make important course corrections as necessary. As founder Joan Ganz Cooney has said, "Without research, there would be no Sesame."138

A key driver behind Pratham's success resides in its emphasis on experimentation and learning. This includes an openness and honesty about where things are not working. Pratham has used this evidencebased approach for making critical decisions. In this way, it has managed to multiply impact in the face of competing needs and scarce resources. Over the past 20 years, Pratham has combined essons from rigorous evidence with field-level experience to formulate and inform strategies and programs. To track the progress of more than a million children a year, Pratham uses simple tools and methods to measure and monitor learning gains made by each group in learning camps through the year. These data are uploaded on a portal from the field and are available for all team members to view at any time. According to Banerji, "The biggest need for data in our system is for us." 139 This learning has been incorporated into a suite of evidence-based options for implementing Read India that is offered to state governments to adopt, as has been taken up to various degrees with the states of Bihar, Maharashtra, and Uttar Pradesh.

Bridge International Academies is somewhat of a unique case in its ability to continuously strengthen its programs. It collects and mines an enormous amount of data in real time through the use of

\section{A common feature of}

interventions that have successfully scaled is that they rarely follow a linear path of research to action. Rather, they undergo a more circular process of experimentation, learning, and course corrections. then able to very quickly, efficiently, and effectively roll out any changes across its more than 450 schools, as it controls the entire supply chain-from school construction to curriculum design to teacher training. Room to Read, meanwhile, uses data to evolve and improve its programs, as it considers transparency central to its success. When findings showed that the national curriculum in Vietnam was already achieving strong outcomes in foundational reading skills among students, Room to Read decided to focus its Literacy Program resources on growing its network of learning environments and publishing quality reading materials. It was therefore able to save financial and human resources in this area and divert them into other more pressing work in Vietnam and elsewhere in the Room to Read network.

\section{Sustain scale}

The role of data extends beyond persuading decision-makers to invest scarce resources into scaling an initiative-data can also have an impact on an initiative's sustainability. Once data demonstrate improvements, it is difficult to reverse progress. In their seminal scaling work, Hartmann and Linn argue that welldesigned evaluations can build political support even if political parties change ${ }^{140}$

As the former secretary of education in Rio de Janeiro, Costin explained, while discussing Schools of Tomorrow, "In Latin America, there are lots of laws that are written but that do not happen, things that cannot be enforced. Through my experience as a public policy specialist, see the best way to ensure continuity of any program is to really bring results, as then it becomes something desirable."14
The role of data extends beyond persuading decisionmakers to invest scarce resources into scaling an initiative-data can also have an impact on an initiative's sustainability. Once data demonstrate improvements, it is difficult to reverse progress. 



\section{Introduction}

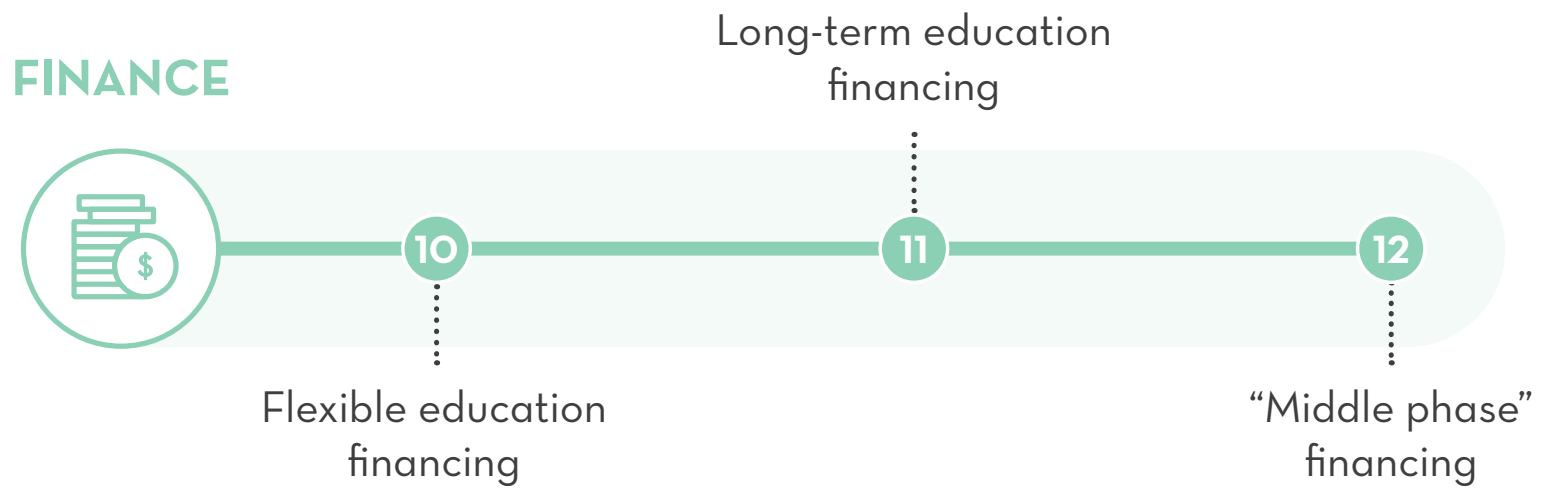

Designing and delivering at scale require resources-and the more you grow, the more resources you need. To complicate matters, when it comes to scaling quality learning, how financing is structured and allocated seems to be at least as important as total financing available. The cases demonstrate, and the literature supports, the notion that stability and flexibility of financing are necessary for scale to occur in ways that contribute to lasting change. Regardless

of the source, financing for scale needs to take a long-term approach, invest in core organizational capacity, and activate middle-phase funding.

When it comes to scaling quallity learning, how fin ancing is structured and allocated seems to be at least as important as total financing available.
10. Flexible education financing:

Financing should be flexible, including to build core operational capacity.

Case studies reveal that flexible funding was instrumental in allowing for experimentation, learning, and growth: governments and donors that focused on agreed-upon results to achieve but were flexible and had trust in the implementer about the best way to achieve them. This included investments in activities that were most needed to support the scaling process at various points, which frequently required developing core operational capacity.

If the overall goal is to have an effective learning intervention go to scale, financing from government is key Domestic governments remain the largest source of basic education financing, and the percentage of national budgets dedicated to education has continued to steadily increase since 2002 in many low- and low-middle-income countries. The cases examined highlight a range of ways that governments are providing financing that is key to scaling. In the case of SAT, the Honduran government is paying for the largest recurrent cost of the alternative secondary education program run by the NGO Asociación Bayán-tutors', or teachers', salaries. Pratham was able to reach 5 million children across India last year with its teaching at the right level approach by working through government-funded schools where teachers were trained in the approach. While the government of Zambia invited the JICA to provide technical support in adapting and rolling out Lesson Study across the country, it has provided approximately 90 percent of the financing over the past 10 years for the in-service, peerto-peer teacher training practice. These cases offer powerful examples of where governments provided predictable and flexible financing that facilitated the expansion of quality learning initiatives.

External donors can also play an important role in the scaling process, particularly in investing in earlier stages of experimentation before an idea or approach is proven. Foundations, generally have a greater appetite immediate resuls to their constivents. Despite this comparative advantage and best intentions, donors at times short-term or more restrictive funding The average development assistance "project" lasts less than two years from start to completion ${ }^{142}$ and does not allow

Flexible funding was instrumental in allowing for experimentation, learning, and growth. individuals, and corporate donors for risk taking than governments that can undermine the scaling process with 
for much time for the type of investments required for building systems and capacity. Ultimate results being targeted, such as improved learning, can take years.

Therefore, given the need for much improved financing approaches from

external, nongovernmental sources, we focus in the following sections on the role that donors can play in better facilitating the scaling process and how external funders and governments can work together more effectively to help quality learning interventions spread.

\section{Financing for core operational support}

According to Chris West, former director of Shell Foundation, creating scalable and sustainable enterprises requires building "core capacity, operating systems, and robust infrastructure."143 In focusing on why some businesses scale successfully and many others do not, Verne Harnish, author and founder of Entrepreneurs Organization, identifies three challenges in scale: inability to grow enough leaders, failure to address increased competitive pressure, and lack of systems and structures to handle the complexities of growth. ${ }^{144}$

Building core operational capacity and ensuring a smooth transition between innovation and scale require flexible financial support. Unfortunately, this type of flexible financing for core system support is more often the exception than the norm. Arguably, some of the cases reviewed were held back from expanding or spreading more quickly because of limitations with core support. Because scaling at its essence is about people and process, it is ironic that often these are the most difficult components to fund. Managers of some cases felt pressure in fundraising to keep their overhead low, especially as the organization grew and needed the support more than ever to develop systems to monitor larger programs efficiently and build human resources and capacity to manage them. For example, as it continued to expand, Worldreader required an investment in product and software development that was particularly difficult to get funded. This is not to argue for limitless or even proportional growth of but to support the core systems needed to scale impact.

The rise of rating agencies and attempts to boil down an organization's effectiveness based on a single metric-a percentage going to "overhead" expenses-can intentionally or unintentionally reward those who do not invest in building systems andinfrastructure. Donor restrictions often and politicians might prefer investments in buildings, books, computers, and other tangible inputs and outputs that can be evaluation systems, that are required for scaling. A McKinsey and Company study on philanthropy in India found that while 90 percent of donors and experts believe that investing in institutional strengthening and policy change is important for of interventions supported were in the (n) category of providing direct support to
beneficiaries, which included outcomes an organization or institution as it scales, seen by their constituents, rather than more intangible systems, such as monitoring and overall transformation, 60 to 65 percent that were more "tangible, measurable, attributable and controlled."145 This is not to argue against investments in direct support, but to argue that investments in institution building are needed as well.

Network secretariats often play an important role in scaling, including by helping to share lessons, maintain quality, and ensure fidelity to a model as it expands and is adapted to new contexts. Networks are also critical for the coalition- and fieldbuilding often required for large-scale reforms.

However, in many of the case studies reviewed, the secretariat was often the most difficult part to get funded. Teach For All is an example where the global organization provides critical support to each of the 39 independent partner organizations to adapt and implement the approach in their respective countries. This support includes providing a global platform for sharing of ideas and supporting partners in adapting the ideas to their local contexts. Initially, despite the central role that it plays, Teach For All found it challenging to demonstrate the value of its support and to generate funding for a global approach to education. Fortunately, as the Teach For All network has grown over the past eight years, it has become easier to make the case that the organization's role in providing support to partners is critical.

As Alice Gugelev and Andrew Stern at the Global Development Incubator describe, too often donors are inhibiting scale by supporting only one-off initiatives. "Instead of supporting an organization's overall mission, funders often prefer to provide grants to programs that target a particular issue over a limited period of time. Corporate foundations, in particular, often allocate capital to efforts that align with their own institutional goals but not necessarily with the broad goals of the nonprofits they fund." This prevents organizations from growing and further developing their capacity. ${ }^{46}$

In an encouraging sign, Grantmakers for Effective Organizations President and CEO Kathleen Enright arques in favor of investing in capacity building that can help organizations boost their impact. ${ }^{147}$ Over the past eight years, the group has built tools and resources to support grant makers to do so. In 2013, GuideStar, Charity Navigator, and the Better Business Bureau Wise Giving Alliance joined forces to encourage donors to stop the practice of bluntly evaluating nonprofits based on what they refer to as an "overhead myth"-"the false conception that financial ratios are the sole indicator of nonprofit performance," and instead focus on results. They have published two open letters to U.S.-based donors, challenging them to change their practices..$^{148}$

Recently, the Ford Foundation announced an important transformation of its funding strategy to provide grantees with greater access to general funds More than 40 percent of all Ford Foundation funds will
Network secretariats often play an important role in

scaling, including by helping to share lessons, maintain quality, and ensure fidelity to a model as it expands and is adapted to new contexts. 
be allocated to general operating support, twice what was previously available. Harkening back to the foundation's contributions to the civil rights movement, Ford Foundation President Darren Walker believes that this commitment will enable the foundation to have a greater impact on such issues as inequality, which will require social movements to tackle entrenched social problems. "We're going to move away from bending our grantees to fit into our boxes and do a better job of listening and learning."149 Ruth Levine director of the global development and population program at the William and Flora Hewlett Foundation, advocates for grantees and funders to be more realistic about what it takes to start a new program or organization, which may require building a "zero year" into budgets and timelines-that crucial initial year of development and planning
According to Pratham's leaders, the most helpful donors were those who were openminded in terms of what Pratham did on the ground but were systematic in holding its leaders accountable to what they said they were going to achieve. These donors had spent time with Pratham in the field and were along for the journey, keen to see results influence governments. Donor agencies and foundations, such as the Hewlett Foundation, played a catalytic role by encouraging Pratham just enough and at just the right time to help Read India follow its charted path, but they did not suffocate Pratham by questioning its every move.

Particularly with interventions originated by non-state actors, donors can play a critical role in providing flexible support that helps to build core operational capacity needed to scale effective ideas and approaches.

\section{Long-term education financing:}

Stable and predictable support is essential.

In addition to flexible support scaling requires stable, predictable financing, often for a decade or more. ${ }^{151}$ This often does not align with politicians' or funders' timelines. A new administration or government official may discontinue funding for a predecessor's program or policy. Meanwhile, a key conclusion in the literature is that while donors at times support scaling, they often ack a systematic scaling focus and approach. ${ }^{152}$ They also systematically underestimate how much trial and error will be involved in the scaling process. ${ }^{153}$ The German development agency Deutsche Gesellschaft für Internationale Zusammenarbeit (GIZ) candidly reflected that the timelines often envisioned by development cooperation agencies are "overly ambitious and not adapted to the pace of reform in the partner country."154 The case studies revealed that reform processes are slow. This contrasts with the average donor engagement of 613 days from start to completion. ${ }^{15}$

Successful efforts at scaling learning interventions often benefited from long term intell as supportive policymakers and donors who understood the realities of what it would take to achieve the effort's desired impact. According to INJAZ, the USAID long-term financial commitment is what truly allowed the skills building program to become established and grow. This commitment also came with USAID's know-how and auditing systems, from which INJAZ learned and began building its own systems. ${ }^{150}$

The practice of Lesson Study, a peer-topeer in-service teacher learning method, did not scale across Zambia overnight. It took a step-by-step approach over 10 years to cover all 10 provinces. The expansion of Lesson Study closely followed and aligned with the government's policies for continuing professional development for teachers. The gradual scaling expansion allowed the program to continuously refine its implementation strategies. Similarly, by gradually expanding Lesson Study across the country, the Zambian government could observe its impact such as improved math and science pass rates, before incorporating the method within its national development plans. ${ }^{157}$ JICA has remained a constant partner throughout these 10 years. This longterm commitment and phased approach by all partners has been an important aspect to Lesson Study's success in Zambia.

Aflatoun International supports partners in civil society organizations to start social
Successful efforts at scalling earning interventions often benefited from long-term financial and technical support, as well as supportive policymakers and donors who understood the realities of what it would take to achieve the effort's desired impact.

and financial education programs to demonstrate the viability of its material within the education system and to kickstart the development of relevant content for the national context. It estimates that the average time between the start of such a program and work on curriculum integration to commence to be almost five years.

In the Quality Education in Developing Countries initiative, the Bill and Melinda Gates and Hewlett foundations pooled resources and were willing to invest a substantial amount of long-term funding for something they believed would have a significant impact on learning. Pratham responded with a proposal that outlined the first generation of Read India. It was appropriate for a number of reasons, including its ambition to go "for all of India." "158 This support lasted more than eight years.

A long-term commitment is behind Room to Read's requirement that it must first raise funding for a minimum of three years before starting operations in a new country with full program implementation. The principle is that an effective program and commitments to communities and countries requires building networks and establishing roots without fear of 
discontinuing the program mid-stride. This finding is reinforced by research in other sectors, such as health, which found that more predictable funding at adequate levels enabled the system required for scaling health innovations to work. ${ }^{159}$

While ensuring that deep and lasting impact can take time, the cases also underscored the importance of demonstrating intermediate results. It is unrealistic to expect public or private funds to support an initiative for multiple years without seeing any results. Specific guideposts are needed to signal progress toward the achievement of desired final outcomes. Larry Cooley, founder of MS Worldwide, and Linn found that securing and maintaining the commitment and resources needed to scale over this period requires "tangible milestones, strategic communications, and an explicit strategy for maintaining momentum "160 Pratham's Read India program's "learning camps" focuses on low-cost, intensive bursts of teaching and learning activity

generally delivered between one to three months that lead to measurable improvements in young children's reading and mathematics. The Sesame Street approach focuses on more immediate learning improvements, in addition to its ong-term, positive impacts on children. ${ }^{161}$ For example, in Indonesia, researchers found that children who watched "Jalan Sesama" (the Indonesian co-production) regularly showed greater improvements in tests of early cognitive skills, letter recognition, number recognition, counting, health and safety knowledge, social development, environmental awareness, and cultural awareness than those who had no exposure to the show. ${ }^{162}$

While ensuring that deep and asting impact can take time, the cases also underscored the importance of demonstrating intermediate results.

\section{2. "Middle phase" financing:}

Financing is required to bridge the critical stage between pilot and broad uptake.

Without flexible and long-term funding, manyinterventions die in the "middle phase" of scaling. This phase, which occurs after prototype or proof of concept but before implementation at scale, is particularly important but often neglected. Chandy and colleagues describe this "valley of death" as where most creative ideas and innovations end up. ${ }^{163}$ Experience and literature reviewed found that new ideas and pilots generally had little difficulty finding funding-"donors love to fund promising innovative new ideas; ministers will push their pet project; and venture capitalists provide startup capital."164 At the other end of the spectrum, large, established programs sustain their funding from national budgets. What is often missing in terms of development assistance, domestic budgets, and capital markets is support for the middle stage of scaling. ${ }^{165}$

Bridging this middle phase requires greater clarity and transparency regarding who funds which stage of the scaling cycle. Domestic funding is clearly needed to scale and sustain any efforts to improve learning at a national scale. Earlier on, external support in the form of financial, in-kind, or technical assistance is often needed during experimentation and adaptation of a model or approach. Over the past few decades, there has been a movement by the global community for improving donor effectiveness through greater harmonization or coordination of assistance. ${ }^{166}$ However, to date, frameworks and policies calling for a clearer division of labor among donors have focused on financing across countries and sectors, and not on the phases or processes being financed. A greater focus on scaling could provide an opportunity for more rigorous research and data on funding along various stages of scaling.
Fundación Escuela Nueva managed to cross this valley of death, expanding an initial pilot of 150 rural primary schools in Colombia in the mid-1970s to eventually reaching more than 20,000 public schools by 1988. No single factor was responsible for this journey, but rather a number of mutually reinforcing drivers, including founder Colbert's appointment as vice minister of education in 1982 evidence of the model's impact, community mobilization and support, and long-term financing from international partners, such as USAID, the InterAmerican Development Bank, the United Nations Children's Emergency Fund (UNICEF), and the World Bank. Escuela Nueva also demonstrates that even after crossing the middle phase, sustainability is not guaranteed. While the model reached a scale of 24,000 schools and became a national policy, the program has been shown to be susceptible to political and administrative changes. Over the years, as Colombia has become decentralized, Escuela Nueva's implementation and sustainability have been highly dependent on the political will and the technical and financial capacity of the local and regional educational authorities. In turn, the level of implementation of the program across the country is not consistent.

Silicon Valley could be a useful model to consider in terms of how it embraces and New ideas receive mininaling to risk.

New ideas receive minimal funding and
Crossing the "valley of death" requires greater coordination and collaboration among government agencies and donors, including greater segmentation and transparency around who funds at which stage of the scaling cycle. 
as they prove themselves, they are able Omidyar Network, Sida, and Australia's to attract more financial support. The Department of Foreign Affairs and Trade. more proved and less risky the initiative, capital approaches and experien development agencies-such as USAID's for development innovation through the Development Innovations Venture and the use of "a tiered financing model [that] Innovation Against Poverty by the Swedish offers three stages of funding." Each International Development Cooperation stage is characterized by the level of (Sida)-have been experimenting with advancement of the innovation and "by this approach. Both of these initiatives the level of evidence that supports its have fed into the more recently launched potential for success."168 aims to cor "innovators with scaling partners" to successfully scale social innovations and reach millions in the developing world. GIF partners have committed more than \$200 million over five years, and include DFID, USAID,
Crossing the "valley of death" requires greater coordination and collaboration among government agencies and donors, including greater segmentation and transparency around who funds at which stage of the scaling cycle. 



\section{Introduction}

ENABLING

ENVIRONMENT

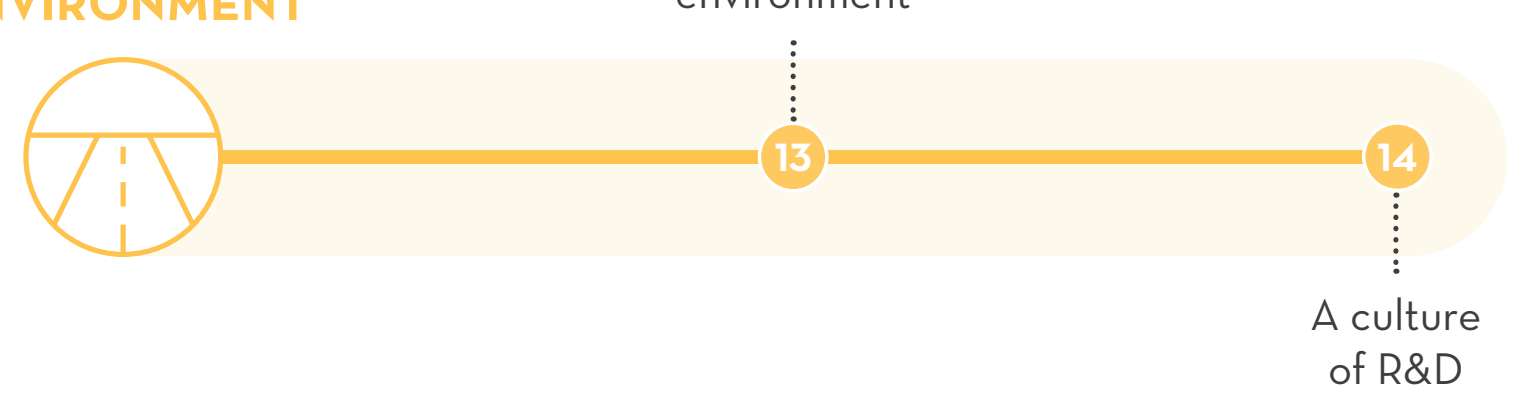

\section{Supportive policy environment:}

Government policy must safeguard every child's right to a quality education while remaining open to a diversity of ideas and actors to contribute to this common aim.

Evidence from cases and literature shows that government policy space that was open to innovation was key for a number of good ideas to flourish and scale. In many of the more successful case studies reviewed, the government provided a platform for a multiplicity of actors to be involved in the provision or financing of quality learning opportunities, or both. In the cases

reviewed, it was not that the government stepped aside to allow a free-for-all, but that it continued to play a prominent role, particularly in regulating and monitoring any new initiatives. Driven by a commitment to ensure that all children receive a quality education, these governments reached out to a range of partners and considered new ways of improving learning.

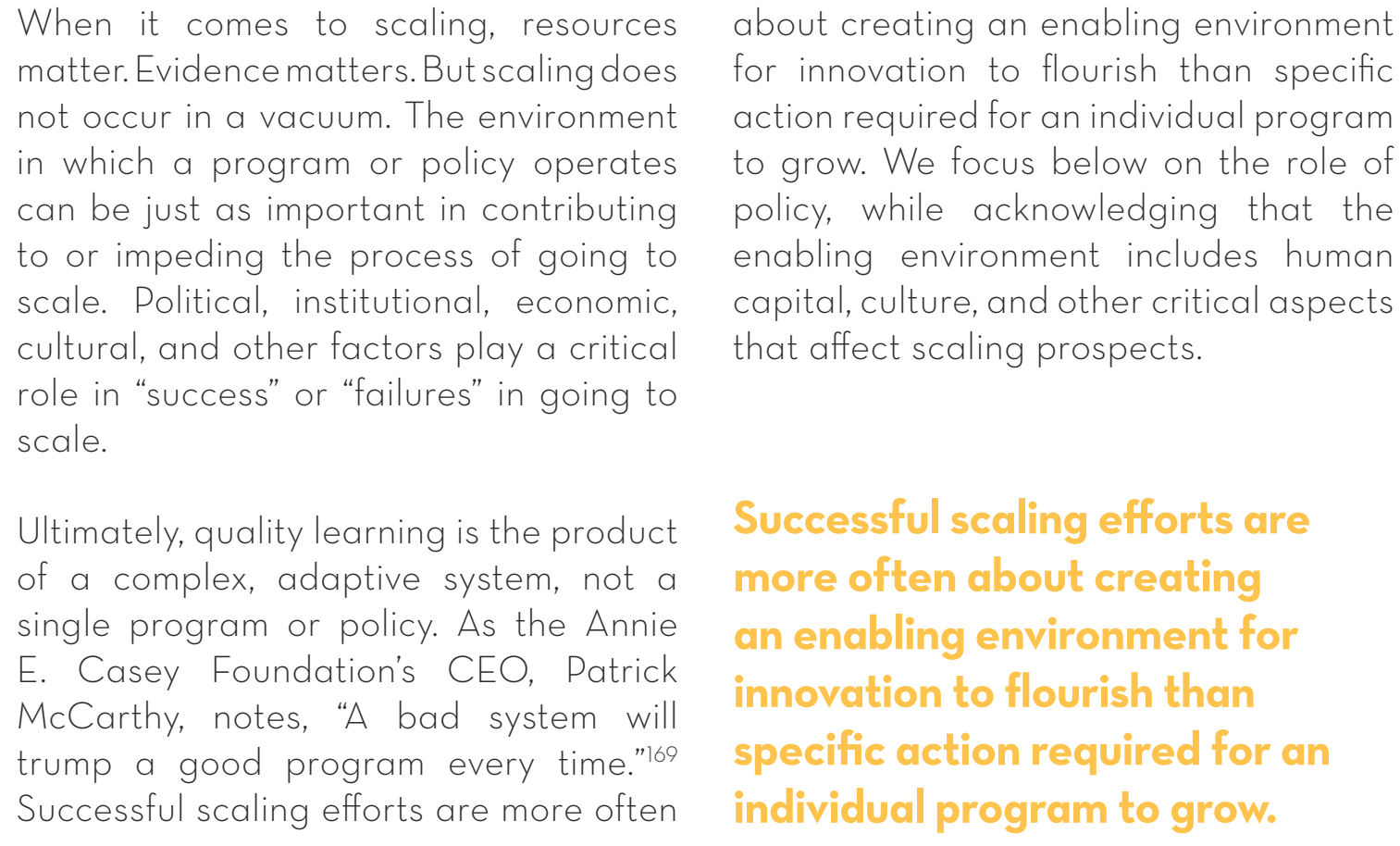

When it comes to scaling, resources matter. Evidence matters. But scaling does not occur in a vacuum. The environment in which a program or policy operates can be just as important in contributing to or impeding the process of going to scale. Political, institutional, economic cultural, and other factors play a critical role in "success" or "failures" in going to scale.

Ultimately, quality learning is the product of a complex, adaptive system, not a single program or policy. As the Annie E Casey Foundation's CEO, Patrick McCarthy notes, "A bad system wick trump a good program every time" 160 Successful scaling efforts are more often

about creating an enabling environment for innovation to flourish than specific action required for an individual program to grow. We focus below on the role of policy, while acknowledging that the enabling environment includes human capital, culture, and other critical aspects that affect scaling prospects.

Successful scalling efforts are more often about creating an enabling environment for innovation to flourish than specific action required for an individual program to grow.

Evidence from cases and literature shows that government policy space that was open to innovation was key for a number of good ideas to flourish and scale. In many of the more successful case studies reviewed, the government provided a platform for a multiplicity of actors to be involved in the provision or financing of quality learning opportunities.

Defending the mission of quality education, not a model or institution

As economist Lant Pritchett writes in The Rebirth of Education "the price of better education is allowing freedom, giving choices and hence ceding power."170 choices and hence ceding power."170 possibilities. As educator and author
Governments that provided space for Frederick Hess describes, these are innovation to take root and spread did model but were open to a diversity of 
governments that defend the mission of quality education, as opposed to the institution./There are examples of this from all around the world.

Amazonas State Government's Media Center is an example of a program that benefited from a supportive policy environment, where the national government set clear quality targets, while leaving states and schools free to choose how best to achieve them. As discussed above, SEDUC seized this opportunity and creatively designed a distance-learning model based on the realities of the region. With the space to experiment and iterate, along with clear national standards and regulations, Amazonas was able to ensure that hundreds of thousands of teenagers

had a chance to complete a quality high school education-something that was unthinkable only a few years prior.

Governments that provide a supportive policy environment for scaling quality learning know that they do not have to assume all roles of education delivery and financing. In the case of SAT in Honduras, the government recognized that it needed thevision of secondary school to the rural population while faced with limited resources and capacity. Therefore, as described above, it made the bold decision to allow a local NGO, Asociación Bayán, to recruit, train, and manage a cadre of teachers (or "tutors" as they are referred to in the program), while the government paid for their salaries as contract teachers.

\section{Regulating education quallity and standards with a multiplicity of actors}

As governments move to recognize multiple education models, regulating education quality and standards becomes more complex. Schools may vary significantly in terms of student demographics, teaching techniques, use of technology, and other important factors. While the diversity may lead to more rapid innovation and discovery of improved methods, policymakers may struggle to ensure that their regulatory tools-such as standardized tests or curriculums-evolve as rapidly as the sector. This gap has impeded progress in a number of sectors worldwide. ${ }^{172}$

This tension for governments between providing space for innovation while maintaining quality control played out in many of the cases reviewed. In Peru, the government initially did not allow fellows with Enseña Perú (EP), Teach For All's partner in the country, to be employed as fulltime public school teachers on the Ministry of Education payroll, which significantly limited EP's ability to place fellows in the highest-needs schools and communities. This started to change two years ago with the arrival of a new minister of education, who prioritized leveraging human capital in the education sector. In addition, ED's alumni working across regions in the public sector built the right national, regional, and local relationships and helped construct a more complete understanding of the needs and opportunities within the education community. Furthermore, a teacher deficit resulting from the increase of teaching hours in the public school day led to a policy

Governments that provided space for innovation to take root and spread did not adhere rigidly to a single educational model but were open to a diversity of possibilities.

adjustment that allowed for non-education professionals to fast-track into open positions. These deficits were prevalent in the highest-need, most remote areas of the country-precisely the communities EP sought to serve. These changes have allowed EP to work with the public school system to scale and serve disadvantaged children in Peru.173

Bridge International Academies is an example where the low-cost private school chain was able to initially grow rapidly in Kenya-opening a new school every 2.5 days-in the midst of new regulations being drafted for non-state schools. This process of drafting regulations took place over seven years, creating significant ambiguity over government intent for the sector. In the lead-up to new regulations for the "alternative" or "complementary" education sector being released, the ministry issued new guidelines revoking such schools' registration as testing centers, in a move to ensure that only ministry-registered schools could enroll children to sit for the mandatory national primary exit examinations. In 2015, the Ministry of Education also asked that

\section{Role of civil society in monitoring educational developments}

However, monitoring quality and standards advocacy groups play a pivotal role in is hardly the responsibility of policymakers validatingthequality ofeducation, identifying alone. In many countries, civil society promising practices, and influencing policy watchdogs, social intermediaries, and reforms. Their participation can lead to a 
richer public dialogue on education and accelerate improvements.

One such example is the Annual Status of Education Report (ASER) survey conducted in India each year by the ASER Centre, an autonomous unit of the Pratham Network, which is now replicated in Pakistan, Kenya, Tanzania, Uganda, Mali, Senegal, and Mexico 175 ASER conducts an annual, nationwide household survey of children's ability to read simple text and do basic arithmetic by deploying about 30,000 volunteer data collectors from partner organizations, including colleges, universities, NGOs, and youth groups. ${ }^{176}$ The release of the results is timed with discussions about the national budget and shared through various media outlets with simple, easy-tounderstand charts and comparisons. ${ }^{177}$

A multi-country study by Results for Development in 2015 found that citizenled surveys, such as ASER, have been extremely effective in making the low quality of education much more visible at the global and national level. ${ }^{178}$ They also have successfully generated much more dialogue among key stakeholders about the state of education and, in some cases, have influenced policy or budget allocations. ASER has had an impact on policy in some Indian states and, in general, the surveys have greatly empowered local civil society organizations to target and strengthen their advocacy efforts.

Rather than criticizing or ignoring the findings, government engagement has been particularly important in contributing to the effectiveness of citizen-led monitoring efforts. The Results for Development evaluation found that including key government actors at the national level
Ultimately, it is about the government putting in place enough controls to protect its citizens, particularly those most disadvantaged, without stifling innovation or growth.

as advisors in assessment activities, such as in the survey design process, helps to increase institutional buy-in. ${ }^{179}$ Results from Uwezo, which has administered large-scale, citizen-led household-based assessments in Kenya, Tanzania, and Uganda, have been cited in some government reports as contributing to government's renewed focus on learning outcomes. ${ }^{180}$ According to an official with the Kenya Ministry of Education, developing a strong partnership between the agency and other civil society actors such as Uwezo and the Kenyan Head Teachers Association, among others, has been particularly important in addressing learning challenges in the country. The rich information on learning provided by Uwezo has been especially useful in helping the Kenyan government understand the scope and scale of the problem. ${ }^{181}$

Drawing from cases reviewed, it appears that innovations have the greatest likelihood of successful scaling where policymakers provide space for experimentation and allow for alternative forms of delivery if necessary, while providing the necessary safeguards and regulations to ensure quality for all. Often these are governments that value flexibility, focus on outcomes (rather than on process), and promote information sharing. Ultimately, it is about the government putting in place enough controls to protect its citizens, particularly those most d those most
Box 17. Government action to create space for scaling quality learning

Research by Dembélé, Samoff, and Sebatane points to specific roles that national governments can play in order to create space for scaling of learning. These are summarized here and illustrated through the Media Center case study: ${ }^{182}$

SET APPROPRIATE TARGETS: Establish broad objectives and national standards that provide clear targets for the country. In the case of Media Center, the federal government of Brazil established a coherent vision along with clear national goals for learning for all children, while leaving it up to states and municipalities to determine the specifics of what students should know and do at each grade level.

PROVIDE A COHERENT SYSTEM OF ACCOUNTABILITY: This includes tracking how children are faring in regard to meeting national targets and ensuring transparency and availability of results. In the case of Media Center. Brazil established a national assessment system, the Brazilian Education Quality Index (IDEB), using an internationally benchmarked index to measure progress of all schools against a baseline.

ENSURE STABILITY AND SET CLEAR RULES OF THE GAME: Put into place and provide complete information on clear regulations and policies that allow foa stable environment for engagement in the education system. In Brazil, there is a clear division between federal, state, and municipal governments in regards to the enrollment of children. The new state-level mandate for high school education encouraged the A mazonas state government to be creative and experiment with more efficient ways to reach a greater number of rural youth across the region.

PROVIDE RESOURCES: These can include financial, human, and technical resources. In the case of Media Center, the federal government of Brazil has steadily increased its investment in education-from 4 percent of GDP in 2000 to 6.3 percent in $2012^{183}$-while more equitably distributing funds to resourcepoor states. ${ }^{184}$ At the same time, the Amazonas State government did not wait for sufficient funding from the federal government and allocated state funds for initiatives, such as Media Center.

While the specifics of these roles vary, what is clear is that without participation and leadership from the public sector, it is virtually impossible to ensure the necessary enabling environment for interventions to scale systematically, sustainably, and equitably. 


\section{A culture of R\&D:}

Ensuring that more children learn requires a strong ethos of experimentation, collecting learning data, and using it for continuous improvement.

The cases exhibited an adept use studies, the key drivers behind creating of evidence plus a strong culture of this culture were to collect and utilize experimentation, collecting learning data data on learning and other key outcomes and using it for continuous improvement, to ensure impact. They also were not while iterating without fear of failure. afraid to take risks and learn from failure Education lacks the kind of research and whenever possible. On top of that, many development (R\&D) culture that many of the cases used a strong foundation in other sectors employ, investing large sums research when developing and scaling in developing new products or solutions, their approaches. These strategies should plus the subsequent experimentation be employed across the entire ecosystem that allows the most successful ideas to of actors to create a shift in education to adapt and go to scale. Across the case this kind of culture.

"We still lack a lot of basic information in the education sector, which is particularly shocking when compared with the health sector. The explanation is straightforward, though: there was and there is an underinvestment in data in the education sector. There is also no doubt that the data gap has a negative impact on the level of international funding for education."185

\section{Strengthening data collection systems on learning}

Data, and particularly data on learning experimentation. This is especially Dutcomes, are the foundation of an culture of evidence, research, and important for systems focused on scaling effective approaches, in order to identify which interventions improve learning outcomes and ensure they continue to as they scale. Data on learning are especially needed if countries and the global education community wants to shift from scaling access to scaling access plus learning. Actors across the ecosystem need to be able to review and learn from what they and others are doing across a number of dimensions and especially how their actions affect children's learning.

Too few developing countries have the robust and relevant learning assessment systems needed to support evidencebased changes in policy and practice. As discussed earlier, developing countries have a range of snapshot assessments, but what is needed are robust and systematic methods to collect relevant learning data that can be regularly used by all actors across the education ecosystem. These systems include classroom-level learning data that teachers can use to help each student all the way up to national-level assessments

\section{Prioritizing education R\&D}

R\&D has been identified in many sectors as a key driver of innovation and improvement. In comparing the scaling of education to health, Colette Chabbott, professor at George Washington University, argues that, "Early investments in science enable faster scaling up later. The education sector has not made necessary investments in the types of basic research that can improve the conventional, slow-expanding mode of primary school and/or provide the scientific foundation for simple, gamechanging innovations. That sort of that provide a picture of what students know and can do. ${ }^{18}$

The cases reviewed provide good examples of how different types of actors collected and used data. For example, in Brazil, significant improvements in the country's overall learning outcomes have been attributed partly to systemic monitoring of progress and greater accountability 187 The federal government's IDEB, which sets targets for schools based on each school's trajectory, evaluates a school's performance against its past performance and not against arbitrary targets for all schools. The public nature of the index provides a real incentive for states to use effective strategies and improve student achievement. 188 In the case of Amazonas, SEDUC had the mandate and freedom to develop initiatives, such as Media Center. as students test score and pass rates were monitored and held accountable to national targets. research may require research centersnot program evaluation-embedded in countries with the farthest to go to meet EFA [Education For All] goals and with closetiestoresearch centers of excellence in other countries." ${ }^{189}$ According to 2008 data from Organisation for Economic Cooperation and Development countries, public R\&D spending in the sectors of health and defense is 15 times the level of spending on education. ${ }^{190}$ Hungary, for example, earmarks 73 times as much of cearch budget for health as it does for education. ${ }^{191}$ 
Some of the most impactful R\&D processes occur at the local level through micro-studies and systems that collect and feed data immediately back into the system.

Similarly, sustained investment in agriculture R\&D was found to be vital to developing country's agricultural development. As the Millions Fed study identified, "The critical role of longterm public investment in science and technology plays out across the entire developing world, from Asia to Latin America and Sub-Saharan Africa and a range of successes from major food crops such as rice, wheat...to livestock and fisheries. ${ }^{\prime 192}$

One theory as to why sectors such as health receive more investment is that the outcomes are more easily measured and the impacts are more apparent to decision-makers, unlike the results of poor education investment. ${ }^{1.3}$ Educational researchers Nora Sabelli and Dede suggest a combination of efforts to increase educational research and make it more practical. They emphasize that reform is an iterative process, requiring long-term investment and also an interplay between theory and experiment"-particularly involving practitioners in the process. 194 Therefore, a culture of R\&D must be present in research institutes, as well as

When considering R\&D in education, the key is that it be undertaken on a systematic basis and used to devise new applications. within each critical component of the education system, among practitioners, policymakers, and funders.

When considering R\&D in education the key is that it be undertaken on a systematic basis and used to devise new applications. Cases reviewed effectively translated research discoveries into improved practices. This has been seen in the partnership over the past decade between MIT's Abdul Latif Jameel Poverty Action Lab (J-PAL) and Pratham in India. As results are gathered by J-PAL, an organization devoted to rigorous impact evaluation, from experimenting with different variations of the teaching at the right level model, these lessons have been incorporated into Pratham's work and the menu of options available for state governments as they consider adopting the approach. Bridge Internationa Academies invested large sums of capital into R\&D before its first pupil was even admitted. The company found that it was "imperative to continue this rigorous development process until the highest levels of academic performance and operational effectiveness are achieved so that the lst, lOOth and 100 oth pupils receive the same level of education as the

Some of the most impactful R\&D processes occur at the local level through micro-studies and systems that collect and feed data immediately back into the system Room to Read, for example, has invested in research, monitoring, 100,000th and the 1,000,000th."195 in which it implements its direct services. hitial investments in research contributed to the development of tools and training for school-level implementers to collect strategic information about program implementation and outcomes in ways that implementers can work immediately and directly with schools on program improvement This approach also allows some information to feedup into thelarger country-level monitoring system to explain trends and modify program content or implementation strategies as necessary. 196 



\section{Toward the future:}

The need for inclusive and adaptive education ecosystems in a changing world.

The 14 core ingredients we have identified have all been instrumental, in different combinations depending on the context, for enabling scaling of quality learning. The case studies discussed in this report have looked retrospectively to programs and policies that brought new ideas and practices into education over the past several decades. What if we look forward toward the potential for a transformation in education on the horizon? What can the 14 ingredients and the notion of scaling from the margins tell us then?

We often hear that the world is on the cusp of significant advances in technology, rapid globalization, and societal changes that have the potential to disrupt current systems for better or worse. Some argue that as technology has been evolving since the beginning of time, people have always faced high degrees of uncertainty. Others point to exponential increases in computing power as proof that a new paradigm is at hand.

Either way, the evidence points to a future filled with uncertainty In The Second Machine Age, Erik Brynjolfsson and Andrew McAfee, optimistic technologists from MIT, claim, "computers and other digital advances are doing for mental power-the ability to use our brains and understand the shape of our environment-what the steam engine and its descendants did for muscle power." 197
"Computers and other digital advances are doing for mental power-the ability to use our brains and understand the shape of our environmentwhat the steam engine and its descendants did for muscle power."

This is leading to the automation of professions that have traditionally been thought of as requiring a human element, from taxi drivers to doctors, leading to the hollowing out of the job market that Autor, Levy, and Murnane have quantified.198

While we cannot predict what the jobs and societies of the future will look like, we do know that they will require lifelong learners who can adapt, learn new knowledge and skills, and filter and analyze increasing amounts of information, not to mention be good global citizens. To foster these skills along with key academic knowledge, education ecosystems will need to be responsive to change by adapting, learning, and innovating themselves to best meet the needs of the future.

Nor can we predict what education will look like for future generations. The combination of massive failures in schooling and the promise of new methods and technologies to create a different learning environment has many people asking whether schooling as we know it is even necessary. When access to the world's best professors has the potential to be a few keystrokes away, when programs can adapt to a student's evel and assess the student's progress in real time, and when teachers no longer need to be a "sage on the stage," many are wondering if classrooms are even needed anymore. 199

To date, most innovations in education have not been what innovation scholar Clayton Christensen would call "disruptive innovation," or those that completely break with current practice. 200 Pritchett describes how education systems do not allow for disruptive innovation because they focus on best practices rather than on the underlying factors that gave rise to them. "The response to low learning is to strive to imitate best practice schools instead of the ecosystem conditions that created those good schools." ${ }^{201}$

The role of technology in changing this ecosystem in the future is still unknown. A 2007 World Bank survey across Africa of information and communication technologies in education showed that placing computers in classrooms was the priority in most developing countries policies. ${ }^{202}$ More than radio or television, computers are a powerful symbol of joining the $21^{\text {st }}$ century and hence very politically appealing. Unfortunately, this approach has yielded few useful educational outcomes, ${ }^{203}$ for these interventions have often fallen into the trap of choosing a technology first and then looking for an educational problem to solve with it, rather than the other way around.
Widening equity gaps represent another failure of technological progress. The World Bank's 2016 World Development Report focused on creating "digital dividends" rather than digital divides, yet found that most technological advancements have left the poorest and most marginalized far behind. For 60 percent of the world's population, "the internet remains unavailable, inaccessible, and remains unavilable, inaccessible, and mobile phone penetration, nearly 2 billion people do not own a phone. ${ }^{204}$ So while new technology and connectivity hold great potential for transforming the lives of the world's poorest, there is much work to be done in scaling and spreading these advances to close the digital divide.

What the case studies explored in this report demonstrate is exactly what Pritchett calls for, developing the ecosystem conditions, or what the World Bank calls a set of "analog foundations" for the digital future that allow for effective innovations to scale rather than trying to identify and mimic specific programs or policies. What follows here are recommendations based on the findings from Millions Learning for creating a new norm in education where ecosystems are inclusive and adaptive, responding to the needs of an uncertain future and reaching all the world's children.

To move to this new norm of inclusive and adaptive education ecosystems, we recommend that all stakeholders commit to the step change required to meet the demands of learning in the $21^{\text {st-century. }}$

This calls for education ecosystems that provide space for innovation and experimentation to thrive, and then 
actively help facilitate the spread of new ideas or approaches that most effectively improve learning. Governments play a pivotal role in this ecosystem. Not only is it their responsibility to deliver on every child's right to a quality education, but they must also actively foster an environment where all actors can effectively contribute their expertisefrom households, to communities, to sector, to academia. These ecosystems must be inclusive and adaptive, leveraging all assets these actors bring as well as ensuring that the most marginalized children are reached. This is the best way to move forward based on evidence of what has successtully scaled to date. ecosystem ready adapt to whatever the future holds.

We offer the following five recommendations to scale effective practices and approaches to ensure necessary skills and competencies to lead healthy, safe, and productive lives. The five actions needed to create inclusive and adaptive education ecosystems are:

\section{Millions Learning recommendations}

We need inclusive and adaptive education ecosystems that:

\section{DEVELOP}

A CULTURE OF R\&D IN EDUCATION

SHARE

NEW IDEAS THROUGH A NETWORK OF IDEA HUBS

ACTIVATE

TALENT AND EXPERTISE OUTSIDE THE CLASSROOM

\section{FUND}

THE MIDDLE PHASE

MEASURE AND LEARN WHAT WORKS THROUGH BETTER LEARNING AND SCALING DATA 


\section{DEVELOP}

A CULTURE OF R\&D IN EDUCATION

Leaders across all parts of the education ecosystem-from government to civil society to business-must embrace new approaches to solving problems at scale. Building a strong culture of R\&D within the education ecosystem is a key step. A culture of $R \& D$ is one where ideas are exchanged openly, new education approaches to seemingly intransigent problems, such as improving earning outcomes for marginalized children, are tried and evaluated, failures are honestly shared, and data inform decisions on changes to practice and policy. All the actors in the ecosystem are flexible and creative, adapting to different contexts as they develop and scale solutions. The Zambian government embraced a culture of R\&D when its Lesson Study practice empowered teachers to experiment with new ways of supporting their own development through peer learning. So did the NGO BRAC when experimenting with an accelerated learning program to bring more children into the formal school system in Bangladesh. But to truly develop an inclusive and adaptive education ecosystem, this culture of R\&D must extend beyond individual initiatives and become a shared ethos across the education community. To develop a shared culture of R\&D in education:

Leaders in government should provide full encouragement, space, and support for trying new ways to tackle persistent education problems. This includes:

Adapting rules and policies to allow a new approach to be tried The national education ministry in Brazil, for example, allowed the state ministry in Amazonas to test a new appro

Funding new approaches that hold promise. The Honduran government pays the salaries of tutors in the Sistema de Aprendizaje Tutorial program who teach in the alternative secondary school reaching young people living in rural areas.

Providing infrastructure support that helps new approaches flourish. The Kenyan government's National Library Service is working with Worldreader to incorporate e-readers loaded with digital books throughout the country's public library network.
Leaders across philanthropy, civil society, government, and business should actively cultivate a cohort of Learning Leaders. To truly shift to a culture of R\&D throughout the education ecosystem, leaders at all levels should be equipped with the competencies to embrace this approach, such as risk taking, experimentation, continuous learning, and adaptation. Within each country context, an initiative to support leaders to take on this approach should be actively pursued. Such initiatives could seek to develop the capacity of a cohort of leaders that cuts across levels and sectors, for example from senior policymakers, NGO leaders, and donor heads to poricals, program officers, and portfolio managers. Such an initiative would be highly collaborative and multisectoral, building off what exists in each country and drawing from global expertise in leadership development. Philanthropy, government, and business leaders should contribute funding as well as, together with civil society leaders, relevant mentoring, training, and in-kind expertise.

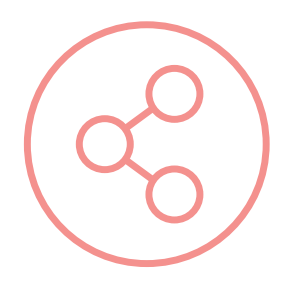

\section{SHARE}

NEW IDEAS THROUGH A NETWORK OF IDEA HUBS

Leaders in governments should establish Idea Hubs for identifying, adapting, and sharing effective approaches to improving learning and scaling them. Approaches led by all actors-government, educators, business, civil society-should be discussed. The goal of the Idea Hubs is to provide a nimble mechanism for government decision-makers to stay up to date with new approaches being tried, to review evidence around the approaches, and to identify the ones that could usefully be scaled up by government or with government involvement. This should include a concerted effort to identify local, homegrown innovations that hold promise to improve education in more contexts or communities, but require additional technical support, funding, or capacity building to do so. Idea Hubs will be especially important to help government decision-makers adapt to future changes, such as near-constant evolution in technology that is increasingly used as a tool to address educational problems. These hubs should be linked through a global network to allow for experiences and lessons shared among regional and national Idea Hubs, contributing to a global knowledge bank of effective approaches and conditions that facilitate learning at large scale. The formation of Idea Hubs around learning could draw lessons from innovation units that exist in some governments around the world to identify and facilitate public sector adoption of innovations. 


\section{ACTIVATE}

TALENT AND EXPERTISE OUTSIDE THE CLASSROOM

To scale quality learning, especially in communities that are hardest to reach, a creative injection of support and energy is needed. Teachers and other education personnel who are on the front lines are overburdened and require tangible assistance. For addressing tough education problems, expertise from diverse actors outside the school can be one important source of this support. From nonprofit workers and young graduates to business professionals and parents, different types of expertise can be strategically tapped to assist educators, types of ex elevate them in their roles, and reach children when educators are not available. In Jordan, for example, INJAZ leverages the expertise of entrepreneurs and business leaders to teach entrepreneurship in secondary schools, taking the work of preparing a new subject off the shoulders of already overloaded teachers. Around the world, Sesame Street channels the expertise of artists, media specialists, and parent outreach workers to bring quality early childhood development programming to many communities where none exists. To active talent and expertise from communities outside the classroom:

Governments, civil society, and the business community should lounch bold All-in Community initiatives suport teachers and other education personnel in their respective countries. Building off the effective ways community support is already being tapped, these initiatives could strategically activate expertise to provide assistance to teachers and other education personnel in several ways. They could ensure teachers have more time to interact with students, for example, by strategically deploying other people to assist with particular tasks that teachers would normally perform. Unburdening teachers can take many forms, from reducing classroom management and administrative burdens, to reducing time needed for lesson plan preparation, to reducing time needed for supporting struggling students. This would also include support for education administrators through activities such as monitoring schools and disseminating school data to parents.

Donors and the technology community should actively develop appropriate ways for technology to be used to support teachers and other education personnel in the developing world. Activating the expertise of the technology community with the support of donors to find pragmatic and sustainable ways to deploy the power of technology is a key strategy for injecting creative energy and tangible support to education actors. Low-cost, easy-to-use technological tools that can unburden teachers and education administrators or provide resources where none existed before can play an important role in scaling quality learning.

\section{FUND}

\section{THE MIDDLE PHASE}

This is crucial to help effective education approaches cross the "valley of death" to scale. Too often, there is a funding gap between new ideas or prototypes and implementation at a national level. Bridging this middle phase requires greater clarity of what government entities, investors, and donors fund at which stage of the innovationscaling cycle-from prototypes or ideas to national programs. It also requires greater coordination and segmentation of education financing, including more attention and support for this middle phase after proof of concept but before large-scale national adoption. Pratham benefits from long-term funding from Pratham USA, a foundation set up to raise awareness and mobilize resources among the Indo-American community Flexible financing from Pratham USA has helped Pratham's evidenced-based approaches to reach a much greater scale across India. The Amazonas state government in Brazil provided sufficient funds to ensure that the Media Center pilot was able to continue to reach many more communities and expand to include more grades. To catalyze middle phase funding:

Governments, donor agencies, foundations, and investors should develop a more organized ecosystem of education funding to support scaling. Education funders, particularly outside of business investors, must actively work together to align their respective investment strategies to be complementary. In any given context, funders should know who is supporting innovative pilots, who (crucially) is supporting middle phase funding to help sustain and build scaling capacity, and who is providing predictable, long-term funding for implementing effective approaches at scale.

Donor agencies and foundations should provide flexible support, including for core costs. One important strategy to help effective 
approaches scale is to provide flexible funding that can be used for the activities that are most needed to support scaling. Often developing core operational capacity especially within civil society organizations, is required to bring effective ideas and approaches to scale.

\section{MEASURE AND LEARN}

WHAT WORKS THROUGH BETTER LEARNING AND SCALING DATA

Systematic data on children's learning is a crucial input for the success of all prior recommendations. For example, having regular and accessible data on children's learning facilitates spreading a culture of continuous improvement across the education ecosystem. From data that are used by teachers, to data that are put into parents' hands, to data that are aggregated from each country to track global progress, information on what students are learning is an important foundation to inform action. In addition to identifying what is contributing to children's learning, a better understanding is needed on how it is doing so at large scale. This requires understanding the process by which effective ideas and approaches are adapted, spread, and taken up by more actors in more locations. To collect and use learning and scaling data

Government and donor agencies should strengthen national student assessment systems. Data on student learning are needed to inform actions to scale effective approaches to improving learning. In many countries in the developing world today, the main source of data on student performance are project-specific achievement data or results every few years from large-scale regional or international assessments. A better approach is for governments to build the capacity of national assessment systems that are systematic, transparent, and housed in-country. This is in line with the Learning Metrics Task Force recommendation on learning data as a global good. As data are meant to be used, they should be collected and disseminated in a way that is maximally useful. For example, classroom-level data on learning can be immediately used by teachers to see the levels at which children are learning, and nationally aggregated data on learning can be used by policymakers.
The research community should improve data on scaling through a Real-time Scaling Lab. Such a forum would provide space to examine and document the process of scaling effective approaches to learning as they unfold, contributing to building a body of evidence on how to scale quality learning interventions. A laboratory-type setting would approach scaling as a learning process, encouraging self-reflection and providing more opportunities to make course corrections and adjustments. A Real-time Scaling Lab would also provide space for peer-to-peer learning among government officials, social entrepreneurs, funders, and researchers to share common experiences in their efforts to expand and deepen effective approaches and to exchange ideas and resources. It would draw on existing scaling knowledge, resources, and tools in education, development, and other disciplines more broadly.

Education actors at the global, national, and local levels should explore ways of teaching and assessing $21^{\text {st-century skills-or a }}$ breadth of learning opportunities-beyond literacy and numeracy. breadth of learning opportunities-beyond literacy and numeracy.
For education ecosystems to adapt to the needs of the future, they will need to measure their success across a broad range of learning domains. Educators are seeking ways to integrate these into their teaching, learning, and assessment practice strategies. Models need to be explored of how to guide children in the development of such skills as collaboration, critical thinking, innovation, and problem solving. The assessment of these skills poses a challenge to both measurement specialists and teachers in classrooms. The function of assessment as a tool to inform teachers' understanding of the skills as well as the competencies of their students should be a focus of innovation in the assessment space. 


\section{Endnotes}

Rebecca Winthrop and Eileen McGivney, "Why Wait 100 Years? Bridging the Gap in Global Education" (Washington: Brookings Institution, June 2015).

2. Rebecca Winthrop, "Education in Africa: The Story Isn't Over," Current History 110, no. 736 (May 2011).

3. Rebecca Winthrop and Eileen McGivney, "Why Wait 100 Years? Bridging the Gap in Global Education" (Washington: Brookings Institution, June 2015)

4. Education For All Global Monitoring Report, "Teaching and Learning: Achieving Quality for All" (Paris: UNESCO, 2014).

5. A. Gove and P. Cvelich, Early Reading: Igniting Education for All, revised ed., Early Grade Learning Community of Practice (Research Triangle Park, NC: Research Triangle Institute, 2011).

6. "Annual Status of Education Report Data Query" (New Delhi: ASER Centre, 2014).

7. Uwezo, "Are Our Children Learning? Literacy and Numeracy Across East Africa 2013" (Nairobi: Hivos/

8. Lant Pritchett, The Rebirth of Education: Schooling Ain't Learning, Center for Global Development (Washington: Brookings Institution Press, 2013

9. Rebecca Winthrop and Eileen McGivney, "Why Wait 100 Years? Bridging the Gap in Global Education" (Washington: Brookings Institution, June 2O15)

10. UNICEF, “Early Childhood Development: A Statistical Snapshot” (New York: UNICEF, 2014)

Ibid.

12. UNESCO, World Inequality Database on Education; Indicator: Out-of-School Children (Paris: UNESCO, 2016).

13. Learning Metrics Task Force, "Toward Universal Learning: A Global Framework for Measuring Learning" (Montreal and Washington: UNESCO Institute of Statistics and Center for Universal Education at Brookings,

2013).
The Learning Metrics Task Force (LMTF), co-convened by the UNESCO Institute of Statistics and the Center for Universal Education at Brookings from 2012 to 2016 , consisted of 30 member organizations, The task force worked to build a consensus on what skills and competencies are important for all children to learn, and developed a small set of indicators to measure those skills.

14. "Assessment for Learning (A4L): An International Platform to Support National Learning Assessment Systems Discussion Docy ment" Prepared for the Learning Metrics Task Force 20 , December $1,2015$.

15. Education For All Global Monitoring Report, "Pricing the Right to Education: The Cost of Reaching New Targets by 2030", Policy Paper 18 (Paris. UNESCO, July 2015).

16. Liesbet Steer and Katie Smith, "Financing Education: Opportunities for Global Action" (Washington: Center for Universal Education at Brookings, July 2O15).

17. The Education Commission, "The Education Commission," accessed March 4, 2016, http:// educationcommission.org/.

18. James J. Heckman, “The Economics of Investing Early in Children," Policy Briefing no. I (Dublin: UCD Geary Institute, 2006).

19. James J. Heckman "Skills, Schools, Synapses," Discussion Paper no. 3515 (Bonn. IZA May 2008)

20. Art Rolnick and Rob Grunewald, "Early Childhood Development: Economic Development with a High Public

21. UNESCO, "Education Transforms Lives" (Paris: UNESCO, 2013)
22. Eric Hanushek and Ludger Woessmann, The Knowledge Capital of Nations: Education and the Economics of Growth (Cambridge: MIT Press Books, 2016)

23. David H. Autor, Frank Levy, and Richard Murnane, "The Skill Content of Recent Technological Change: An Empirical Exploration," Quarterly Journal of Economics 118, no. 4 (2003).

24. Cristian Aedo et al. "From Occupations to Embedded Skills: A Cross-Country Comparison," background paper for the World Development Report (Washington: World Bank, June 10, 2013).

25. Emmanuela Gakidou et al., "Increased Educational Attainment and Its Effect on Child Mortality in 175 Countries between 1970 and 2009: A Systematic Analysis," Lancet 376 (2010): 959-74.

26. Rebecca Winthrop and Gene Sperling, What Works in Girls' Education: Evidence for the World's Best Investment (Washington, DC: Brookings Institution Press, 2015)

27. Kharas, Homi and Rebecca Winthrop. 2016. "Want to save the planet? Invest in girls' education." Milwaukee Journal Sentinel. February 13, 2016.

28. Brian Blankespoor et al., "Adaptation to Climate Extremes in Developing Countries: The Role of Education," Policy Research Working Paper 5342 (Washington: World Bank, 2010)

29. P. Coombs with R. Prosser and M. Ahmed, "New Paths to Learning" (New York: International Council for Educational Development, 1973).

30. There is a range of initiatives that focus on system-wide reforms. Some of the more important include the World Bank's Systems Approach for Better Education Results (SABER), UK Department for International Development (DFID)-supported Research on Improving Systems of Education (RISE), the Overseas Development Institute's Development Progress initiative, McKinseys "How the worlds best-performing schools and most improved school systems" series, and Lant Pritchett, The Rebirth of Education: Schooling

31. John Hattie, "What Works Best in Education: The Politics of Collaborative Expertise" (London: Pearson, 2015).

32. "Hattie Ranking: Influences and Effect Sizes Related to Student Achievement," Visible Learning blog, accessed February 18, 2016, http://visible-learning.org/hattie-ranking-influences-effect-sizes-learningachievement/; Katharine Conn, "Identifying Effective Education Interventions in sub-Saharan Africa: A Meta-analysis of Rigorous Impact Evaluations," submitted for Ph.D., Columbia University, 2014; Patrick J. MeEwan, "mproving leos I

33. D. Fixsen et al., "Implementation Research: A Synthesis of the Literature" (Tampa: NIRN, 2005); Laurence Chandy et al., eds., Getting to Scale: How to Bring Development Solutions to Millions of Poor People
(Washington. Brookings Institution Press, 2013). Ruth Simmons and Jeremy Shiffman "Scaling Up Health Service Innovations. A Framework for Action," in Scaling Up Health Service Delivery from Pilot Ip Heavtions to Policies and Programmes, ed Ruth Simmons, Deter Fajans, and Laura Ghiron (Geneva. World Health Organization, 2006), 1-30; lan Anderson, "Scaling Up Development Results: A Literature Review and Implications for Australia's Aid Program" (Canberra: Australian Agency for International Development, February 2OI2).

34. Martial Dembélé, Joel Samoff, and E. Molapi Sebatane, "'Going to Scale': Nurturing the Local Roots of Education Innovation in Africa," EdQual Working Paper 28 (EdQual, September 2011).

35. A focus on scaling successful development interventions has a long history at Brookings, going back at least to when former World Bank president James Woltensohn directed the Center for Der Brookings, where scaling was the main thematic focus of work from 2005 to 2010 . Work during this period and beyond has included a stocktaking of the literature and experience with scaling by Hartmann and Linn (2008); a book on Mexico's Progresa-Oportunidades by Santiago Levy (2006); and a series of Brookings Global Working Papers authored by Johannes Linn and Laurence Chandy. Most recently,

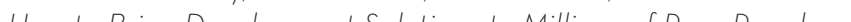

36. O. Pidufala, "Scaling Up and Aid Effectiveness: Annotated Bibliography," Washington, 2008.

37. Center for Universal Education, "2013 Global Compact on Learning Donor Network Mapping Results" (Brookings Institution, Washington, 2013).

38. Laurence Chandy et al., eds., Getting to Scale: How to Bring Development Solutions to Millions of Poor People (Washington: Brookings Institution Press, 2013): 33. 
39. Arntraud Hartmann and Johannes F. Linn, "Scaling Up: A Framework and Lessons for Development Effectiveness from Literature and Practice" (Washington: Brookings Institution, 2008),

40. This definitions draws from some of the most influential papers on scale, including Meyers (1984); Uvin
and Miller (1994): Samoff et al. (2001). Coburn (2003). Expand Net. MSI, and World Health Organization and Miller (1994); Samoff et al. (200); Coburn (2003); ExpandNet, MSI, and World Health Organization (201); and Chandy ot a (2013)

41. Cynthia E. Coburn, "Rethinking Scale: Moving Beyond Numbers to Deep and Lasting Change," Educational Researcher 32, no. 6 (2003): 3.

42. These four pathways are drawn from Uvin and Miller (1994); Uvin (1995); Dunst et al. (2006); Simmons and Shiffman (2006); and Hartmann and Linn (2008). Arntraud Hartmann and Johannes F. Linn, "Scaling Up: A Framework and Lessons for Development Effectiveness from Literature and Practice" (Washington: Brookings Institution, 2008); C. J. Dunst et al., Scaling Up Early Childhood Intervention Literacy Learning "Scaling, Up. Thinking through the losse", (Providence Brown University 1994). D. Uvin "Fighting Hunger at the Grassroots: Paths to Scaling Up." World Develooment 23, no. 6 (1995): 927-39; Ruth Simmons and Jeremy Shiffman, "Scaling Up Health Service Innovations: A Framework for Action," in Scaling Up Health Service Delivery from Pilot Innovations to Policies and Programmes, ed. Ruth Simmons, Peter Fajans, and
Solion Laura Ghiron (Geneva: World Health Organization, 2006), 1-30

43. Learning Metrics Task Force, "Toward Universal Learning: What Every Child Should Learn" (Montreal and Washington: UNESCO Institute for Statistics and Brookings Institution, Center for Universal Education, 2013). 44. Learning Metrics Task Force, "Toward Universal Learning: Recommendations from the Learning Metrics
Task Force" (Montreal and Washington: UNESCO Institute for Statistics and Center for Universal Education at Brookings, September 2013).

45. UNESCO, International Standard Classification of Education (Paris: UNESCO, 1997), http://www.vis.unesco. org/Library/Documents/isced97-en.pdf.

46. World Bank, "Country and Lending Groups", http://data.worldbank.org/about/country-and-lending. groups\#Low income.

47. This is what Johannes Linn refers to as a "type 2" (wrong scaling) vs "type l" (no or too little scaling) scaling

48. Everett M. Rogers, Diffusion of Innovations, 5th ed. (New York: Free Press, 2003).

49. Arntraud Hartmann and Johannes F. Linn, "Scaling Up: A Framework and Lessons for Development Effectiveness from Literature and Practice" (Washington: Brookings Institution, 2008)

50. Geoffrey Moore, Crossing the Chasm: Marketing and Selling High-Tech Products to Mainstream Customers (New York: Harper, 1999)

51. Martial Dembélé, Joel Samoff, and E. Molapi Sebatane, "Scaling Up by Focusing Down: Creating Space to Expand Educational Reform Association for the Development of Education for Africa" (Abidjan, Côte d'voire: Association for the Development of Education in Africa, 20 1); Martial Dembele," Joel Samoff, and Working Paper 28 (EdQual, September 2011).

52. Johannes Linn, "Internal Concept Note for Project on Scaling Up," October 21, 2013

53. ExpandNet and World Health Organization, "Beginning with the End in Mind: Planning Pilot Projects and Other Programmatic Research for Successful Scaling Up" (Geneva: WHO, 2Oll); Larry Cooley and Richard March 2006). Larry Cooley and Johannes F Linn. "Taking Innovations to Scale. Methods, Applications and Lessons" (Washington. Results for Development Institute, September 2014). Peter Fajans et al "2O Questions for Developing a Scaling Up Case Study," Management Systems International, ExpandNet, and World Health Organization, 200\%; Madeleine Gabriel, Making It Big: Strategies for Scaling Social Innovations" (London: Nesta, July 2014); World Health Organization and ExpandNet, "Nine Steps for Developing a Scoling Up Strotegy" (Genevo. World Hedth Orgarization, 2010 )

54. Alice Gugelev and Andrew Stern, "What's Your Endgame?" Stanford Social Innovation Review (Winter 2015).
55. Barbara Pozzoni and Nalini Kumar, "A Review of the Literature on Participatory Approaches to Local Development for an Evaluation of the Effectiveness of World Bank Support for Community based and

56. Jeffrey Bradach and Abe Grindle, "Transformative Scale: The Future of Growing What Works," Stanford Social Innovation Review (February 19, 2014 .

57. Ashish Karamchandani, Michael Kubzansky, and Paul Frandano, "Emerging Markets, Emerging Models: Market-based Solutions to the Challenges of Global Poverty" (Cambridge: Monitor Group, March 2009).

58. Erin Murphy-Graham, Opening Minds, Improving Lives: Education and Women's Empowerment In Honduras (Nashville: Vanderbilt University Press, 2012); Patrick J. McEwan, "Improving Learning in Primary Schools of no. 3 (September 2O15).

59. Emily Gustafsson-Wright and Eileen McGivney, "Fundación Escuela Nueva: Changing the Way Children Learn from Colombia to Southeast Asia," Brookings.edu (blog), April 23, 2014, http://www.brookings.edu/ blogs/education-plus-development/posts/2014/04/23-colombia-southeast-asia-learning-gustaffsonwright.

60. Scott Macmillan, "Glorious Failure: The Joy of Learning from Your Mistakes," The Guardian, March 30, 2015. Ibid.

62. Laurence Chandy et al., eds., Getting to Scale: How to Bring Development Solutions to Millions of Poor People (Whoshington: Brookngs Instition Press, 2013).

63. "World Development Report 2004: Making Services Work for Poor People" (Washington: World Bank, 2O13).

64. Cory Heyman, email communication with Jenny Perlman Robinson, February 17, 2016.

65. YouTube, "Punjab, Pakistan, Education Reform Roadmap," published on January 22, 2014, https://www. youtube.com/watch?v=gjATVO3l-sO.

66. PESRP, "School Councils," http://www.pesrp.edu.pk/pages/School-Councils.

67. Larry Cooley, "Millions Learning: Role of Partnerships in Bringing Education Initiatives to Scale" (meeting at the Brookings Institution, Washington, June 2014)

68. Ian Thorpe, "The Next Innovation: Scaling Up," "kmonadollaraday.wordpress.com (blog), December 18, 2013, https://kmonadollaraday.wordpress.com/2013/12/18/the-next-innovation-scaling-up/

69. Robert I. Sutton and Huggy Rao, Scaling Up Excellence: Getting to More without Settling for Less (New York: Crown Business, 2014).

70. Patrick McEwan, "Cost-effectiveness Analysis of Education and Health Interventions in Developing Countries" Jounat of Development Efrthe

71. Arntraud Hartmann and Johannes F. Linn, "Scaling Up: A Framework and Lessons for Development Effectiveness from Literature and Practice" (Washington: Brookings Institution, 2008).

72. Stuart Gillespie, Purnima Menon, and Andrew Kennedy, "Scaling Up Impact on Nutrition: What Will It Take?" Advances in Nutrition 6, no. 4 (2015). 440-51.

73. It is often assumed that the process of going to scale will bring economies of scale, but this is not necessarily the case. In fact, this is often not the case when it comes to education. Expanding coverage to those more and more difficult to reach becomes increasingly expensive as there are often higher unit costs of training, transport, supervision, and admistration. Where expansion may ach it economies of scale, costs can

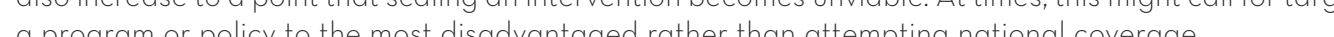

74. Martial Dembélé, Joel Samoff, and E. Molapi Sebatane, "'Going to Scale': Nurturing the Local Roots of Education Innovation in Africa," EdQual Working Paper 28 (EdQual, September 2011).

75. Patrick J. McEwan, "Improving Learning in Primary Schools of Developing Countries: A Meta-analysis of Randomized Experiments," Review of Educational Research 85, no. 3 (September 2015). 
76. Laurency Chandy et al., eds., Getting to Scale: How to Bring Development Solutions to Millions of Poor People (Washington: Brookings Institution Press, 2013).

77. Personal communication, Vicky Colbert and Rebecca Winthrop, November 5, 2015, Doha, Qatar

78. Bridge International Academies, "Reach," accessed August 24, 2015, http://www. bridgeinternationalacademies.com/approach/reach/.

79. The average cost of Bridge International Academies has been contested with some claiming average costs per month are closer to $\$ 16-\$ 2 \mathrm{O}$ when factoring in fees for such things as exams, uniforms, school supplies, per month are closer to $\$ 10-\$ 2 O$ when factoring in fees for such things as exams, uniforms, school supplies,
and meals.

80. Rahman Rahman Huq, "Cost Comparison of BRAC NFP and Government Primary Schools" (Dhaka, Bangladesh: Academy for Educational Development, July 1992):

81. A cluster is usually a group of $10-15$ schools in a confined geographic area. The Cluster Resource Center is used for teacher meelings, teacher tranng, and administrative work. The coordinator is usually a senior

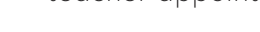

82. Room to Read, "Solving the Puzzle: Children's Literacy and Girls' Education," Annual Report, 2014 ed., http:///www.roomtoread.org/AnnualReport/2014/; Cory Heyman, email communication with Jenny Perlman

83. Madeleine Gabriel, "Making It Big: Strategies for Scaling Social Innovations" (London: Nesta, July 2O14).

84. Larry Cooley and Richard Kohl, "Scaling Up-From Vision to Large-Scale Change" (Washington Management Systems International, March 2006).

85. Anna Davies, "Spreading Social Innovations: A Case Study Report," TEPSIE, 2015

86. Madeleine Gabriel, “Making It Big: Strategies for Scaling Social Innovations" (London: Nesta, July 2O14).

87. Amita Chudgar and Vyjayanthi Sankar, "The Relationship between Teacher Gender and Student Achievement: Evidence From Five Indian States," Journal of Comparative and International Education 38 . no. 5 (2008): 027-42; Eric A. Hanushek and Steven G. Rivkin, "Generalizations about Using Value-Added Measures of Philippines" IFDRI Discussion Paper (Washington. International Food Policy Research Institute, 2011):-

88. Barbara Bruns and Javier Luque, Great Teachers: How to Raise Student Learning in Latin America and the Caribbean (Advance ed.) (Washington: World Bank, 2014).

89. Frances Vavrus, Desire and Decline: Schooling Amid Crisis in Tanzania (New York: Peter Lang, 2003).

90. Education For All Global Monitoring Report, "Teaching and Learning: Achieving Quality for All" (Paris: UNESCO, 2O14).

91. Rebecca Winthrop and Corrinne Graff, "Beyond Madrassas: Assessing the Links between Education and 2010).

92. Janice Dolan et al., "Building Effective Teacher Salary Systems In Fragile and Conflict-Affected States," Dolicy Report (Washington: Center for Universal Education at Brookings; CfBT Education Trust, 2012).

93. UNESCO Institute of Statistics, "Sustainable Development Goal For Education Cannot Advance without More Teachers," UIS Fact Sheet No. 33 (Montreal: UIS, 2O15)

94. UNESCO Institute of Statistics, "A Teacher for Every Child: Projecting Global Teacher Needs from 2015 to 2030," UIS Fact Sheet no. 27 (Montreal: UIS 2O13) 95. Mark Bray, "Double-shift Schooling: Design and Operation for Cost-effectiveness" (Paris: UNESCO
International Institute for Educational Planning, 2OO8).

96. Rukmini Banerji interview by Jenny Perlman Robinson and Shushmita Chatterji Dutt, July, 18, 2015

97. Interview with teacher at Bridge International Academy in Gicagi, Nairobi, Jenny Perlman Robinson, April

98. Michael Staton, "Unbundling Higher Education: Taking Apart the Components of the College Experience," in Stretching the Higher Education Dollar. How Innovation Can Improve Access, Equity and Affordability ed. Kevin Carey and Andrew P Kelly (Cambridge: Harvard Education Press, 2013).
99. Preston Smith in discussion with Rebecca Winthrop and Eileen McGivney on December 2, 2015. Confirmed with Chris Murphy, Vice President, Marketing and Communications at Rocketship Education on February

100. Jooseop Kim, Harold Alderman, and Peter Orazem, "Can Cultural Barriers Be Overcome in Girls' Schooling? The Community Support Program in Rural Balochistan," Working Paper on Impact Evaluation of Education Reforms 10 Washington: World Bank,

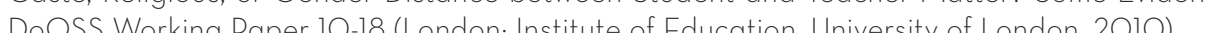

101. Sharath Jeevan, "What Do We Know about Teacher Motivation?... Our Learning at STIR So Far (with Much More Learning Ahead)," internal document shared with Jenny Perlman Robinson and Eileen McGivney February 9, 2016. 102. Laurency Chandy et al., eds., Getting to Scale: How to Bring Development Solutions to Millions of Poor

103. Geoff Mulgan with Simon Tucker, Rushanara Ali, and Ben Sanders, "Social Innovation: What It Is, Why It Matters, and How Con Be Accelerated,"Workng Daper (Oxhord. Skoll Centre for Social Entrepsen 2007.

104. Laurency Chandy et al., eds., Getting to Scale: How to Bring Development Solutions to Millions of Poor People (Washington: Brookings Institution Press, 2013 ).

105. These principles are drawn from cases and literature reviewed, including research by Hartmann and Linn (2008), Cooley and Kohl (2006), Simmons and Shiffman (2007), Bradach and Grindle (2014), and Ostrom et al. (2001).

106. E. Ostrom et al., "Aid, Incentives, and Sustainability: An Institutional Analysis of Development Cooperation" (Stockholm: Sida, 2001).

107. Arntraud Hartmann and Johannes F. Linn, "Scaling Up: A Framework and Lessons for Development Effectiveness from Literature and Practice" (Washington: Brookings Institution, 2008).

108. David Risher in discussion with Jenny Perlman Robinson, December 1, 2014.

109. "Our Work," Naandi, accessed March 2, 2016, http://www.naandi.org/programmes-phased-out/hungrychildren-cannot-learn/; Naand, Naandi Foundation's Centralized Kitchens for Midday Meal Programme,"

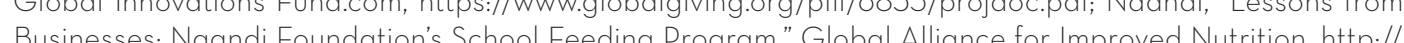

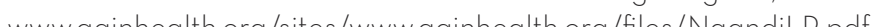

10. Arntraud Hartmann and Johannes F. Linn, "Scaling Up: A Framework and Lessons for Development Effectiveness from Literature and Practice" (Washington: Brookings Institution, 2008).

111. Leadership was identified as a key driver in the Overseas Development Institute's "Development Progress Series, Center for Global Development's Millions Saved, and International Food Policy Research Institute's Mevelopment (Washington International Food Policy Research Institute, 2009) Orerseas Devicultural Institute, "Development Progress Series" (London: Overseas Development Institute, 2Oll-2Ol2). Ruth Levine, What Works Working Group, Molly Kinder, Millions Saved: Proven Successes in Global Health (Washington: Center for Global Development, November 2004).

112. Arntraud Hartmann and Johannes F. Linn, "Scaling Up: A Framework and Lessons for Development Effectiveness from Literature and Practice" (Washington: Brookings Institution, 2008),

113. Erik Ramirez-Ruiz in discussion with Jenny Perlman Robinson and Samantha Spilka, July 24, 2015.

114. Michael Barber, Chinezi Chijioke, and Mona Mourshed, "How the World's Most Improved School Systems Keep Getting Better," McKinsey and Company, November 2010

115. Ruth Levine, What Works Working Group, Molly Kinder, Millions Saved: Proven Successes in Global Health (Washington: Center for Global Development, November 30, 2004).

116. Sarabeth Berman, e-mail message to Jenny Perlman Robinson and Eileen McGivney, January 4, 2016.

Teach First, "2014 Annual Report", 2014, https://www.teachfirst.org.uk/sites/default/files/ar/pdf/TF_AR_

Robert Hill, "Teach First: Ten Years of Impact" (London: Teach First, 2012). 
119. Jenny Perlman Robinson, "Ensuring Lasting Education Reforms by Delivering Results: A Discussion with Claudia Costin, Senior Director for Education at the World Bank," Brookings Institution (blog), January claudia-costin-perlman-robinson.
clag/education.plus-development/posts/2015/O//O/-education-reforms.

120. Zambia Ministry of General Education, "School-Based Continuing Professional Development (SBCPD) Through Lesson Study-Implementation Guidelines," 5th ed. (Lusaka, Zambia: Ministry of General Education

121. "STIR Education: Empowering Teachers to Be Changemakers," STIR Education, 2015, http://www. stireducation.org/.

122. R. Bille, "Action without Change? On the Use and Usefulness of Pilot Experiments in Environmental Management," Sapiens 3, no. 1 (2010)

123. Ibid.

124. Daron Acemoglu and James Robinson, "The Role of Institutions in Growth and Development," Working Daron Acemoglu and James Robinson, "The Role of Institutions in Growth and Develop
Paper 10, Commission on Growth and Development (Washington: World Bank, 2008).

125. According to Tessa Bold and colleagues, two possible explanations for the intervention's scaling failure are implementation restrictions and political economy limitations. In terms of the former issue, the contract in the government treatment arm received fewer monitoring visits and teachers underwent tonner salary delays, ultimately affecting student test scores. In terms of the latter issue, the program's potential to introduce 18,000 new contract teachers into the workforce spurred organized resistance from Kenya's national teachers union, adversely affecting incentives for government-employed teachers to experiment, thereby weakening teacher performance. Tessa Bold et al., "Scaling Up What Workings: Experimental Evidence on External

26. Larry Cooley, "Millions Learning: Role of Partnerships in Bringing Education Initiatives to Scale" (meeting at the Brookings Institution, Washington, June 2O14).

127. Gerard J. Tellis, Jaideep C. Prabhu, and Rajesh K. Chandy, "Radical Innovation across Nations: The Preeminence of Corporate Culture," Journal of Marketing 73, 2009.

128. Chris Dede, James P. Honan, Laurence C. Peters. et al., Scaling Up Success: Lessons Learned from Technologybased Educational Improvement (San Francisco: Jossey-Bass, 2005).

129. UNESCO, "Global Initiative on Out-of-School Children: Brazil" (Paris: UNESCO, August 2012), http://www.uis. unesco.org/Education/Documents/OOSC1\%2OReports/brasil-oosci-summary-2O12-en.pdf.

130. Lewis S. Teh, "Education to Be Revised," The New Dawn, June 4, 2015, http://www.thenewdawnliberia.com/ general/7553-education-to-be-revised. 131. Adele Cassola and Jody Heymann, Lessons in Educational Equality: Successful Approaches to Intractable

132. Michael Barber and Saad Rizvi, eds., Asking More: The Path to Efficacy (Pearson, 2013).

133. Everett M. Rogers, Diffusion of Innovations, 5th ed. (New York: Free Press, 2003).

134. Tina Rosenberg, "Making Change Happen, on a Deadline" New York Times (blog), September 29, 2011, http:// opinionator.blogs.nytimes.com/2011/09/29/making-change-happen-on-a-deadline/? r=O 135. Laurency Chandy et al, eds., Getting to Scale: How to Bring Development Solutions to Millions of Poor People
(Washington: Brookings Institution Press, 2O13), 138-64.

136. Ian Anderson, "Scaling Up Development Results: A Literature Review and Implications for Australia's Aid Program" (Canberra: Australian Agency for International Development, February 2012).

137. Martial Dembélé, Joel Samoff, and E. Molapi Sebatane, "'Going to Scalé: Nurturing the Local Roots of Education Innovation in Africa," EdQual Working Paper 28 (EdQual, September 2OII).

138. J. G. Cooney, Foreword in "G" Is for Growing: Thirty Years of Research on Children and "Sesame Street," ed. S. Fisch and R. Truglio (Mahwah, NJ. Erlbaum, 2001):

139. Rukmini Banerji in discussion with Jenny Perlman Robinson and Shushmita Chatterji Dutt, July 18, 2015. 140. Arntraud Hartmann and Johannes F. Linn, "Scaling Up: A Framework and Lessons for Development
Effectiveness from Literature and Practice" (Washington: Brookings Institution, 2008).
141. Jenny Perlman Robinson, "Ensuring Lasting Education Reforms by Delivering Results: A Discussion with Claudia Costin, Senior Director for Education at the World Bank," Brookings Institution (blog), January

142. Laurency Chandy et al., eds., Getting to Scale: How to Bring Development Solutions to Millions of Poor People (Washington: Brookings Institution Press, 2013).

143. Ibid.

144. Verne Harnish, Scaling Up: How Few Companies Make It and Why the Rest Don't (Ashburn: Gazelles, 2014).

45. Ramesh Mangaleswaran and Ramya Venkataraman, "Designing Philanthropy for Impact: Giving to the Biggest Gaps in India," (McKinsey and Company, October 2013).

146. Alice Gugelev and Andrew Stern, “What's Your Endgame?” Stanford Social Innovation Review (Winter 2015).

147. GEO, "Smarter Philanthropy for Greater Impact: Rethinking How Grantmakers Support Scale" (Washington: Grantmakers for Effective Organizations, February 2014).

148. The Overhead Myth, "Moving toward an Overhead Solution," http://overheadmyth.com/

149. Alex Daniels, "Ford Shifts Grantmaking to Focus Entirely on Inequality," Chronicles of Philanthrophy, June 11. 2015

150. Ruth Levine, "Friday Note: The Zero Year," Hewlett Foundation (blog), July 10, 2015, http://www.hewlett. $\mathrm{org} / \mathrm{blog} /$ posts/friday-note-zero-year.

151. Hartmann and Linn (2008) found successfully scaling programs to national scale can take 5-10 years or longer. Other seminal studies found scaling typically extends over 10-15 years (Hancock 2003; Ahmed and French 200\%; Binswanger and Alyer 2003). Arntraud Hartmann and Johannes F. Linn, "Scaling Up: A Framework and Lessons for Development Effectiveness from Literature and Practice "Washington:
Brookings Institution, 2008): Hans P. Hans D Binswanger-Mkhize, Jacomina D de Regt, and Stephen Spector, eds., Scaling Up Local Community Driven Development: A Real World Guide to Its Theory and Practice (Washington: World Bank, 2009); J. Hancock, "Scaling Up the Impact of Good Practices in Rural Development" (Washington: World Bank, 2003); S. Ahmed and M. French, "Scaling Up: The BRAC Experience," BRAC University Journal, 2003

152. Arntraud Hartmann and Johannes F. Linn, "Scaling Up: A Framework and Lessons for Development Effectiveness from Literature and Practice" (Washington: Brookings Institution, 2008).

153. Colette Chabbott, email communication with Jenny Perlman Robinson, February 3, 2016.

154. GIZ, "Scaling Up in Development Cooperation: Practical Guidelines" (Eschborn, Germany: GIZ, 2O10).

155. Laurence Chandy et al., eds., Getting to Scale: How to Bring Development Solutions to Millions of Poor People (Washington: Brookings Institution Press, 2O13)

156. Muhannad al-Jarrah in discussion with Mayyada Abu Jaber on April 6, 2015.

57. B. Banda et al., "Lesson Study Practice of Science Teachers in Zambia: Its Effects, Enhancing and Hindering Factors." New Perspectives in Science Education, 3rd ed. (Florence, Italy: 2014).

158. Madhav Chavan in discussion with Jenny Perlman Robinson and Shushmita Chatterji Dutt, July 16, 2015.

59. Ruth Levine, What Works Working Group, Molly Kinder, Millions Saved: Proven Successes in Global Health (Washington: Center for Global Development, November 2004).

160. Larry Cooley and Johannes F. Linn, "Taking Innovations to Scale: Methods, Applications and Lessons" (Washington: Results for Development Institute, September 2014).

161. Sesame Workshop "Early Education" http.//wwwsesameworkshop.org/what-we-do/our-initiatives/early education/

162. D. L. G. Borzekowskiand H. K. M. Henry, "The Impact of Jalan Sesama on the Educational and Healthy Development of Indonesian Preschool Children: An Experimental Study," International Journal of Behavioral Development of Indonesian Pr.
Development 35 (2011): $169-79$

163. Laurence Chandy, Kemal Dervis, and Steven Rocker, “Clicks into Bricks, Technology into Transformation, and the Fight against Poverty", report for Brookings Blum Roundtable on Global Poverty (Washington: Brookings 
164. Arntraud Hartmann and Johannes F. Linn, "Scaling Up: A Framework and Lessons for Development ectiveness from Literature and Practice" (Washington: Brookings Institution, 2008).

165. Ibid.

166. These international agreements include Accra Agenda for Action, OECE (2008); Busan Partnership (2011), and Paris Declaration on Aid Effectiveness, OECD (2OO5).

167. Adam Davidson, "Saving the World, Startup-style," New York Times, November 17, 2015.

168. GIF. "Transforming Ideas into Impact." Global Innovation Fund. http://www.globalinnovation.fund.

169. Jeffrey Bradach and Abe Grindle, "Transformative Scale: The Future of Growing What Works," Stanford Social Innovation Review (February 19, 2014).

170. Lant Pritchett, The Rebirth of Education: Schooling Ain't Learning (Washington: Brookings Institution Press, 2Ol3).

171. Frederick M. Hess, Same Thing Over and Over (Cambridge: Harvard University Press, 2010).

172. Jacques Pelkmans and Andrea Renda, "Does EU Regulation Hinder or Stimulate Innovation?" CEPS Special Report (Brussels: Centre for European Policy Studies, November 2014).

173. Laura Lewis, email communication with Jenny Perlman Robinson, March 18, 2016

174. David Herbling, "Ministry Stops Expansion of Low-Cost Schools," Business Africa Daily, September 24, 2015.

175. ASER Centre, "Citizen-led, Household Based Assessments around the World" (New Delhi: ASER Centre), www.asercentre.org/p/76.htm!

176. "Overview," ASER Centre, 2016, http://www.asercentre.org/Survey/Basic/Pack/Sampling/History/p/54

177. ASER Centre, "Citizen-led, Household Based Assessments around the World" (New Delhi: ACER Centre), www.asercentre.org/p/76.htm

178. Molly Jamieson Eberhardt et al., "Bringing Learning to Light: The Role of Citizen-Led Assessments in Shifting the Education Agenda" (Washington: Results for Development Institute, June 2015).

179. Ibid.

180. Ibid.

181. Dersonal communication with Darius Mogaka Ogutu and Rebecca Winthrop, February 5, 2015. Livingstone, Zambia

182. These roles are based on Martial Dembélé, Joel Samoff, and E. Molapi Sebatane, "Scaling Up by Focusing Down: Creating Space to Expand Educational Reform Association for the Development of Education for Africa" (Abidjan, Côte d'Ivoire: Association for the Development of Education in Africa, 2001).

183. World Bank, "World Development Indicators: Brazil" (Washington: World Bank), http://data.worldbank.org/ data-catalog/world-development-indicators.

184. Organisation for Economic Co-operation and Development, "Lessons from PISA for the United States Strong Performers and Successful Reformers in Education," (Paris: OECD, 2011).

185. Jean-Marc Bernard, "Data Are Not Just to Please Statisticians,", Global Partnership for Education (blog), August 5, 2014, www.global partnership.org/blog/data-not-just-please-statisticians.

186. Robust learning data are a public good that can be used to research and develop effective education approaches and foster collaboration within and across countries among teachers, policymakers, and spearheaded at the UNESCO Institute of Statistics, and the Assessment for Learning (A4L) platform proposed by the Global Partnership for Education. 187. Organisation for Economic Co-operation and Development, "Lessons from PISA for the United States:
Strong Performers and Successful Reformers in Education," (Paris: Organisation for Economic Co-operation and Development, 2011): Barbara Bruns, David Evans, and Javier Luque, "Achieving World-Class Education in Brazil: The Next Agenda" (Washington: World Bank, 2O12)
188. Organisation for Economic Co-operation and Development, "Lessons from PISA for the United States: Strong Performers and Successful Reformers in Education," (Paris: $O E C D, 2 O 11$ ).

189. Collette Chabbott, "Blueprints, Bureaucrats, and Scaling Up: Lessons for Education from BRAC's Fight against Cholera in Bangladesh," Brookings.edu (blog), August 18, 2015, http://www.brookings.edu/blogs/ education-plus-development/posts/2015/08/8-choleranducalion-bangladesh-chabbott.

190. OECD Directorate for Education Centre for Educational Research and Innovation (CERI) Governing Board, "Innovation Strategy for Education and Training: Progress Report no. 5" (Paris: OECD, 2011).

191. Collette Chabbott, "Blueprints, Bureaucrats, and Scaling Up: Lessons for Education from BRAC's Fight against Cholera in Bangladesh," Brookings.edu (blog), August 18, 2015, http://www.brookings.edu/blogs/ education-plus-development/posts/2015/08/18-cholera-education-bangladesh-chabbott.

192. David J. Spielman and Rajul Pandya-Lorch, eds., Millions Fed: Proven Successes for Agricultural Development (Washington: International Food Policy Research Institute, 2009).

193. Caroline Fiennes and Sarah Gupta. Getting Better II: What Education in Less Economically Developed Countries Can Learn About Evidence from Evidence. (London: Giving Evidence, forthcoming).

194. Nora Sabelli and Chris Dede, "Reconceptualizing the Goals and Process of Educational Research Funding: 195. Bridge International Academies, "Model," accessed August 24, 2015, http:///www.
bridgeinternationalacademiescom/approach/model/,

196. Cory Heyman, email communication with Jenny Perlman Robinson, February 17, 2016.

197. Erik Brynjolfsson and Andrew Mcafee, The Second Machine Age. Work. Progress, and Prosperity in a Time of Brilliant Technologies (New York: W. W. Norton, 2014)

198. David H. Autor, Frank Levy, and Richard Murnane, "The Skill Content of Recent Technological Change: An Empirical Exploration," Quarterly Journal of Economics 118, no. 4 (2003)

199 Madhav Chavan, "Who Needs Classrooms?" in Reimagining India: Unlocking the Potential of Asia's Next Superpower, eds. Clay Chandler and Andadil Zainulbhai (New York: Simon \& Schuster, 2O13).

200. Clayton Christensen, The Innovator's Dilemma: When New Technologies Cause Great Firms to Fail (Boston: Harvard Business School Press, 1997.

201. Lant Pritchett, The Rebirth of Education: Schooling Ain't Learning (Washington: Brookings Institution Press, 2013).

202. Glen Earrell and Shafika Isaacs, "Survey of ICT and Education in Africa" (Washington: Infodev/World Bank, 2007).

203. Marshall S. Smith and Rebecca Winthrop. "A New Face of Education: Bringing Technology into the Classroom in the Developing World" (Washington: Brookings Institution, January 2O12).

204. World Bank, "World Development Report 2016: Digital Dividends" (Washington: World Bank, 2016). 


\section{Bibliography}

Acemoglu, Daron, and James Robinson. "The Role of Institutions in Growth and Development." Working Paper no. 10, Commission on Growth and Development. Washington: World Bank, 2008

Aedo, Cristian et al. "From Occupations to Embedded Skills: A Cross-Country Comparison." Background paper for the World Development Report. Washington: World Bank, June 10, 2013

Ahmed, S., and M. French. "Scaling Up: The BRAC Experience." BRAC University Journal, 2003

American Educational Research Association. "Lead the Change Series: Q\&A with Vicky Colbert," no. 29 (August 2013).

Anderson, Ian. "Scaling Up Development Results: A Literature Review and Implications for Australia's Aid Program." Canberra: Australian Agency for International Development, February 2012.

ASER Centre. "Annual Status of Education Report Data Query". New Delhi: ASER Centre, 2014

ASER Centre. "Citizen-led, Household-based Assessments around the World." New Delhi: ASER Centre, www. g/p/76.html.

ASER Centre. "Overview," New Delhi: ASER Centre, 2016. http://www.asercentre.org/Survey/Basic/Pack/ Sampling/History/p/54.htm

"Assessment for Learning (A4L): An International Platform to Support National Learning Assessment Systems." Discussion document prepared for the Learning Metrics Task Force 2.O. December 1, 2015.

Autor, David H., Frank Levy, and Richard Murnane, "The Skill Content of Recent Technological Change: An Empirical Exploration." Puarterly Journal of Economics 118, no. 4 (2003).

Banda, B., V. Mudenda, E. Tindi, and K. Nakai. "Lesson Study Practice of Science Teachers in Zambia: Its Effects, Enhancing and Hindering Factors N New Perspectives in Science Educetion 3 rded. Florence, Italy. 2014

Barber, Michael, and Saad Rizvi, eds. Asking More: The Path to Efficacy. Pearson, 2013.

Barton, Dominic et al. "The World at Work: Jobs, Pay and Skills for 3.5 Billion People." McKinsey Global Institute, June 2012 .

Bernard, Jean-Marc. "Data Are Not Just to Please Statisticians." Global Partnership for Education (blog), August 5, 2014

Bille, R. "Action without Change? On the Use and Usefulness of Pilot Experiments in Environmental Management" Sapiens 3, no. 1 (2010).

Binswanger, Hans P., and Swaminathan Aiyar. "Scaling Up Community-Driven Development: Theoretical Underpinnings and Program Design Implications." Policy Research Working Paper no. 3039. Washington: World Bank, 2003

Binswanger-Mkhize, Hans P., Jacomina P. de Regt, and Stephen Spector, eds. Scaling Up Local Community Driven Development: A Real World Guide to Its Theory and Practice. Washington: World Bank, 2009

Blankespoor, Brian Susmita Dasqupta, Benoit Laplante, and David Wheeler. "Adaptation to Climate Extremes in Developing Countries: The Role of Education." Policy Research Working Paper 5342. Washington: World Bank. 2010.

Bold, Tessa, Mwangi Kimenyi, Germano Mwabu, Alice Ng'ang'a, and Justin Sandefur. "Scaling Up What Workings: Experimental Evidence on Externo Borzekowski, D. L. G., and H. K. M. Henry. "The Impact of Jalan Sesama on the Educational and Healthy Development of Indonesian Preschool Children: An Experimental Study." International Journal of Behavioral Development 35 (2OII):
Bradach, Jeffrey, and Abe Grindle, "Transformative Scale: The Future of Growing What Works." Stanford Social Innovation Review (February 19, 2014).

Bradach, Jeffrey L., "Scaling Impact." Stanford Social Innovation Review (Summer 2010).

Bray, Mark. "Double-shift Schooling: Design and Operation for Cost-effectiveness." Paris: UNESCO International Institute for Educational Planning, 2008.

Bridge International Academies. "About." Accessed August 24, 2015. www.bridgeinternationalacademies.com/company/

Bridge International Academies. "Model." Accessed August 24, 2015, www.bridgeinternationalacademies.com/ approach/model/.

Bruns, Barbara, and Javier Luque. Great Teachers: How to Raise Student Learning in Latin America and the Caribbean. Advance ed. Washington: World Bank, 2014.

Brynjolfsson, Erik, and Andrew Mcafee. The Second Machine Age: Work, Progress, and Prosperity in a Time of Brilliant Technologies. New York: W. W. Norton, 2014

Cassola. Adele, and Jody Heymann. Lessons in Educational Equality. Successful Approaches to Intractable Problems around the World. Oxford: Oxford University Press, 2012.

Center for Universal Education. "2013 Global Compact on Learning Donor Network Mapping Results." Washington: Brookings Institution, 2013.

Chabbott, Collette. "Blueprints, Bureaucrats, and Scaling Up: Lessons for Education from BRAC's Fight against Cholera in Bangladesh." Brookings.edu (blog), August 18, 2015. http://www.brookings.edu/blogs/education-plus-development/ posts/2015/08/18-cholera-education-bangladesh-chabbott

Chandy, Laurence, Akio Hosono, Homi Kharas, and Johannes Linn, eds. Getting to Scale: How to Bring Development .

Chandy, Laurence, and Johannes F. Linn. "Taking Development Activities to Scale in Fragile and Low Capacity Environments." Global Working Papers no. 41. Washington: Brookings Institution, September 2011.

Chandy, Laurence, Kemal Dervis, and Steven Rocker. "Clicks into Bricks, Technology into Transformation, and the Fight against Poverty." Report for Brookings Blum Roundtable on Global Poverty. Washington: Brookings Institution, 2012. http://www.brookings.edu/research/reports/2013/02/brooking-blum-roundtable-2012

Chavan, Machav. "Who Needs Classrooms?" In Reimagining India: Unlocking the Potential of Asia's Next Superpower. edited by Clay Chandler and Andadil Zainulbhai. New York: Simon \& Schuster, 2013

Christensen, Clayton. The Innovator's Dilemma. When New Technologies Cause Great Firms to Fail. Boston. Harvard Business School Press, 1997.

Chudgar, Amita, and Vyjayanthi Sankar." "The Relationship between Teacher Gender and Student Achievement: Evidence from Five Indian States," Journal of Comparative and International Education 38, no. 5 (2008): 627-42.

Clark, Simon, and Matina Stevis. "Zuckerberg-backed Startup Seeks to Shake Up African Education." Wall Street nal, March 13, 2015

Coburn, Cynthia E.. "Rethinking Scale: Moving Beyond Numbers to Deep and Lasting Change." Educational Researcher 32 , no. $6(2003)$.

Colbert, Vicky. "Improving Educational Quality and Access in Colombia through Innovation and Participation: The Escuela Nueva Model." Journal of Education for International Development 3, no. 3 (2009).

Conn, Katharine."Identifying Effective Education Interventions in sub-Saharan Africa: A Meta-analysis of Rigorous Impact Evaluations." Submitted for Ph.D., Columbia University, 2014.

Cooley, Larry, and Johannes F. Linn. "Taking Innovations to Scale: Methods, Applications and Lessons." Washington: Results for Development Institute, September 2014

Cooley, Larry, and Rajani R. Ved. "Scaling Up-From Vision to Large-Scale Change." Washington: Management Systems

Cooley, Larry, and Richard Kohl. "Scaling Up-From Vision to Large-Scale Change." Washington: Management Systems International March 2006 
Cooley, Larry. "Millions Learning: Role of Partnerships in Bringing Education Initiatives to Scale." Meeting at the Brookings Institution, Washington, June 2014

Coombs, P. with R. Prosser and M. Ahmed. "New Paths to Learning." New York: International Council for Educational Development, 1973

Thirty Years of Research on Children and "Sesame Street" edited by S. Fisch and R. Truglio. Mahwah, NJ: Erlbaum, 20OI.

Daniels, Alex "Ford Shifts Grantmaking to Focus Entirely on Inequality" Chronicle of Philanthrophy, June 11,2015

Davidson, Adam. "Saving the World, Startup-style." New York Times, November 17, 2015

Davies, Anna. "Spreading Social Innovations: A Case Study Report." TEPSIE, 2014.

Dede, Chris, James P. Honan, and Laurence C. Peters, et al. Scaling Up Success: Lessons Learned from Technology-Based Dedcational Improvement. San Francisco: Jossey-Bass, 2005

Dembééé, Martial, Joel Samoff, and E. Molapi Sebatane. 'GGoing to Scalé: Nurturing the Local Roots of Education Innovation Dedrica" EdQual Working Paper 28. EdQual: September 2O11

Dembélé, Martial, Joel Samoff, and E. Molapi Sebatane. "Scaling Up by Focusing Down: Creating Space to Expand oire: Association for the

Dolan, Janice, April Golden, Susy Ndaruhutse, and Rebecca Winthrop. “Building Effective Teacher Salary Systems in Fragile and Conflict-affected States." Policy Report. Washington: Center for Universal Education at Brookings; CfBT Education Dunst, C. J. et al. "Scaling Up Early Childhood Intervention Literacy Learning Practices." Center for Early Literacy Learning
(CELL) Papers I, no. 2 (2006): 1-1O.

Eberhardt, Molly Jamieson, Michelle Engmann, Tara Hill, and Daniel Plaut, "Bringing Learning to Light: The Role of CitizenLed Assessments in Shifting the Education Agenda," Washington: Results for Development Institute, June 2015.

ECDPM and ODI. "Case Study Summary: Material Wellbeing, Education and Employment." Maastricht and London: European Centre for Development Policy Management and Overseas Development Institute, 2015.

The Education Commission. “The Education Commission." Accessed on March 4, 2016. http://educationcommission.org/. Education For All Global Monitoring Report. "Pricing the Right to Education: The Cost of Reaching New Targets by 2030.” Policy Paper 18 Paris UNESCO July 2015

Education For All Global Monitoring Report. “Teaching and Learning: Achieving Quality for All." Paris: UNESCO, 2014 ExpandNet and World Health Organization. "Beginning with the End in Mind: Planning Pilot Projects and Other Programmatic Research for Successful Scaling Up." Geneva: World Health Organization, 200 .

Fajans, Peter, Laura Ghiron, Richard Kohl, and Ruth Simmons. "20 Questions for Developing a Scaling Up Case Study." Management Systems International. ExpandNet, and World Health Organization, 2007.

Farrell, Glen, and Shafika Isaacs. "Survey of ICT and Education in Africa." Washington: Infodev/World Bank, 2007

Fixsen, D. et al. "Implementation Research: A Synthesis of the Literature." Tampa: NIRN, 2005

Foray, Dominique, and Julio Raffo. "Business-driven Innovation: Is It Making a Difference in Education? An Analysis of Educational Patents." OECD Education Working Paper no. 84. Paris: OECD Publishing, 2012.

Fultz, Elaine, and John Francis. "Cash Transfer Programmes, Poverty Reduction and Empowerment of Women: A Comparative Analysis Experiences from
International Labour Organization, 2013 .

Gabriel, Madeleine. "Making It Big: Strategies for Scaling Social Innovations." London: Nesta, July 2014.

Gakidou, Emmanuela, Krycia Cowling, Rafael Lozano, and Christopher J. L. Murray. "Increased Educational Attainment

GEO. "Smarter Philanthropy for Greater Impact: Rethinking How Grantmakers Support Scale." Washington: Grantmakers for Effective Organizations, February 2O14. http://docs.geofunders.org/?filename=geo_2O14_ssir__supplement_final.pdf. Gerard J. Tellis, Jaideep C. Prabhu, and Rajesh K. Chandy. "Radical Innovation across Nations: The Preeminence of Corporate Culture." Journal of Marketing 73 (2009).
GIF. "Transforming Ideas into Impact." Global Innovation Fund. http://www.globalinnovation.fund Gillespie, Stuart, Purnima Menon, Andrew Kennedy. "Scaling Up Impact on Nutrition: What Will It Take?" Advances in Nutrition 6, no. 4 (2015): 440-51.

GIZ. “Scaling Up in Development Cooperation: Practical Guidelines." Eschborn, Germany: GIZ, 2010.

Global Alliance for Improved Nutrition. "Lessons from Businesses: Naandi Foundation's School Feeding Program," http:// wwwoinhealthorg/sites/wwwgainhealtherg/fles/NaandiLp

Gompers, Paul A. et al. "Performance Persistence in Entrepreneurship." Working Paper 09-028. Cambridge: Harvard Business School, July 2008

Gove, A., and P. Cvelich. Early Reading: Igniting Education for All. Revised ed. Early Grade Learning Community of Practice. Research Triangle Park, NC: Research Triangle Institute, 2011 .

Gugelev, Alice, and Andrew Stern. "What's Your Endgame?" Stanford Social Innovation Review (Winter 2015)

Gustafsson-Wright, Emily, and Eileen McGivney. "Fundación Escuela Nueva: Changing the Way Children Learn from Colombia to Southeast Asia." Brookings.edu (blog), April 23, 2014. http://www.brookings.edu/blogs/education-plusdevelopment/posts/2014/04/23-colombia-southeast-asia-learning-gustaffson-wright.

Hancock, J. “Scaling Up the Impact of Good Practices in Rural Development." Washington: World Bank, 2003.

Hanushek, Eric A., and Steven G. Rivkin. "Generalizations about Using Value-Added Measures of Teacher Quality." American Economic Review 100, no. 2 (May 2010): 267-71.

Hanushek, Eric, and Ludger Woessmann. The Knowledge Capital of Nations: Education and the Economics of Growth. Cambridge: MIT Press, 2016 .

Harnish, Verne. Scaling Up: How Few Companies Make It and Why the Rest Don't. Ashburn: Gazelles, 2014.

Hartmann, Arntraud, and Johannes F. Linn. "Scaling Up: A Framework and Lessons for Development Effectiveness from Literature and Dractice" Washington. Brookings Institution. 2008

Hattie, John. "What Works Best in Education: The Politics of Collaborative Expertise." London: Pearson, June 2015. Heckman, James J. "Skills, Schools, Synapses." Discussion Paper no. 3515. Bonn: IZA, May 2008.

Heckman, James J. "The Economics of Investing Early in Children." Policy Briefing no. 1. Dublin: UCD Geary Institute,

Herbling, David. "Ministry Stops Expansion of Low-Cost Schools." Business Africa Daily, September 24, 2015.

Hess, Frederick M. Same Thing Over and Over. Cambridge: Harvard University Press, 2010.

Hill, Robert. "Teach First: Ten Years of Impact." London: Teach First, 2012

Huq, Rahman Rahman. "Cost Comparison of BRAC NFP and Government Primary Schools." Dhaka, Bangladesh: Academy for Educational Development, July 1992

International Standard Classification of Education. Paris. UNESCO, 1997 http.//wwwwis.unesco.org/Library/Documents/ isced97-en.pdf.

Ishtiaque Hussain et al. "What Does It Take to Have Social Impact at Scale?" BRAC, October 2014. http://innovation. brac.net/images/what\%2Odoes\%2Oit\%2Otake\%2Oto\%2Oscale\%2Osocial\%2Oimpact.pdf.

Jeevan, Sharath. "What Do We Know about Teacher Motivation?... Our Learning at STIR So Far (with Much More Learning Ahead)." Internal document shared with Jenny Perlman Robinson and Eileen McGivney, February 9, 2016.

Kaneza, Yves, Paul Moclair, and Daniel Shephard. “Financial Education for Children: What Curriculum? Which Methods? ACluster Randomized Controlled Trial of Social and Financial Education in Rwanda." Budapest: Aflatoun International 2015.

Karamchandani, Ashish, Michael Kubzansky, and Paul Frandano. “Emerging Markets, Emerging Models: Market-based Solutions to the Challenges of Global Poverty." Cambridge: Monitor Group, 2009.

Khan, Zia, Isabel Guerrero, Harish Hande, and Jeffrey L. Bradach. "Creating a Funding Environment for Scaling Up Social Impact." Stanford Social Innovation Review (Spring 2O16)

Kharas, Homi, and Rebecca Winthrop. "Want to Save the Planet? Invest in Girls' Education." Milwaukee Journal Sentinel, February 13,2016 
Kim, Jooseop, Harold Alderman, and Peter Orazem. "Can Cultural Barriers Be Overcome in Girls' Schooling? The Community Support Program in Rural Balochistan." Working Paper on Impact Evaluation of Education Reforms no. 10

Learning Metrics Task Force. "Toward Universal Learning: Recommendations from the Learning Metrics Task Force." (I)

Learning Metrics Task Force. "Toward Universal Learning: What Every Child Should Learn." Montreal and Washington: UNESCO Institute for Statistics and Center for Universal Education at Brookings, 2013.

Levine, Ruth, and the What Works Working Group with Molly Kinder. Millions Saved: Proven Successes in Global Health Washington: Center for Global Development, 2004.

Levine, Ruth. “Friday Note: The Zero Year.” Hewlett Foundation (blog), July 10, 2015. http://www.hewlett.org/blog/posts/ friday-note-zero-year.

Linn, Johannes. "Internal Concept Note for Project on Scaling Up." October 21, 2013

Macmillan, Scott. "Glorious Failure: The Joy of Learning from Your Mistakes." The Guardian, March 30, 2015. Mangaleswaran, Ramesh, and Ramya Venkataraman. "Designing Philanthropy for Impact: Giving to the Biggest Gaps in India." McKinsey and Company, October 2013.

McCray, J. "Is Grantmaking Getting Smarter? A National Study of Philanthropic Practice 2014." Grantmakerse for Effective Organizations, 2014. http://www.Geofunders.Org/Storage/Docs/Geo_2O14_Field_Study.pdf.

McEwan, Patrick J. "Cost-effectiveness Analysis of Education and Health Interventions in Developing Countries." Journal of Development Effectiveness 4, no. 2 (June 2O12): 189-213.

McEwan, Patrick J. "Improving Learning in Primary Schools of Developing Countries: A Meta-analysis of Randomized Experiments," Review of Edveational Research 85, no. 3 (September 2015)

McGivney, Eileen, and Rebecca Winthrop. "Why Wait 100 Years? Bridging the Gap in Global Education." Washington:

Meyer, Robert G. "Going to Scale." New York: UNICEF, 1984

Michael Barber, Chinezi Chijioke, and Mona Mourshed, "How the World's Most Improved School Systems Keep Getting Better," Mckinsey and Company, November
Education Intro Standalone Nov\%2O26.pdf.

Miller, D., and P. Uvin. "Scaling Up: Thinking through the Issues." Providence: Brown University, 1994

Moore, Geoffrey. Crossing the Chasm: Marketing and Selling High-Tech Products to Mainstream Customers. New York: Harper Publishing, 1999

Mulgan, Geoff, with Simon Tucker, Rushanara Ali, and Ben Sanders. "Social Innovation: What It Is, Why It Matters, and How It Can Be Accelerated." Working Paper. Oxford: Skoll Centre for Social Entrepreneurship, 2007.

Murphy-Graham, Erin. Opening Minds, Improving Lives: Education and Women's Empowerment in Honduras. Nashville: Vanderbilt University Press, 2012 Naandi. "Naandi Foundation's Centralized Kitchens for Midday Meal Programme." Global lnnovations Fund.com. https://
www.globalgiving.org/pfi//6853/projdoc.pdf.

Naandi. “Our Work." Accessed March 2, 2016. http://www.naandi.org/programmes-phased-out/hungry-children-cannotlearn/

National Science Foundation. "Definitions of Research and Development: An Annotated Compilation of Official Sources." Accessed January 15, 2016. http://www.nsf.gov/statistics/randdefffedgov.fm.

Nicolai, Susan, Chris Hoy, Tom Berliner, and Thomas Aedy. "Projecting Progress: Reaching the SDGs by 2030.” London: Overseas Development Institute, September 2015

NU Health. "Insights for Taking Results Based Financing to Scale." UKAID, August 2015. http://resources.healthpartnersint.co.uk/wp-content/uploads/2015/10//nsights-for-taking-RBF-to-scale___olicy-Brief_NU-Health-2O15.pd

ODI. "Development Progress Series." London: Overseas Development Institute, 2011-2012.

OECD Directorate for Education Centre for Educational Research and Innovation (CERI) Governing Board. "Innovation Strategy for Education and Training: Progress Report no. 5." Paris: OECD, 2O11.
OECD. "Lessons from PISA for the United States: Strong Performers and Successful Reformers in Education." Paris: Organisation for Economic Co-operation and Development, 2011.

Ostrom, E., C. Gibson, S. Shivakumar, and K. Andersson. "Aid, Incentives, and Sustainability: An Institutional Analysis of Development Cooperation." Stockholm: Sida, 200

The Overhead Myth. "Moving toward an Overhead Solution." http://overheadmyth.com/.

Pelkmans, Jacques, and Andrea Renda. "Does EU Regulation Hinder or Stimulate Innovation?" CEPS Special Report. Brussels. Centre for European Policy Studies, November 2014

PESRP. “School Councils." http://www.pesrp.edu.pk/pages/School-Councils.

Pidufala, Oksana. "Scaling Up and Aid Effectiveness: Annotated Bibliography." Washington: Wolfensohn Center for Development at Brookings, August 2008. http://www.brookings.edu//media/Research/Files/Papers/2008/10/ scaling-up-aid-linn/10_scaling_up_aid_linn_bibliography.pdf.

Pozzoni, Barbara, and Nalini Kumar. "A Review of the Literature on Participatory Approaches to Local Development for an Evaluation of the Effectiveness of World Bank Support for Community-Based and -Driven Development Approaches. OED Working Papers no. 52233. Washington: World Bank, 2005.

Pritchett, Lant. The Rebirth of Education: Schooling Ain't Learning. Washington: Brookings Institution Press, 2013.

Rawal, Shenila, and Geeta Kingdon. "Akin to My Teacher: Does Caste, Religious, or Gender Distance between Student and Teacher Matter? Some Evidence from India." DoQSS Working Paper 10-18. London: Institute of Education, University of London, 2010.

Robinson, Jenny Perlman. "A Global Compact on Learning." Washington: Center for Universal Education at Brookings Institution, June 2017.

Robinson, Jenny Perlman. "Ensuring Lasting Education Reforms by Delivering Results: A Discussion with Claudia Costin, Senior Director for Education at the World Bank." Brookings Institution (blog), January 7, 201O. www.brookings. Rogers, Everett M. Diffusion of Innovations. 5th ed. New York: Free Press, 2003.

Rolnick, Art, and Rob Grunewald. "Early Childhood Development: Economic Development with a High Public Return." Fedgazette, March 2003

Room to Read. "Solving the Puzzle: Children's Literacy and Girls' Education." Annual Report, 2014 ed. http://www. roomtoread.org/AnnualReport/2014/http://www.roomtoread.org/AnnualReport/2014/.

Rosenberg, Tina. "Making Change Happen, on a Deadline." New York Times (blog), September 29, 2011. http:// opinionator.blogs.nytimes.com/2011/09/29/making-change-happen-on-a-deadline/? r=O.

Sabelli, Nora, and Chris Dede. "Reconceptualizing the Goals and Process of Educational Research Funding. Interconnecting Scholarship and Practice." H2O Project. Cambridge: Harvard University 1999. Sahni, Nikhil R., Maxwell Wessel, and Clayton M. Christensen. "Unleashing Breakthrough Innovation in Government."

Sesame Workshop. "Early Education." http://www.sesameworkshop.org/what-we-do/our-initiatives/early-education/. Simmons, Ruth, and Jeremy Shiffman. "Scaling Up Health Service Innovations: A Framework for Action." In Scaling Up Health Service Delivery from Pilot Innovations to Policies and Programmes, edited by Ruth Simmons. Peter Fajans, and Laura Ghiron. Geneva: World Health Organization, 2006.

Smith, Marshall S., and Rebecca Winthrop. "A New Face of Education: Bringing Technology into the Classroom in the Developing World." Washington: Brookings Institution, January 2012.

Spielman, David J., and Rajul Pandya-Lorch, eds. Millions Fed: Proven Successes for Agricultural Development. Washington: International Food Dolicy Research Institute, 2009.

Staton, Michael. "Unbundling Higher Education: Taking Apart the Components of the College Experience." In Stretching the Higher Education Dollar: How Innovation Can Improve Access, Equity, and Affordability, edited by Kevin Carey and Andrew P Kelly. Cambridge: Harvard Education Press, 2013.

Steer, Liesbet, and Katie Smith. "Financing Education: Opportunities for Global Action." Washington: Center for

STIR Education. "STIR Education: Empowering Teachers to Be Changemakers." 2015. http://www.stireducation.org/. 
Sutton, Robert I., and Huggy Rao. Scaling Up Excellence: Getting to More without Settling for Less. New York: Crown Business, 2014

Teach First. "All Of Us: Teach First Annual Review." London: Teach First, 2014

Thorpe, lan. "The Next Innovation: Scaling Up." kmonadollaraday.wordpress.com (blog), December 18, 2013. https:// kmonadollaraday.wordpress.com/2013/12/18/the-next-innovation-scaling-up/.

UNESCO "Education Transforms Lives." Paris: UNESCO, 2013

UNESCO. "Global Initiative on Out-of-School Children: Brazil." Paris: UNESCO, August 2012. http://www.uis.unesco org/Education/Documents/OOSC1\%2OReports/brasil-oosci-summary-2O12-en.pdf.UNESCO

UNESCO Institute of Statistics. "A Teacher for Every Child: Projecting Global Teacher Needs from 2015 to 2O3O." UIS Fact Sheet no. 27. Montreal: UIS 2013

UNESCO Institute of Statistics. "Sustainable Development Goal for Education Cannot Advance without More Teachers." UIS Fact Sheet No. 33. Montreal: UIS, 2015.

UNESCO. World Inequality Database on Education. Indicator: Out-of-School Children. Paris: UNESCO, 2016. http:// www.education-inequalities.org/.

UNICEF “Early Childhood Development: A Statistical Snapshot"” New York: UNICEF, 2014

Uvin, P. "Fighting Hunger at the Grassroots: Paths to Scaling Up." World Development 23, no. 6 (1995): 927-39.

Uwezo. "Are Our Children Learning? Literacy and Numeracy Across East Africa 2013." Nairobi: Hivos/Twaweza, 2013.

Vaurus, Frances. Desire and Decline: Schooling Amid Crisis in Tanzania. New York: Peter Lang, 2003.

Visible Learning blog. "Hattie Ranking: Influences and Effect Sizes Related to Student Achievement." Accessed February 18, 2016 http://visible-learning.org/hattie-ranking-influences-effect-sizes-Jearning-achievement/.

Wasserman, Noam. "The Founder's Dilemma." Harvard Business Review (February 2008)

Winthrop, Rebecca, and Corrinne Graff. "Beyond Madrassas: Assessing the Links between Education and Militancy in Pakistan." Working Paper no. 2. Washington: Center for Universal Education at Brookings, 2010.

Winthrop, Rebecca, and Gene Sperling. What Works in Girls' Education: Evidence for the World's Best Investment. Washington. Brookings Institution Press, 2015

World Bank. "Country and Lending Groups." http://data.worldbank.org/about/country-and-lending-groups"Low_

World Bank. "Education Global Practice Snapshot: The Rise of Results-based Financing in Education." Washington: World Bank, August 2015

World Bank. "Leveraging Urbanization in South Asia: Managing Spatial Transformation for Prosperity and Livability." Washington: World Bank, 2016.

World Bank. "World Development Indicators: Brazil." Washington: World Bank. http://data.worldbank.org/datacatalog/world-development-indicators

World Bank, "World Development Report 2004: Making Services Work for Poor People." Washington: World Bank, 2013. World Bank. "World Development Report 2016: Digital Dividends." Washington: World Bank, 2016

World Health Organization and ExpandNet. "Nine Steps for Developing a Scaling-Up Strategy." Geneva: WHO, 2010.

Yamauchi, Futoshi, and Yanyan Liu. "Girls Take Over: Long-term Impacts of an Early Stage Education Intervention in the Philippines" IEDRI Discussion Daper. Washington. International Food Dolicy Research Institute, 201 .

YouTube. "Punjab, Pakistan, Education Reform Roadmap." Published on January 22, 2014. https://www.youtube. com/watch?v=gjATVO3I-sO.

Zambia Ministry of General Education. "School-Based Continuing Professional Development (SBCPD) Through Lesson Study Implementation Guidelines" 5th ed. Lusaka, Zambia: Ministry of General Education and Japan Insenationaly

\section{Annex 1.}

\section{Millions Learning case study selection}

process

To contribute to the Millions Learning study, CUE issued a global call for case studies in June 2014 to identify examples of programs and policies from early childhood development through secondary education that have scaled up effective approaches to improving learning. We focused on education interventions, which we defined programs or policies that take place in format or nonformal settings where intentional learning takes place. In issuing a global call for case studies, we endeavored to draw evidence not only from well-known cases but also from local, less wellknown examples of where learning had improved.

In addition to issuing the call for case studies, the Millions Learning team conducted background research to uncover interventions to consider in the study. This included an analysis of international and regional learning assessment data to look across countries at their learning outcomes and identify where progress had been made. Specific countries and subnational regions were then selected for further investigation and analysis. We also conducted a wide-ranging literature review in education and other sectors, including health, agriculture, social innovation, and broader development efforts.
Recommendations from consultations, meetings, and interviews with key informants also helped to identify cases that warranted additional study.

Ultimately, as a result of the global call for case studies, we received 75 case study submissions, and with our independent research, we considered more than 100 case studies in total. Of these case studies, we identified approximately 30 that met our case study criteria (see "Case Study Selection Criteria" below) and were strong candidates for inclusion in the final study. In doing so, we requested additional information to address gaps or lingering questions as needed.

Our Millions Learning International Advisory Panel then assisted us in evaluating the short-listed case studies based on the qualifying and evaluative criteria with the aim of selecting approximately 12 cases to review in-depth for the Millions Learning study. Ultimately, we selected 14 cases for a more in-depth review.

These cases were selected first and foremost because they met our criteria of demonstrating an improvement in learning at scale (to varying degrees) in a low- or middle-income country. 
Beyond that, we believed that there was an interesting story to tell-some contentious issue addressed, some bold course correction made in the process of expanding a new angle or aspect that had yet to be explored. This was al balanced against the desire to identify a range of scaling pathways and types of interventions from early childhood to secondary programs, as well as diversity in geography and populations reached.

These case studies were not meant to represent the best models or approaches to improving learning; in fact, there are ongoing debates regarding some of the approaches. They also were not selected to provide any recipe or blueprint to scaling. Rather, the purpose of the cases was to shed some light on the

\section{Case study selection criteria}

The Millions Learning team developed the following criteria to help identify the 14 case studies for in-depth review.

\section{Impact:}

There should have been evidence of a clear and measurable improvement in learning, or in a few instances, a strong indication of learning, along with proxy indicators such as decreases in dropout rates and increases in progression rates. An improvement in learning was broadly defined and could include progress across multiple competencies, as defined by the Learning Metrics Task Force, including physical well-being, literacy and communications, numeracy and mathematics, social and emotional well-being, and science and technology.

\section{Scale:}

nuances and drivers behind large-scale success in improving learning outcomes, particularly among the children who are most marginalized and difficult to reach. They were meant to uncover not only the technical design of the interventions that demonstrated learning gains but additionally-and perhaps more importantly-the stories behind their implementation. For example, what made them effective in one location but not in another? What obstacles were confronted that had to be addressed in order to expand? What key decisions, events, or processes led to millions of more children learning valuable skills? And how could all of these lessons inform future efforts around scaling effective learning approaches, especially in light of achieving the SDGs?
Low- or middle-income country:

The intervention must have been operational in at least one low-, lowmiddle-, or high-middle-income country as defined by the World Bank, which classifies economies based upon GNI, or an equivalent classification that was current when the intervention was implemented.
Additional factors for consideration:

Additional foctors to impact, scale, and country income, other criteria in the selection process included: a focus on marginalized communities: progress sustained over time; focus on one of four areas of thematic interest in the study-financing, partnerships, data, and technology; and cost-efficiency.

Nominations should have clearly defined the assessment method used, such as international, regional, or national assessments, household surveys, or evaluations. Preference was given to case studies with stronger evidence.

The policy or program should have been mplemented (or been in the process regional, to multiple country contexts. To qualify as achieving scale, a significant share of the total target population must have been reached. Interventions targeting a specific population or geographic area were subnational-level commitment. 


\section{Annex 2.}

14 Millions Learning case studies

\begin{tabular}{|c|c|c|c|c|}
\hline NAME & LOCATION & $\begin{array}{l}\text { EDUCATION } \\
\text { LEVEL }\end{array}$ & FOCUS AREA & NUMBERS REACHED \\
\hline $\begin{array}{l}\text { Aflatoun } \\
\text { International }\end{array}$ & $\begin{array}{l}116 \text { countries, } \\
\text { starting in India }\end{array}$ & $\begin{array}{l}\text { Early childhood, } \\
\text { Primary, } \\
\text { Secondary }\end{array}$ & $\begin{array}{l}\text { Entrepreneurial } \\
\text { development, } \\
\text { Social and } \\
\text { financial education }\end{array}$ & $\begin{array}{l}\text { Almost } 4 \text { million } \\
\text { students \& } 34,000 \\
\text { teachers, facilitators, } \\
\text { and peer educators } \\
\text { each year }\end{array}$ \\
\hline $\begin{array}{l}\text { Amazonas } \\
\text { State } \\
\text { Government's } \\
\text { Media Center }\end{array}$ & $\begin{array}{l}\text { Amazonas State, } \\
\text { Brazil }\end{array}$ & Secondary & $\begin{array}{l}\text { Formal secondary } \\
\text { school distance } \\
\text { learning program }\end{array}$ & $\begin{array}{l}300,000 \text { students, } \\
2,200 \text { tutoring } \\
\text { teachers, \& } 60 \text { lecturing } \\
\text { teachers to date }\end{array}$ \\
\hline $\begin{array}{l}\text { BRAC, } \\
\text { Non-Formal } \\
\text { Primary } \\
\text { Education }\end{array}$ & $\begin{array}{l}\text { Afghanistan, } \\
\text { Bangladesh, } \\
\text { Pakistan, } \\
\text { Philippines, } \\
\text { South Sudan }\end{array}$ & Primary & $\begin{array}{l}\text { Alternative primary } \\
\text { school program }\end{array}$ & $\begin{array}{l}670,000 \text { students in } \\
\text { Bangladesh \& over } \\
900,000 \text { students } \\
\text { in other four NFPE } \\
\text { countries each year }\end{array}$ \\
\hline $\begin{array}{l}\text { Bridge } \\
\text { International } \\
\text { Academies }\end{array}$ & $\begin{array}{l}\text { Kenya, Nigeria, } \\
\text { Uganda }\end{array}$ & $\begin{array}{l}\text { Pre-Primary, } \\
\text { Primary }\end{array}$ & $\begin{array}{l}\text { Early childhood } \\
\text { development, } \\
\text { Primary (low-cost } \\
\text { private school) }\end{array}$ & $\begin{array}{l}\text { Over } 100, \mathrm{OOO} \\
\text { students \& 8,००० } \\
\text { teachers to date }\end{array}$ \\
\hline Educate! & Rwanda, Uganda & Secondary & $\begin{array}{l}\text { Secondary } \\
\text { education, } \\
\text { Entrepreneurial } \\
\text { development, } \\
\text { Teacher training }\end{array}$ & $\begin{array}{l}120,000 \text { students in } \\
350 \text { partner schools, } \\
\text { or } 12 \% \text { of Ugandan } \\
\text { secondary schools }\end{array}$ \\
\hline $\begin{array}{l}\text { Fundación } \\
\text { Escuela } \\
\text { Nueva }\end{array}$ & $\begin{array}{l}16 \text { countries, } \\
\text { starting in } \\
\text { Colombia }\end{array}$ & $\begin{array}{l}\text { Primary, Lower } \\
\text { secondary }\end{array}$ & $\begin{array}{l}\text { Alternative } \\
\text { primary and lower } \\
\text { secondary school } \\
\text { program }\end{array}$ & Over 5 million students \\
\hline $\begin{array}{l}\text { INJAZ, } \\
\text { Jordan }\end{array}$ & $\begin{array}{l}\text { Jordan (all } 12 \\
\text { governorates) }\end{array}$ & Secondary & $\begin{array}{l}\text { Financial literacy, } \\
\text { Work readiness, } \\
\text { Entrepreneurial } \\
\text { development }\end{array}$ & $\begin{array}{l}1.2 \text { million students } \\
\& \text { over } 23,000 \\
\text { volunteers to date }\end{array}$ \\
\hline $\begin{array}{l}\text { Lesson Study, } \\
\text { Zambia }\end{array}$ & $\begin{array}{l}\text { Zambia (all } 10 \\
\text { provinces) }\end{array}$ & $\begin{array}{l}\text { Primary, } \\
\text { Secondary }\end{array}$ & Teacher training & $\begin{array}{l}1.8 \text { million students \& } \\
46,000 \text { teachers to } \\
\text { date }\end{array}$ \\
\hline
\end{tabular}

\begin{tabular}{|c|c|c|c|c|}
\hline NAME & LOCATION & $\begin{array}{l}\text { EDUCATION } \\
\text { LEVEL }\end{array}$ & FOCUS AREA & NUMBERS REACHED \\
\hline $\begin{array}{l}\text { Pratham, } \\
\text { Read India }\end{array}$ & $\begin{array}{l}\text { India (across } 23 \\
\text { states) }\end{array}$ & $\begin{array}{l}\text { Primary } \\
\text { (Grades 3-5) }\end{array}$ & $\begin{array}{l}\text { Remedial } \\
\text { education }\end{array}$ & $\begin{array}{l}\text { Over } 350,000 \text { students } \\
\text { directly in rural areas } \\
\text { from } 2014-2015 \text { \& over } 6 \\
\text { million students indirectly } \\
\text { via state or district } \\
\text { government partnerships }\end{array}$ \\
\hline $\begin{array}{l}\text { Room } \\
\text { to Read, } \\
\text { Literacy } \\
\text { Program }\end{array}$ & $\begin{array}{l}\text { Bangladesh, } \\
\text { Cambodia, India, } \\
\text { Laos, Nepal, South } \\
\text { Africa, Sri Lanka, } \\
\text { Tanzania, Vietnam, } \\
\text { Zambia }\end{array}$ & $\begin{array}{l}\text { Primary } \\
\text { (Grades 1-2) }\end{array}$ & $\begin{array}{l}\text { Early grade } \\
\text { reading, } \\
\text { Teacher training }\end{array}$ & $\begin{array}{l}110,000 \text { students \& } \\
2,000 \text { teachers (Literacy } \\
\text { Program specifically) and } \\
10 \text { million students (Room } \\
\text { to Read overall) to date }\end{array}$ \\
\hline $\begin{array}{l}\text { Sesame } \\
\text { Workshop, } \\
\text { Sesame } \\
\text { Street }\end{array}$ & $\begin{array}{l}\text { More than } 150 \\
\text { countries, starting } \\
\text { in the United } \\
\text { States }\end{array}$ & Early childhood & $\begin{array}{l}\text { Early childhood } \\
\text { development, } \\
\text { Cognitive } \\
\text { development, } \\
\text { Early grade } \\
\text { reading \& } \\
\text { mathematics }\end{array}$ & $\begin{array}{l}\text { Approximately } 156 \text { million } \\
\text { children }\end{array}$ \\
\hline $\begin{array}{l}\text { Sistema de } \\
\text { Aprendizaje } \\
\text { Tutorial / } \\
\text { Tutorial } \\
\text { Learning } \\
\text { System (SAT) }\end{array}$ & $\begin{array}{l}\text { Brazil, Colombia, } \\
\text { Ecuador, } \\
\text { Honduras, } \\
\text { Nicaragua }\end{array}$ & Secondary & $\begin{array}{l}\text { Alternative } \\
\text { secondary } \\
\text { school program }\end{array}$ & $\begin{array}{l}\text { Estimated } 300,000 \\
\text { students to date }\end{array}$ \\
\hline Teach For All & $\begin{array}{l}39 \text { countries, } \\
\text { starting in the } \\
\text { United States and } \\
\text { United Kingdom }\end{array}$ & $\begin{array}{l}\text { Early childhood, } \\
\text { Primary, } \\
\text { Secondary }\end{array}$ & $\begin{array}{l}\text { Alternative } \\
\text { pathways to } \\
\text { teaching }\end{array}$ & $\begin{array}{l}1.1 \text { million students \& } \\
52,323 \text { teachers and } \\
\text { alumni to date }\end{array}$ \\
\hline Worldreader & $\begin{array}{l}69 \text { countries, } \\
\text { starting in Ghana }\end{array}$ & $\begin{array}{l}\text { Primary, } \\
\text { Secondary }\end{array}$ & Literacy & $\begin{array}{l}\text { Over } 5.6 \text { million people to } \\
\text { date \& } 1.1 \text { million people } \\
\text { reading digital books per } \\
\text { month }\end{array}$ \\
\hline
\end{tabular}




\section{Annex 3.}

\section{Acknowledgements}

We are extremely grateful to a wide-range of colleagues who generously shared their knowledge and feedback on the individual case studies and report throughout its various stages, including: Sani Abdullahi, Tara Abrahams, Aliyu Abubakar, Alhaji its various stages, including: Sani Abdullahi, Tara Abrahams, Aliyu Abubakar, Alhaji Ibrahim Jnyas Abubakar, Karabi Acharya, Samuel Yalew Adela, Adeyemi Adeyemo, Amrita Ahuja, parents of Akhetwara School in Bihar, Rasha Al-Akkad, Blessed Grace Aleng, Marcelo Peréz Alfaro, Khaled Almasri, Omar al-Momani, Omar al-Nimri, the team at Amazonas State Secretariat of Education, Nezar Ammari, former secretary of education Gedeã Amorim, Kate Anderson, Manos Antoninis, Magge Shehan A education Gedeão Amorim, Kate Anderson, Manos Anton,is, Maggie Shehan Appleton, Clarita Arboleda, James Arinaiwte, Beatrice Asamoah, Hassan Bani Ata Tamar Manuelyan Atinc, Mario Ayala, Abeer Azem, Simon Bailey, Reena Bajaj, Mallam Balarabe, Benson Banda, Sashwati Banerjee, Sourav Banerjee, Rukmini Banerji, Nikhat Banu, Omar Ali Barishi, Jorge Baxter, Christine Beggs, parents of Begumpur Girls Middle School of Patna, Reyes Benedict, Regis Benedith, Teodora Berkova, Sarabeth Berman, Desmond Bermingham, James Bernard, Jean-Marc Bernard, Averil Besier, Joyce Patricia Bheeka, Manisha Bhinge, Deema Bibi, Nguyet Bich, Jeroo Billimoria, Elizabeth Binder, Amy Black, Soledad Boas, Funke Bolaji, Andrew Bollington, Talya Bosch, Jo Bourne, Geordie Brackin, Jeffrey Bradach, Lucy Bradlow, Amanda Braga, Unmesh Brahme, the teachers at the Bridge International Academy in Gicagi, Nairobi, Maria Brindlmayer, teachers at the Broadway Secondary School in Zambia, Katherine Brown, Barbara Bruns, Ellen Buchwalter, Trang Bui, Boris Bulayev, Canh Buon, Andrew Byrd, Ron Cammaert, Nick Canning, Esther Care, Tim Carlberg. Andrew Carruthers, Colette Chabbott, Sharanya Chandrana, Laurence Chandy, Maria Cherono, Fridah Musounda Chileshe, Charles Anthony Chisanga, Esvah Chizambe, Malonga Christine and the teachers at the Ngungu Primary School in Zambia, Punam Chuhan-Pole, AnMe Chung, Elia del Cid, Vicky Colbert, Charlotte Cole, Peter Colenso, Bita Correa, Loren Crary, Luis Crouch, Raoul Davion, Susan Davis, Gbolahan Dawodu, Chris Dede, Malek Abu Deeb, Michael Deich, Natasha de Marcken, Joseph DeStefano, Pingla Devi, Balmurugan Devraj, Ngoc Dinh, Carolina Dominguez, Soheil Dooki, Meghan Duffy, George Durham, Ralf Dürrwang, Molly Jamieson Eberhardt, John Edeh, the Educate! mentors, Nada Elattar, Pius Elumeze, Eliza Erikson, Khaled Estitieh, Ariel Evans, Eric Eversmann, Chinelo Ezeobi, Mutaz Faza, Mary Fearnley-Sander, Caroline Fiennes, Filipe from Tres Unidos community and classmates in Amazonas, Ariel Fiszbein, Heriberto Flores, John Floretta, Marcelo Campbell Fonseca, Nadine Freeman, Anna French, Nora Fyles, Orlando Gabarrete, Jenifer Gamble, Amanda Gardiner, Sophie Gardiner, Shurahbeel Gharaibeh, Laura Ghiron, Shivani Ghosh, Michael Gibbons,
Gannon Gillespie, Gibson Gisore, Amanda Glassman, Maria Gonzalez de Asis, Holly Gordon, Lauren Greubel, Bethan Grillo, Randa GrobZakhary, Emily GustafssonWright, Tran Ha, Oliver Haas, Lauren Hadi, Melen Hagos, Nguyen Thi Hong Hahn, Ross Hall, Yoshie Hama, Per Havgaard. Cory Heyman, teachers at the Hilltop Secondary School in Zambia, Razan Hindawi, Rachel Hinton, Ngoc Hoang, Nguyen Thu Huong, Huong Huyen, Clare Ignatowski, Miki Inaoka, Danilo Iraheta, Sheik Tanjeb Islam, Eiko Izawa, Sarah Jaffe, Cornelia Janke, Muhannad Jarrah, Shuba Jayaram, Sharath Jeevan, Mahachi John, Tressa Johnson, Kasongo Joseph, Matthew Jukes, Ihano Mulako Kapanda, Vishnu Karki, Alia Kawasmi, Solomon Kayiwa, Sarah Kayondo, Caroline Kayoro, Esther Kazeze, Liz Kellison, Darrin Kerr, Kimberley Kerr, Bayan Abu Khadra, Deepali Khanna, lyke Kimeminhia, Mwangi Kimenyi, Jay Kimmelman, Richard Kohl, Jonas Koll, Wendy Kopp, Nasko Koprivshtitsa, Jarika Kumari, Sunita Kumari, Lucy Lake, Jeff Lansdale, Phong Le, Charles Leadbeater, June Lee, Suezan Lee, Sun Lei, Filip Lenaerts, Laura Lewis, Emily Leys, Marie Leznicki, Helen Licata, Sandra Licon, teachers and students at Light High in Kampala, Johannes Linn, Cynthia Lloyd, Vu Manh Loi, Joan Lombardi, Zev Lowe, teachers at Lusaka Secondary School, Godfrey Luwo, Viston Machiko, Scott MacMillan, Mallam Ahmad Abdullahi Madana, Musonda Madrine, Bronwen Magrath, Luckson Malambo, Nuzhat Malik, Joyce Malombe, Venkatesh Malur, Adnan Mansour, Wendy Mantamba, Jonas Marcello, Erum Mariam, Kevin Marinacci, Alejandro Martinez, Yesenia Martinez, Marwan Mashriay, Atsushi Matachi, Ambassador Steve Matenje, Mineko Matsumoto, Nadim Matta, Renee McAlpin, John McArthur, Phil McComish, Patrick McEwan, Eugenia McGill, Kate McQueston, Media Center teachers, Edward Mfumblwa, Shuaibu Dabo Mohammed, Kristen Molyneux, Roeland Monasch, Ives Morales, Trang Nauyen More, Caitlin Moss, John Mugo, teachers at Mukonchi Secondary School in Zambia, Anthony Mullen, Maria Eugenia Munaretto, Lynn Murphy, Erin Murphy-Graham, Anna C. Murru, Joshua Muskin, Lazarous Mutale, Sujatha Muthayya, Joan Mwachi, Paxina Mwenga Mweba, Mercy Mwiya, Hawah Nabbuye, Zulfa Nafees, Rhoda Nanre Nafziger, Jordan Naidoo, Kazuyoshi Nakai, Dorothy Namubiru, Ola Natour, Ahmed Nayef, José Augusto de Melo Neto, Nguyen Thi Thanh Nga, Elizabeth Mwila Ngonga, Susan Nicolai, Sylvia Njoroge, Hisanao Noda, Assem Nofal, Hugo Ñopo, Milena Novy-Marx, Ndidi Nwuneli, Huda Obeidat, Daniel Obus, Tayo Odekunle, Chris Okoro, Oluwafunmi Olalusi, Martine James Omondi, Katherine Onorato, Neil O'Reilly, Katherine Onorato, Doyin Orogun, Daniel Ortega, Akira Oshima, Juan Pablo Giraldo Ospino, Adam Parker, Shama Parvee, Ramnaresh Patel, Harry Patrinos, Evgenia Peeva, Sara Peracca, Juan Miguel Pérez, Penélope Pérez, Devyani Pershad, Aline Pognonec, Elana Pollak, Pratham Cluster Resource Centre Coordinators in Bihar Xavier Prats-Monne, Lant Pritchett, Gerardo Quijada, Le Thi Quy, Moad Rabbabah, Hamza Raed, Erik Ramirez-Ruiz, Renan Rapalo, Nancy Refki, Fernando Reimers, Michael Rettig, Michael Richards, David Risher, Marcelino Moreno Rivera, Ana Luis Correia Rodriquez, Mark Roland, Shari Rosenfeld, former minister of education in Nigeria Ruqqayat Rufai, Julia Ruiz, Sara Ruto, Nora Sabani, Urvashi Sahni, Olalekan Saidi, Ana Salinas, Justin Sandefur, Kayode Sanni, Alodia Santos, Taigo Sasaki, Ruhollah Sayyah, Patricia Scheid, Dana Schmidt, Philipp Schmidt, Heidi Schubert, Ambassador Molapi Sebatane Babita Shankar Shailendra Sharma Daniel Shephard, Kazuro Shibuya, Bassem Shlul, Jack Shonkoff, Adam Short, 
Ruth Simmons, Heather Simpson, Vikram Singh, Richard Singoyi, Lisa Slifer-Mbacke, Katie Smith, Secretary of Education Rossieli Soares da Silva, Stephen Sobhani, Ajit Solanki, Michael Staton, Anita Stewart, Morgan Strecker, Haija Jummai Suleiman, Hideharu Tachibana, Tina Tam and Worldreader colleagues in Ghana and Uganda, Le Tan, Shinichiro Tanaka, Bessie Tembo, Miriam Temin, Pham Vu Thang, Tran van Thanh, Edward Tindi, Chris Tinning, Joice Toyota, Sarah Troup, Rosemarie Truglio, Rabecca M. Twelasi, Paul Ugwu, Mustapha Salisu Umar, Justin van Fleet, Fred Van Leeuwen, Rebeca Vargas, Ingrid Vasquez, Secretary of Education for Puebla Patricia Vázquez, Emiliana Vegas, Bala Venkatachalam, Kim Wright Violich, VUFO-NGO Resource Center Vietnam, Haruna Wakili, Joe Wales, Ian Walker, Lillian Wamuyu, Andrew White, Laura White, Brett Wigdortz, Matthew Williams, Patricia Wmudenda and the teachers in Kamulanga Secondary School in Zambia, Bruce Wolpe, Augusta Ximenes, Yasmina Zaidman, Noor Abu Zant, Teodora (Teddy) Zareva, Tassew Zewdie, and Alix Zwane.

\section{Lastly, we would like to extend a special thank you to the following:}

our copy-editor, Marcia Kramer; designer, blossoming.it; and printer, The YGS Group. 


\section{BROOKINGS}

1775 Massachusetts Ave., NW

Washington, D.C. 20036

$2 \mathrm{O} 27976000$

www.brookings.edu/universal-education

(C) 2016 The Brookings Institution 